Portland State University

PDXScholar

1979

\title{
An investigation of the relationship of organizational structure to job satisfaction within social service organizations serving elderly clients
}

Anne Marguerite Wilkinson

Portland State University

Follow this and additional works at: https://pdxscholar.library.pdx.edu/open_access_etds

Part of the Organizational Communication Commons, and the Social Work Commons Let us know how access to this document benefits you.

\section{Recommended Citation}

Wilkinson, Anne Marguerite, "An investigation of the relationship of organizational structure to job satisfaction within social service organizations serving elderly clients" (1979). Dissertations and Theses. Paper 2931.

https://doi.org/10.15760/etd.2922

This Thesis is brought to you for free and open access. It has been accepted for inclusion in Dissertations and Theses by an authorized administrator of PDXScholar. Please contact us if we can make this document more accessible: pdxscholar@pdx.edu. 
AN ABSTRACP OF THE THESIS OF Anne Marguerite Wilkinson for the Master of Science in Sociology presented May 18, 1979.

Title: An Investigation of the Relationship of Organizational Structure to Job Satisfaction within Social Service Organizations Serving Elderly Clients.

APPROVED BY MEMBERS OF THE THESIS COMMITTEE:
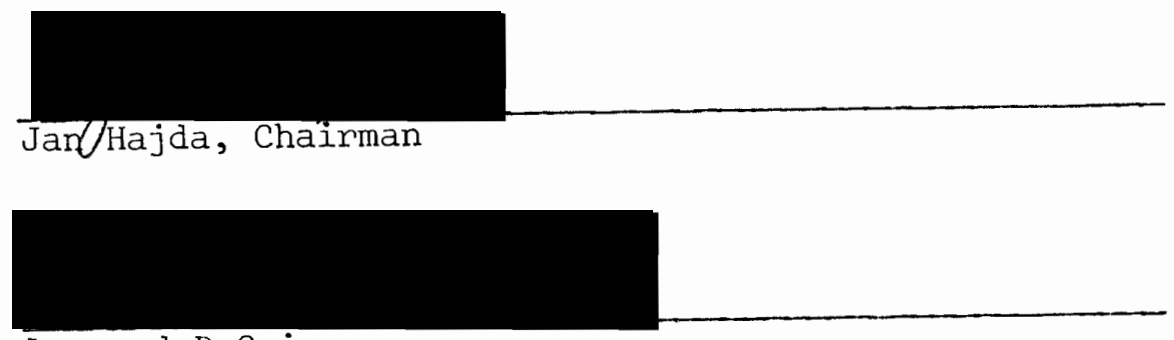
Leonard D Cain

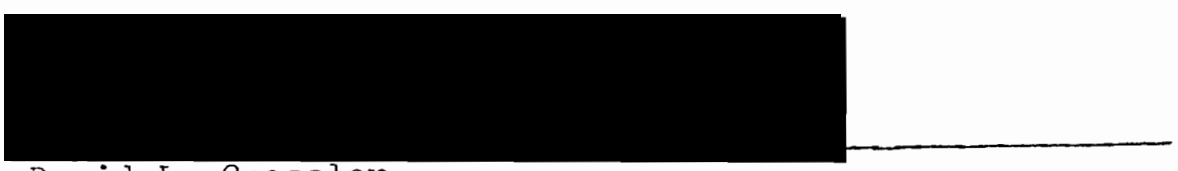

David L. Cressler

Shifts in the nature of the economy have resulted in changing forms of work and a change in the composition of the workforce. With the rise of the post-industrial society has come a proliferation of social and client service organizations which have resulted in a challenge to organizational researchers. The delineation of the similarities and differences between client serving organizations and their business and industrial counterparts due to the unique feature of social service agencies, that of client-service provider 
interaction is necessary if we are to adequately address the changing economic and social circumstances of our society. Organizations involved in client service may confront several problems of structure that are less at issue in organizations processing non-human objects. These structural differences are derived from the capacity of the client to interact with those members of the organization responsible for the delivery of services. Because of the special dependence of the elderly on social service programs (due to their poverty, chronic illnesses, and tendency to live in urban areas), the organizations and workers serving elderly clients are especially useful representatives of service agencies in which to address the question of job satisfaction within social service organizations.

This study investigated the relationships between organizational structure of client serving organizations and the job satisfaction of the members. The exploration of these relationships was conducted using a three dimension model of job satisfaction and seven dimensions of organizational structure. Data was gathered using interview and survey research techniques from 428 service providers within 42 social service agencies serving elderly clients.

Correlational data analysis between the dimensions of organizational structure and job satisfaction dimensions show that overall, organizational structure dimensions were most strongly associated with member recognition of discontent aspects of their job. There were few relationships found between organizational structure dimensions and the other two dimensions of job satisfaction. While there were few consistent relationships to be found across all three dimensions of 
job satisfaction, the relationships that were found were weak. In separating out the contributions of job situation versus clientservice provider interaction to the total job satisfaction score, it was found that discontent with job situation and negative affect toward situation was more related to organizational structural dimensions than negative or positive client attitudes. Thus, the job situation appears to be more highly associated with negative recognition of discontent aspects of job and negative feelings toward job than the client aspects of the job. These findings tend to support the traditional job satisfaction theory that increases in elements of organizational structure tend to be associated with lower member job satisfaction.

Future research needs to address the questions of (1) the identification of elements in the job situation that are associated with recognition of content elements of the job and positive affect of the members within the organization; (2) the delineation of the contribution the kind of client served adds to the member job satisfaction; (3) the contribution the personal characteristics of the members of the organization adds to the total job satisfaction; and (4) the need for a holistic approach to investigating organizations in which the macro, micro, and environmental characteristics of the organizational context are included. 
AN INVESTIGATION OF THE RELATIOINSHIP OF ORGANIZATIONAL STRUCTURE TO JOB SATISFACTION WITHIN SOCIAL SERVICE ORGANIZATIONS SERVING ELDERLY CLIENTS

by

ANNE MARGUERITE WILKINSON

A thesis submitted in partial fulfillment of the requirements for the degree of

\author{
MASTER OF SCIENCE \\ in \\ SOCIOLOGY
}

Portland State University 
TO THE OFFICE OF GRADUATE STUDIES AND RESEARCH:

The members of the Committee approve the thesis of Anne Marguerite Wilkinson presented May 18, 1979.
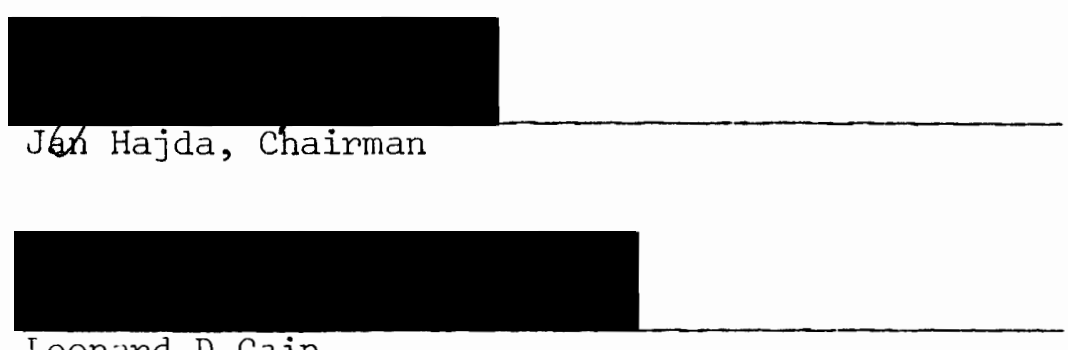

Leonard D Cain

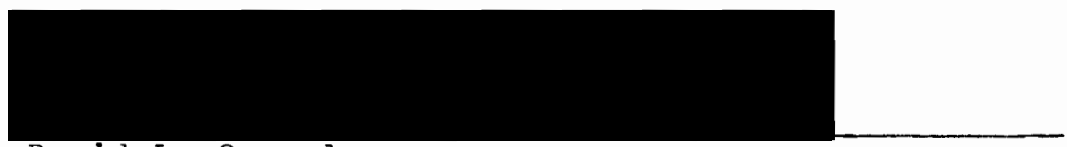

David L. Cressler

\section{APPROVED :}

Robert W. Shotola, Acting Department Head, Department of Sociology 


\section{ACKNOWLEDGMENTS}

The data for this thesis were gathered under a research grant to the Institute on Aging (of Portland State University) from the Administration on Aging; Department of Health, Education, and Welfare. My appreciation is expressed to the Institute on Aging and the staff of the Client Relations Research Project for the use of these data.

I would also like to gratefully acknowledge a number of people who aided and encouraged me during this endeavor, including Dr. Omer S. Ertur, Marilyn Petersen, Dr. Barbara Stewart, Dr. Douglas G. Montgomery, and, for their help in managing the computer, Ellen Jean, Marie Walters, and Karen King. I would also like to express my gratitude to my thesis committee for their kind, generous, and thoughtful contributions of time and expertise to me in this learning experience. Finally, I would like to thank my family for their support, understanding, and sacrifices. 
TABLE OF CONTENTS

PAGE

ACKNOWLEDGMENTS. . . . . . . . . . . . . . . . . . . . iii

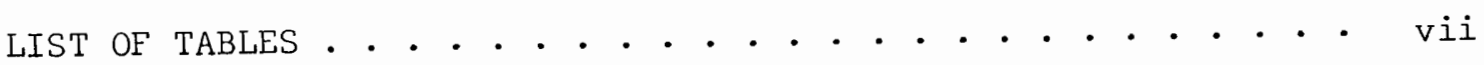

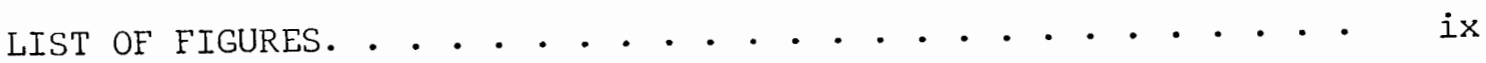

CHAPTER

I THE SOCIAL SERVICE SOCIETY • • • • • • • • • • • • 1

Introduction. . . . . . . . . . . . . . 1

The Service Society . . . . . . . . . . . 1

Shifts in Labor Force Composition . . . . . . . 4

The New Workforce . . . . . . . . . . . 12

Definition of a "Service Sector". . . . . . . . 18

Social Services, Job Satisfaction,

I I DIMENSIONS OF ORGANIZATIONAL STRUCTURE

AND JOB SATISFACTION. • . . . . . . . • . • 28

Introduction. . . . . . . . . . . . . . 28

Organizational Structure. . . . . . . . . 30

Organizational Structure and Attitudes. . . . . 36

Empirical Work. . . . . . . . . . . . . 39

Conclusion. . . . . . . . . . . . . . . . 44

Job Satisfaction. . . . . . . . . . . . . 45

Measurement of Job Satisfaction . . . . . . . 51

Summary . • . . . . . . . . . . . • 55 
CHAPTER

PAGE

III HYPOTHESES AND METHODOLOGY: INVESTIGATING

JOB SATISFACTION WITHIN A SOCIAL

SERVICE CONTEXT. • • • . . . . . . . . . 57

Hypotheses . . . . . . . . . . . . 57

Introduction

Theoretical Framework

Structural Variables

Activity Variables

Job Satisfaction

Methodology . . . . . . . . . . . . 78

Data Source

Introduction

Sample Frame

Selection of Agencies

Data Gathering Procedure:

Organizational Data

Data Gathering: Service

Provider Data

Description of Samples:

Onganizations

General Attitude Questionnaire

Organizational Fact Sheet

Reliability of Instruments

IV A DISCUSSION OF THE RELATIONSHIPS BETWEEN

ORGANIZATIONAL STRUCTURE AND JOB

SATISFACTION . . . . . . . . . . . . . . 100

Administration of Instruments:

Organizational Fact Sheet . . . . . . 100

Administration of Instruments:

General Attitude Questionnaire. . . . . 101

Scale Construction and Scoring:

Organizational Fact Sheet . . . . . . 101

Measurement of Job Satisfaction:

The General Attitude Questionnaire. . . . 109 
IV (Continued)

Intercorrelations of Scales. . . . . . . . 115

Summary. •. . . . . . . . . . . . . . 121

Intercorrelation of Job Satis-

faction Scale... . . . . . . . . 122

Data Analysis. . . . . . . . . . . . 123

Hypothesis Testing . . . . . . . . . . . 127

Summary. . . . . . . . . . . . . . 131

Conclusions. . . . . . . . . . . . . . 139

V A REVIEW OF THE FINDINGS AND A PLEA FOR

FUTURE RESEARCH. . . . . . . . . . . . . . 143

BIBLIOGRAPHY. . . . . . . . . . . . . . . . . . 156 


\section{LIST OF TABLES}

TABLE

I Civilian Labor Force (in millions). . . . . . . . . . 5

II Persons Engaged, By Sector and Major Industry Group,

Selected Years, 1929-65 . . . . . . . . . . 8

III Shares of Total Persons Employed, by Sector and Major

Industry Group, Selected Years, 1929-65 . . . . . 10

IV Occupational Distribution of Labor Force, 1930 and

1960........................

V Women in the Workforce, Total and Professional,

Technical, and Kindred, 1950-1970 . . . . . . . 14

VI Labor Force Characteristics, Industry and Service

Sectors, 1960 . . . . . . . . . . . . 15

VII Distribution of Employment Within the Services-Producing

Sector, 1870-1971, Distribution by Percentages . . . 16

VIII Social Service Types . . . . . . . . . . . . . 80

IX Service Provider Sample and Return Date . . . . . . . 81

X Characteristics of Agencies in Organizational Sample. . . 88

XI Characteristics of Service Provider in General

Attitude Survey Sample . . . . . . . . . . 91

XII Organizational Scale Items with Item Total

Correlations . . . . . . . . . . . 102

XII General Attitude Questionnaire Items Segregated by

Section of Job Satisfaction Dimensions . . . . . 110 
viii

TABLE

PAGE

XIV Intercorrelations of Organizational Structure Dimensions . . . . . . . . . . . . 116

$\mathrm{XV}$ Intercorrelation of Job Satisfaction Dimensions . . . 122

XVI Dimensions of Organizational Structure and

Job Satisfaction ............. . 124 


\section{LIST OF FIGURES}

FIGURE

PAGE

1. Persons engaged by sector, 1929-40, 1946-65. . . . . . . . 7

2. Sector employment as a percentage of total employment, 1929-40, 1946-65. . . . . . . . . . . 9

3. Organizational dimensions. . . . . . . . . . . . . . 58

4. Organization component of theoretical model. . . . . . . 59 


\section{CHAP'IER I}

\section{THE SOCIAL SERVICE SOCIETY}

\section{Introduction}

The effects of organizational structure on members' job satisfaction is considered to be of great importance by organizational researchers. Organizations involved in client serviee may confront several problems of structure that are less at issue in organizations processing non-human objects. These structural differences are derived from the capacity of the client to interact with those members of the organization responsible for the delivery of services. Because of the special dependence of the elderly on social service programs as a result of low or inadequate income, chronic illnesses that limit activities, and the social isolation of many elderly in our society, the organizations and workers serving elderly clients are especially useful representatives of service agencies in which to address the question of job satisfaction within social service organizations. Thus, the research proposed by this thesis will encompass an assessment of organizational structure within social service organizations and a survey of the members of those organizations serving elderly clients measuring their job satisfaction.

The Service Society

One of the hallmarks of a modern society is the number and 
diversity of formal organizations to be found within it. It appears that more of one's life is lived in formal organizations than at any other time in history. With industrialization comes increasing complexity, differentiation, and interdependence within society and man becomes increasingly involved in large-scale formal organizations. Modern society has often been called an "organizational" society.

The transition to an organizational society has been exemplified in the rise of a variety of social welfare programs and organizations in technologically advanced countries. The development of social welfare programs and institutions can be directly related to the development of industrialization and urbanization. With industrialization also comes a rise in the general standard of living and this rise in living standards inevitably leads, to varying degrees, to the rise of formally organized welfare institutions.

These institutions are designed to perform the general welfare functions, previously handled by the family, that are deemed important in technologically advanced society. Thus, industrialization gives rise to social welfare although the exact nature and timing of welfare developments are also contingent on a variety of historical, political, ideological, cultural, and structural elements unique to each society (Zald 1965). As Wilensky (1975) points out:

The welfare state is at once one of the great structural uniformaties of modern society and, paradoxically, one of its most striking diversities. Scholars impressed by the convergence of urban-industrial societies toward some common "post-industrial" condition can see in every rich country seven or eight health and welfare programs with similar content and expanded funding. . . Students impressed with the vast variety of "urban-industrial" 
or "affluent" societies can cite large differences in national effort and organization, in administrative style and related rhetoric, not to mention apparent contrasts in real welfare output (Wilensky 1975, pp. 1-2).

Our tremendous economic and technological development has moved American society from an agricultural phase, through an industrial phase, and is now pressing headlong into what has been called a "service phase" (Gartner and Riessman 1974). Numerous labels have been coined to describe this phase of modern economic development, including such terms as "post-scarcity" society, "post-industrial" society, the "human service" society, and the "welfare state."

[0]ne of the phenomena of the modern world is the proliferation of social welfare programs and their growth. In 1938-39 American state and federal social welfare services cost $\$ 4$ billion. . . In 1967-68 this had increased - . to $\$ 112$ billion. The latter made up $40 \%$ of all government expenditures . . . The total cost of social welfare expenditures, including those of voluntary agencies rose from 13.5\% of the Gross National Product in 1968 to $23 \%$ in 1971 (Macarov 1977, p. 1136).

The increase in social welfare programs has been linked to many factors including: level of economic development, a changing concept of commerce based on superproductivity with a reduced labor force, the impact of progressive and reform movements, a massive depression and subsequent recessions, two world wars, the "aging" of the populations of industrialized countries, and most recently, the "equality revolution" with its rising demands for human rights and a better quality of life for all citizens (Macarov 1977, Wilensky 1975, Bell 1973, Gans 1973, Fuchs 1968, Wilensky and Lebeaux 1965). This shift from a commerce to a welfare state has also been marked by a change in the function of social welfare itself, from 
a conceptualization of "residual" social welfare in which "the government or voluntary sources come to the rescue only when the family and marketplace have failed" (Macarov 1977, p.1135), to a more structural or "institutional" view "in which services are offered to everyone as a right . . " (Macarov 1977, p.1135). Social welfare has thus become an accepted, proper, and legitimate function of modern industrial society.

[T]he essence of the welfare state is government-protected minimum standards of income, nutrition, health, housing, and education, assured to every citizen as a political right, not as charity . . (Wilensky 197.5, p. 1).

These changing social values concerning social welfare have been translated into a profusion of service organizations and agencies designed to "deliver" the social welfare to which each citizen has a right. The result has been that the services have become "good business."

Do-gooding is a major growth industry. From organizations supported principally by voluntary sources, the . . services have become big business, large, complex, and diverse . . . Collectively, the human services constitute millions of consumers and employees and billions of dollars (Damone and Harshbarger 1974, p. xi).

\section{Shifts in Labor Force Composition}

The change from a commerce economy to a welfare or service economy has had an enormous impact on the make-up and placement of the nation's workforce. In 1947, U.S. employment totaled 58 million. The comparable figure for 1965 was 71 million, an increase of 13 million over 18 years. Nearly all this net growth occurred in the 
service sector whereas modest increases in manufacturing and construction were almost completely offset by declines in agriculture and mining. Between 1929 and 1965, service sector employment grew by 20 million while the industry sector increased by only 10 million and agricultural employment declined by 5 million (Fuchs 1968).

The transition in the composition of the workforce is shown in Table I. The shift can most dramatically be seen in sector employment, where goods-producing (agriculture and industry) workers declined from 82 percent of the workforce in 1970 to an expected low of 31 percent by 1980 and services-producing workers moved from a low of 18 percent of the workforce in 1970 to an estimated high of 69 percent by 1980 (Gartner and Riessman 1974).

TABLE I

CIVILIAN LABOR FORCE (IN MILLIONS)*

\begin{tabular}{lccc} 
& Total & $\begin{array}{c}\text { Goods- } \\
\text { producing } \\
\text { workers }\end{array}$ & $\begin{array}{c}\text { Services- } \\
\text { producing } \\
\text { workers }\end{array}$ \\
\hline 1870 & $100 \%$ & $82 \%$ & $18 \%$ \\
1940 & 51 & 49 \\
1947 & 50 & 50 \\
1980 (estimate) & 35 & 65 \\
\hline
\end{tabular}

*Gartner and Riessman 1974

In the decade following World War II, the United States economy, according to a variety of indicators, entered a new phase. About 1950, employment figures showed that 
there were more service-producing than goods-producing workers. During the course of that decade, there came to be more white-collar than blue-collar workers. And by the end of the decade, "professional, technical and kindred" workers exceeded for the first time the number of "managers, officials, and proprietors." In sum, the work done and the workers doing it had changed (Gartner and Riessman 1974, p. 120).

Table II and Figure 1 and Table III and Figure 2 from Fuchs (1968) show the absolute and relative trends in the industrial distribution of employment in the United States since 1929. The war years have been omitted because the changes in employment patterns caused by the war are, for the most part, irrelevant for the study of long-term trends in workforce composition. In 1929, the industry and service sectors were approximately the same size, but by 1965 , the service sector was 40 percent larger than the industry sector (Fuchs 1968). Table II and Figure 1 show absolute numbers of persons engaged in various sectors of the economy. Table III and Figure 2 show the percentage of total employment by sector. As can be seen, the service sector's share of total employment was slightly over 40 percent in 1929; by 1965, it had risen to almost 55 percent.

The tables and figures show the absolute declines in employment in mining and transportation and the sharp growth in importance of the service industry. The data presented in the tables and charts delineate three broad trends underlying the shift in the workforce: (1) the steady decline of agriculture throughout the period;

(2) the rapid growth of employment in government; and (3) the relative stability of employment in manufacturing, especially since the mid-1950's (Fuchs 1968). 


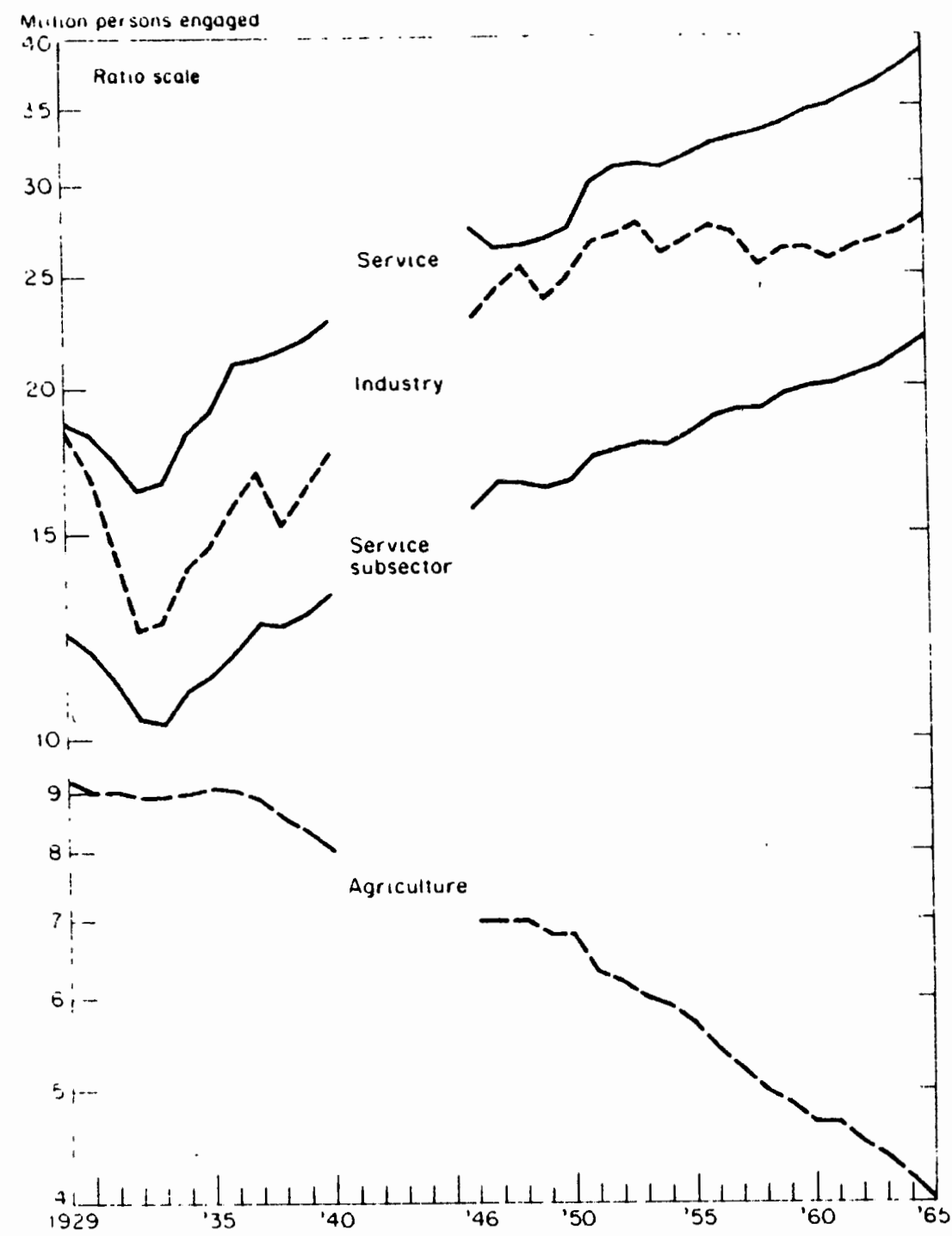

Note: See Table II for sector definitions.

Source: U.S. Department of Commerce, Office of Business Economics.

Figure 1. Persons engaged, by sector, 1929-40, 1946-65*

*Fuchs 1968. 
TABLE II

PERSOINS ENGAGED, BY SECTOR AND MAJOR INDUSTRY GROUP, SELECTED YEARS, 1929-65

(THOUSAINDS):

\begin{tabular}{|c|c|c|c|c|c|}
\hline & 1929 & 1937 & 1947 & 1956 & 1965 \\
\hline Agriculture & 9.205 & 8.864 & 7.006 & 5.425 & 4.039 \\
\hline Industry & 18,356 & 17.125 & 24.294 & 27.464 & 28.194 \\
\hline Service & 18.655 & 21.167 & 26.400 & 32,515 & 39.011 \\
\hline Service subsectior" & 12.26 .3 & 12,596 & 16.718 & 18,836 & 22.141 \\
\hline \multicolumn{6}{|l|}{ Industry } \\
\hline Mınıng & 1.017 & 943 & 97.3 & 884 & 670 \\
\hline Construction & 2.3106 & 1.738 & 3.007 & 3.700 & 3.971 \\
\hline Manufacturing & 10.556 & 10,686 & 15.406 & 17.702 & 18,443 \\
\hline Transportition & 3.034 & 2.333 & 3,045 & 2.803 & 2.486 \\
\hline $\begin{array}{l}\text { Communications and public } \\
\text { utultics }\end{array}$ & 1.034 & 901 & 1.190 & 1.792 & 1.513 \\
\hline Government enterprise & 409 & 474 & 673 & 883 & 1,111 \\
\hline \multicolumn{6}{|l|}{ Service } \\
\hline Wholesale trade & 1.744 & 1.8 .57 & 2.625 & 2.953 & 3.362 \\
\hline Retail irade" & 5.455 & 6.045 & 8.020 & 8.955 & 9.767 \\
\hline Finatlice and insurance & 1,207 & 1.065 & 1.290 & 1.825 & 2.318 \\
\hline Real estalte & 368 & 455 & 576 & 733 & 766 \\
\hline Households and institutions & 3,249 & 3,060 & 3.017 & 3.945 & 5.076 \\
\hline $\begin{array}{l}\text { Professiemal. personal. buss- } \\
\text { ness and teparr services }\end{array}$ & 3.357 & 3.579 & 4.78 .3 & 5.103 & 6.694 \\
\hline $\begin{array}{l}\text { Cienteral government (unctud- } \\
\text { ing as med forces) }\end{array}$ & 2.775 & 5.056 & 0.089 & 8.951 & 11.028 \\
\hline
\end{tabular}

*Fuchs 1968. 


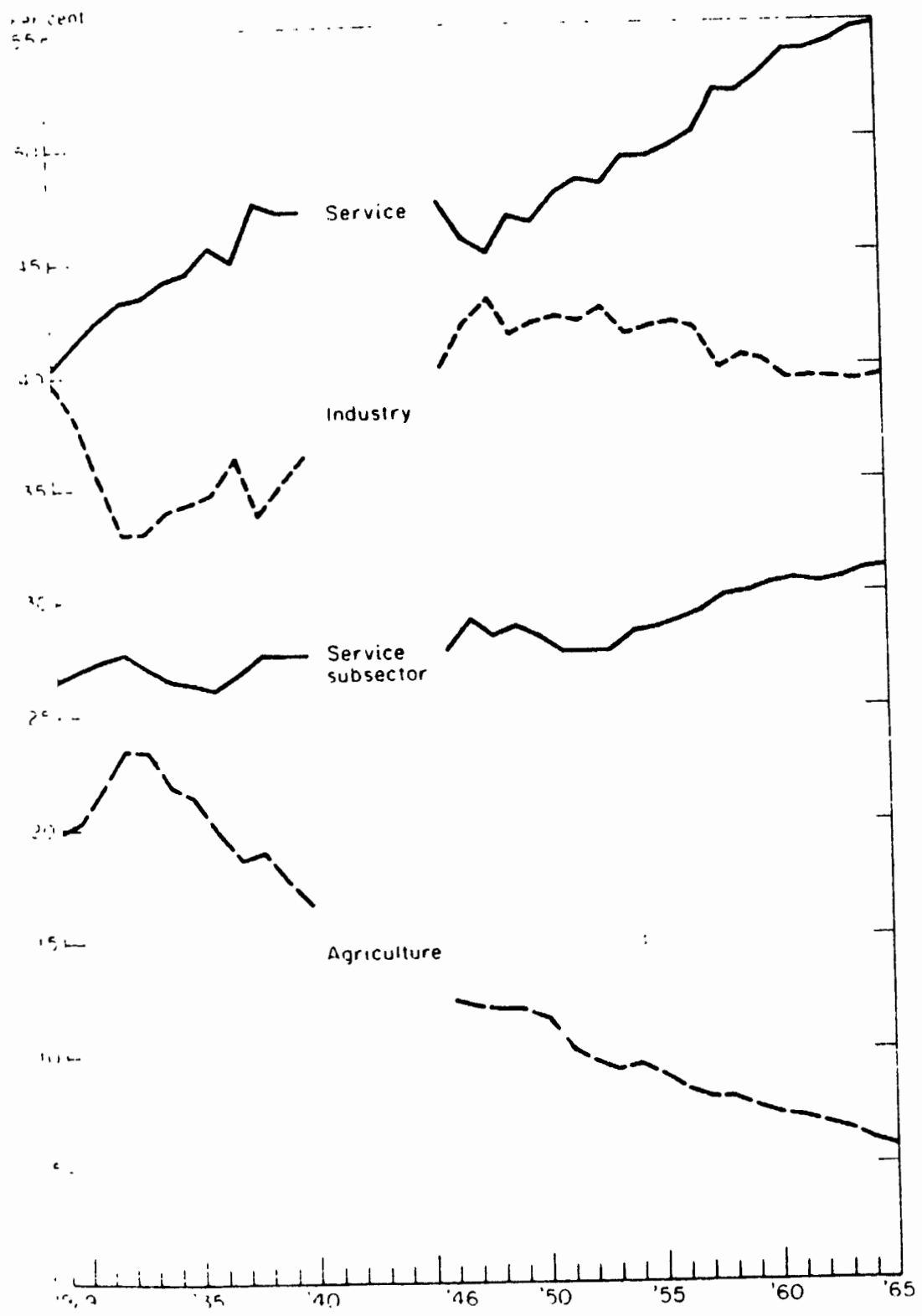

Source: See Figure 1.

Figure 2. Sector Employment as a Percentage of Total Employment, 1929-40, 1946-65 (Fuchs 1968). 
TABLE III

SHARES OF TOTAL PERSONS EMPLOYED, BY SECTOR

AIND MAJOR IINDUSTRY GROUP,

SELECTED YEARS, 1929-65

$($ PERCENT $) *$

\begin{tabular}{|c|c|c|c|c|c|}
\hline & 1929 & 1937 & 1947 & 19.56 & 1965 \\
\hline Agriculture & 19.9 & 18.8 & 12.1 & 8.3 & 5.7 \\
\hline Industry & 39.7 & 36.3 & 42.1 & 42.0 & 39.6 \\
\hline Service & 40.4 & 44.9 & 45.8 & 49.7 & 54.8 \\
\hline Service suhsector & 26.5 & 26.7 & 29.0 & 28.8 & 31.1 \\
\hline \multicolumn{6}{|l|}{ Industry } \\
\hline Mining & 2.2 & 2.1 & 1.7 & 1.4 & 0.9 \\
\hline Construction & 5.0 & 3.7 & 5.2 & 5.7 & 5.6 \\
\hline Manufacturing & 22.8 & 22.7 & 26.7 & 27.1 & 25.9 \\
\hline Transportation & 6.6 & 4.9 & 5.3 & 4.3 & 3.5 \\
\hline Communications and public utilities & 2.2 & 1.9 & 2.1 & 2.3 & 2.1 \\
\hline Government enterprise & 0.9 & 1.0 & 1.2 & 1.4 & 1.6 \\
\hline \multicolumn{6}{|l|}{ Service } \\
\hline Wholesale trade & 3.8 & 3.9 & 4.5 & 4.5 & 4.7 \\
\hline Retail trade & 12.9 & 12.9 & 13.9 & 1.3 .7 & 13.7 \\
\hline Finance and insurance & 2.6 & 2.3 & 2.2 & 2.8 & 3.3 \\
\hline Real estate & 0.8 & 1.0 & 1.0 & 1.1 & 1.1 \\
\hline Households and institutions & 7.0 & 6.5 & 5.2 & 6.) & 7.1 \\
\hline $\begin{array}{l}\text { Professional. personal. husiness and re- } \\
\text { pair services }\end{array}$ & 7.3 & 7.6 & 8.3 & 7.8 & 9.4 \\
\hline $\begin{array}{l}\text { (ieneral government including armed } \\
\text { forces) }\end{array}$ & 6.0 & 10.7 & 10.6 & 13.7 & 15.5 \\
\hline
\end{tabular}

Source: See Table II.

*Fuchs 1968. 
The shift of employment to services does not necessarily represent a sudden departure from previous long-term trends. On the contrary, historically there has been a tendency for the percentage accounted for by the service sector to rise.

Until 1920 the shift to services could be explained entirely by the movement from agricuitural to nonagricultural pursuits; employment in Industry rose as rapidly as employment in Service. After 1920, however, the nonagricultural sectors' rates of growth diverged; Industry's share of total employment tended to decline, and Services' rose sharpiy (Fuchs 1968, p. 22).

When the distribution of the Iabor force within the services is examined closely, it is, in fact, "professional" work that has grown most rapidly. As previously noted, the number of professional technical, and kindred workers, ("the elite categories of the new work") surpassed the number of managers, officials, and proprietors ("the elite categories of industrial work") sometime in mid-century (Gartner and Riessman 1974, pP. 121-122). It is estimated that by 1980, "operatives" (the semi-skilled workers central to mass production), who until 1970 were the single largest occupational category, will be "third in size ranking, outpaced by clerical, which will be the largest, and by professional and technical workers" (Bell 1973, P. 136). By 1970, white-collar workers outnumbered bluecollar workers by more than five to four; it is estimated that by 1980 the ratio will be five to three, with there being more whitecollar workers than all other occupational categories (Bell 1973, p. 17$)$. 
Many of the most important policy questions concerning employment are derived and formulated in terms of industries. Thus, it is important to examine workforce trends by occupation to see if any shift has taken place. Table IV classifies eleven major occupational groups according to "service type" or "goods-type." What appears to be happening is that the service-type group has grown rapidly (2.1 percent per year, 1930-1960) while the "goods-type" occupations showed no net change over the period. This is due to moderate gains in some goods-producing occupations that were offset by absolute declines in others. Thus, these occupational data suggest that the industry shift in employment, far from exaggerating the growth of service employment, may actually understate it, "because even within industries there has been a shift from the direct production of goods to service activities" (Fuchs 1968, pp. 32-34).

\section{The New Workforce}

Just as the kinds of work being done have changed, the composition of the workforce has also changed. Most "new jobs" added to the workforce between 1960 and 1970 were outside the goodsproducing sector. In addition, nearly two-thirds of the new workers were women--65 percent of the 11.9 million jobs added to the workforce were held by women (Gartner and Riessman 1974, p. 122).

Table V shows data for women in the work force, both total and professional, technical and kindred types of work. In 1950, 28 percent of the total labor force'was female, with 33 percent of all 
OCCUPATIONAL DISTRIBUTION OF LABOR FORCE, 1930 AND $1960 \%$

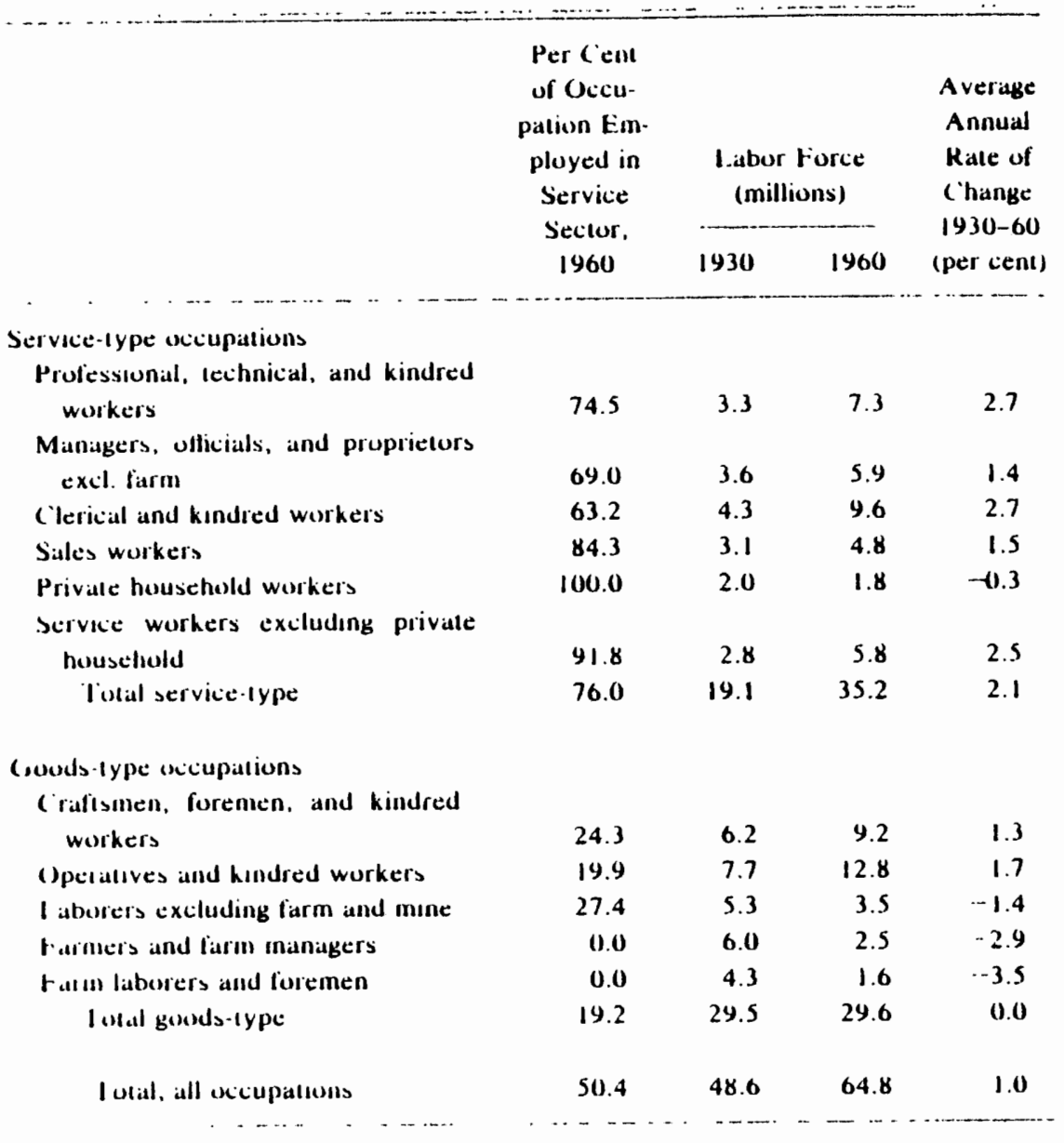

Source: 1930, U.S. Bureau of the Census, Occupational Trends in the United States, 1900 to 1950, Working Paper iNo. 5, 1958, Table I; 1960, U.S. Bureau of the Census, 1960 Census of Population; Vol. 1, Characteristics of the Population, Part l, "U.S. Summary," Table 201, and "Occupation by Industry," Table 1 .

*Fuchs 1968. 


\section{TABLE V}

WOMEN IN THE WORKFORCE, TOTAL AND PROFESSIONAL, TECHNICAL, AlND KINDRED, 1950-1970*

\begin{tabular}{lrrr}
\hline & 1950 & 1960 & 1970 \\
\cline { 2 - 4 } Total employed (in millions) & 65.7 & 72.5 & 76.5 \\
Percent women & $28 \%$ & $32 \%$ & $37 \%$ \\
Total professional, technical, & & & \\
and kindred (in millions) & & & \\
Percent women & 5.0 & 7.3 & 11.3 \\
& $38 \%$ & $36 \%$ & $40 \%$ \\
\hline
\end{tabular}

*Gartner and Riessman 1974, p. 123.

women of working age employed. In 1960, the figures were 32 percent women in the workforce, with 37 percent of all women of working age employed. By 1970, 37 percent of the total labor force was female. And, while white women made up fewer than half the white, professional, technical and kindred job holders, "black women, who in 1970 made up $42 \%$ of the total black employment, made up $55 \%$ of the black professional, technical, and kindred jobholders" (Gartner and Riessman 1974, p. 124).

Table VI presents data on labor force characteristics by sector and distribution of man-hours worked by sector. Again, both tables show that women play and important role in service sector employment with 46 percent of the total service sector composed of women and 60 percent of the total man-hours worked were worked by women. In addition, we find proportionately more older workers in services and more part-tine errployment (27 percent service versus 
TABLE VI

LABOR FORCE CHARACTERISTICS, INDUSTRY AND SERVICE SECTORS, $1960 *$

\begin{tabular}{|c|c|c|c|c|c|}
\hline & & \multicolumn{2}{|c|}{$\begin{array}{l}\text { Percentage of } \\
\text { U.S. Total in }\end{array}$} & \multicolumn{2}{|c|}{$\begin{array}{c}\text { Percentage of Sector } \\
\text { Employment }\end{array}$} \\
\hline & & Industry & Service & Industry & Service \\
\hline \multicolumn{2}{|c|}{ 1. All employed ${ }^{\mathrm{h}}$} & 43 & 50 & 100 & 100 \\
\hline 2. Females & , & 27 & 71 & 20 & 46 \\
\hline 3. Over 6.5 & & 25 & 59 & 3 & 5 \\
\hline \multicolumn{2}{|c|}{ 4. Part-limers } & 34 & 59 & 18 & 27 \\
\hline \multicolumn{2}{|c|}{ 5. Self-employed" } & 16 & 50 & 5 & 13 \\
\hline \multicolumn{2}{|c|}{ 6. Union members } & 82 & 17 & 57 & $y$ \\
\hline \multicolumn{2}{|c|}{ 7. More than 12 years of school } & 30 & 68 & 14 & 28 \\
\hline \multicolumn{2}{|c|}{ 8. Fewer than 9 years of school } & 49 & 37 & 34 & 22 \\
\hline
\end{tabular}

Source: Rows 1-5, U.S. Census of Population, 1960; row 6, H.G. Lewis, Unionism and Relative Wages in the United States, 1963, p. 251; rows 7-8, NBER tabulations of the 1960 U.S. Census of Population $1 / 1,000$ sample.

aFor. sector definitions, see Table II.

bCivilian employment, includes unpair family workers.

CExcludes unpaid family workers.

DISTRIBUTION OF INDUSTRIES AND MAN-HOURS BY PERCENTAGE OF FEMALE EMPLOYMENT, INDUSTRY AND SERVICE SECTORS, 1960*

\begin{tabular}{|c|c|c|c|c|c|c|}
\hline \multirow{2}{*}{$\begin{array}{c}\text { Percentage } \\
\text { remale }\end{array}$} & \multicolumn{2}{|c|}{$\begin{array}{l}\text { Number of } \\
\text { Industries }\end{array}$} & \multicolumn{2}{|c|}{$\begin{array}{l}\text { Percentage of } \\
\text { Industries }\end{array}$} & \multicolumn{2}{|c|}{$\begin{array}{l}\text { Percenlage of } \\
\text { Man-Hours }\end{array}$} \\
\hline & 1 & $\mathbf{S}$ & I & $\mathbf{s}$ & 1 & $\mathbf{S}$ \\
\hline 0 to 15.0 & 39 & 12 & 48.1 & 21.1 & 56.6 & 15.1 \\
\hline 15.11030 .0 & 23 & 16 & 28.4 & 28.1 & 21.5 & 23.3 \\
\hline 30.11045 .0 & 9 & 14 & 11.1 & 24.6 & 12.7 & 17.2 \\
\hline 45.11060 .0 & 6 & 7 & 7.4 & 12.3 & 4.7 & 16.2 \\
\hline 60. 1 and uver & 4 & 8 & 4.9 & 14.0 & 4.4 & 28.2 \\
\hline
\end{tabular}

*Fuchs 1968. 
18 percent in industry). Finally, unionization appears to be more important in industry than in service while higher levels of education are seen in the service sector.

Finally, Table VII presents data on employment shifts within the service sector itself. As can be seen, it is government that has expanded the most rapidly (see also Table II, Figure $l$ and Table III, Figure 2). Between 1929 and 1960 nonprofit and government employment more than tripled, while total employment and servicesproducing employment each less than doubled (Bell 1973, p. 147).

\section{TABLE VII}

DISTRIBUTION OF ELPLOYMENT WITHIN THE SERVICESPRODUCIIS SECTOR, 1870-1971, DISTRIBUTION BY PERCENTAGES*

\begin{tabular}{lrrrrrr} 
& 1870 & 1900 & 1920 & 1940 & 1947 & 1971 \\
\cline { 2 - 6 } & 20 & 23 & 27 & 17 & 16 & 9 \\
Transportation $\varepsilon$ utilities & & & & & & \\
$\begin{array}{l}\text { Trade, finance, real estate, } \\
\text { insurance }\end{array}$ & 28 & 30 & 31 & 36 & 42 & 39 \\
$\begin{array}{l}\text { Personal services } \\
\begin{array}{l}\text { Government } \\
\text { Federal } \\
\text { State and local }\end{array}\end{array}$ & 48 & 42 & 36 & 40 & 20 & 25 \\
\end{tabular}

*Daniel Bell, "Labor in the Post-Industrial Society," Dissent, XIX, I (Winter 1972), p. 166.

In addition, it is at the state and local levels, the primary place that services are delivered, that the greatest increases in employment have occurned. 
Although the relative growth of service employment has been particularly rapid in the past few decades, the trend has been evident for at least the past century in this country, and can also be observed in most growing economies. The pervasiveness of the trend to services is also observable within individual states; almost all have shared in growth of service employment" (Fuchs 1968, pp. 2-3).

What these data suggest is that there has been a major shift in the economy from goods-producing to services-producing work; from blue-collar to white-collar occupations; from nonprofessional to professional categories; that women play a special role in service work; and that traditional industry qualifications (e.g., physical strength, unionization, full-time employment) do not necessarily fit the demands placed on workers in the service sector.

Thus, the importance of the service sector in our modern economy can be seen in a variety of developments, whether in government or the private sector, including (I) the growing percentage of the workforce engaged in such work, (2) the increasing amount of such services delivered in terms of both numbers of recipients and the amount they consume, (3) the increase of women in the workforce, primarily in service delivery jobs, and (4) the growth of government in service delivery.

[An economic] sector that in the aggregate generates nearly half the country's gross national product. . . and that employs more workers than any other sector cannot be treated as a residual area . . . it is simply too important (Gartner and Riessman 1974, p. 17). 
Definition of a "Service Sector"

Service sector definitions vary as to what they include and what they exclude. For example, finance, insurance, real estate, retail and wholesale trade, transportation, communications, and personal services are included in many definitions along with health, education, and welfare services. Other definitions exclude all supportive services to goods production and business, such as transportation, public utilities, communications, wholesale trade, commercial banking, and advertising and emphasize the "human" services category of the service sector. Even in the works of a single author, there are variations in definition. Simon Kuznets included transportation, communications, and public utilities in his earlier work but excluded them in his most recent study (Fuchs 1968).

Primarily, two criteria are utilized when distinguishing the service industries from the goods-producing industries. They are (1) closeness to the consumer and (2) the presence or absence of a tangible product. There are problems with the classificatory ability of these two criteria, as Fuchs (1968) points out:

The notion of primary, secondary, and tertiary industries. . . is related to the degree to which the particular activitiy is distant from, or close to, the ultimate consumer. There are, however, several industries that service business firms--wholesale trade, commercial banking, advertising--but are nevertheless usually classified in the service or tertiary sector. A strict application of the intangibility criterion also presents problems. . . . It is difficult to make a sharp distinction between the activities of an auto assembly plant and those of an automobile repair shop, but the former is invariably classified in Industry and the latter is usually regarded as a service (p. 15). 
Thus, service distinctions based on closeness to the consumer and intangibility of product serve to distinguish the service sector as a whole but have less utility in delineating between service industries within the sector.

In describing the service sector, Victor Fuchs (1968) states that most of the industries within the sector are manned by whitecollar workers, that most of the industries are labor intensive, that most deal with the consumer, and that nearly all of the service industries produce an intangible product. In effect, Fuchs is suggesting four criteria distinguishing the service sector from industry-(1) their workforce composition, (2) labor intensity, (3) closeness to the consumer, and (4) lack of tangible product.

Yet, these four criteria generally apply to all industries within the service sector, to those servicing business as well as those servicing people. Gartner and Riessman (1974) distinguish the "human" services from all other services in two ways; one, human services are intended to produce benefit or well being for the recipient and two, the character of the human services is essentially relational, interpersonal, and humane.

Indeed, for us, the epitomes of the services are those which are most fully beneficial, have the least tangible character, and are closest to the consumer. Counseling, tutoring, and health education are examples of what we mean; each of them involves a one-to-one interpersonal relationship, they do not necessarily produce a tangible product or necessarily involve any physical object between server and served, and they are directly beneficial in purpose (Gartner and Riessman 1974, pp. 18-19). 
While those services that are least tangible, closest to the consumer, and most beneficial in purpose are the "quintessence" of the people-topeople type of services, there are variations within each of these basic characteristics. Profit and non-profit services both include the characteristics of intangibility and closeness to the consumer but the quality of benefit may be affected by the intrusion of the profit-motive. Likewise, the qualities of closeness and intangibility are affected when the service is provided through the intermediary function of a machine, such as a teaching machine (Gartner and Riess$\operatorname{man} 1974)$.

One other central characteristic of the criteria for the "human" services is added by Fuchs (1968), that is, the human services tend to involve the "consumer" in the production of the service. The consumer becomes a unique force in service delivery, both as a recipient and as a participant in the production of the service.

One problem arises because the consumer frequently plays an important role in the production of services . . . Their unmeasured input can have significant effects on productivity . . . In the laundromat and the supermarket, the consumer actually works, and in the doctor's office the quality of medical history the patient gives may influence significantly the productivity of the doctor . . . Thus, the knowledge, experience, honesty, and motivation of the consumer affect Service productivity (Fuchs 1968, p. 12).

Katz and Kahn (1966) also recognize the importance of the consumer in the delivery of services. Without the cooperation of the client, there in fact could be no service.

Human beings as objects of a change process require different organizational processes than materials transformed in a manufacturing plant . . . human beings are 
reactive, participating objects in any molding process, and their cooperation to enter many organizations is essential to its successful outcome (Katz and Kahn 1966, p. 49).

Parsons (1970) discusses three criteria that differentiate human service onganizations from goods-producing organizations: (I) these "social service" organizations must first be able to attract and then motivate clients to be served, that is, recipients must be recruited; (2) the interactions between clients and service organizations is "two-way," that is, both parties interact; and (3) the transactions of service organizations have traditionally not been directly subject to or determined by the requirements of the marketplace, that is, demand in traditional economic terms may not apply to many service organizations due to the association of "social services" to governmental and voluntary agencies. Therefore, service producing onganizations do not function within the same environmental context that goods-producing organizations do, particularly human service organizations. In traditional economic terms, consumers create demand for a product which is satisfied with the rise of goods-producing onganizations to manufacture the product. In the human services, demand may, in some cases, actually be created after the product is there for consumption. In addition, the client interacts with the service deliverer and thereby becomes part of the production process. In many cases, without the cooperation of the client, it may be difficult to deliver the service. The traditional laws of economic production 
may not apply to service organizations in that many are funded by public agencies which mandate the amount and type of service delivered. In addition, in the human services, consumers have a "right" to the service, that is, there is a public concern for the quality of service and increasingly, the quality of that service is not a function of an individual's ability to pay (Gartner and Riessman 1974). Part of these characteristics stem from the fact that many of those who deliver services and the organizations who hire them are supported totally, or in part, by public funds. But even when this is not the case, there is still some sense of the "rights" of the consumer.

For the workers within human service organizations, the central feature of their job, particularly at the direct service level, is serving people. Thus, a service "ethos" permeates the human services that does not affect goods-producing organizations. For the most part, the people delivering human services are doing so because of a desire to help people. There is a humanitarian ethic prevalent in the human services that is not in evidence in the industry sector of the economy. Thus, organizations involved in client service, theoretically at least, confront several problems of structure and activity which may be less at issue in organizations processing nonhuman objects.

Social Services, Job Satisfaction, and the Elderly

Modern man spends nearly one-third of his daily life "working" in some form. This work increasingly is occurring in organizations 
of a bureaucratic nature, particularly in modern, industrialized, technological societies. One distinctive characteristic of such all encompassing involvement in formal organizations has been cllased the "routinization of process"(Gross 1970). That is, the goal of the organization, whatever it is, is reduced to a flow of goods, services, materials, or people constituting an input, which is then treated routinely so that a predictable outcome is achieved. Elliot Friedson (1970) believes that,

[B] ureaucratic principles have come to dominate the process of industrial production and increasingly dominate the commercial organization of sales and many personal services ( $p$. 7l).

In other words, the principles of orderly, systematic administrative procedures designed to ensure that work in organizations is done efficiently influences all types of production in our society. "We have become accustomed to thinking of ourselves as a bureaucratic society" (Kahn et al. 1976, p. 178).

Organizational research has historically focused on performance, productivity, and the ways of attaining these goals. As a result, we actually know very little about the human costs and benefits involved in our ways of organizing for production. We know little of the meaning of work for organizational members and little about the mental and physical outcomes of organizational life.

Traditionally, all organizations have been viewed in the light of the classical economic market context. This is true even for organizations not producing goods but "services." Yet this ideal type of free-market economy may no longer fit an economic sector 
in which the commodities being purveyed are, for the most part, intangible, value is assessed in ways not applied in the goodsproducing sector, and production is "controlled" by state and federal government, numerous local service agencies, the professions, and even the consumers themselves. Thus, the shift to a service economy may also mean a shift in the kind of organizational analysis that needs to be done.

One important implication of this shift in the economy that particularly concerns labor is the issue of job satisfaction with the "new work." For many years the theory that with industrialization comes alienation because the individual has no contact with the final product of his labor and that mass production has resulted in the loss of personal identification with work has been held almost as a truth. Whatever the validity of such theory, the shift in the kind of work being done raises questions as to the nature and degree of satisfaction with work where the worker is in direct contact with the consumer.' Theoretically, the direct contact of provider and client creates the possibility for a more completely human and satisfying work experience. Furthermore; due to the fact that the worker sees the end product of his labors (the client), a more pervasive or widespread level of job satisfaction may be another consequence of the shift to a service economy.

As a result of the aging process, the elderly historically have been particularly dependent on social service organizations (due to their poverty, chronic illnesses, and tendency to live in 
urban areas). Because of this dependency, the quality of life for older Americans is, in turn, dependent on the quality of service delivery programs and organizations. During the late 1960's and early 1970's, the needs of the elderly were addressed in three important ways: first, Social Security benefits were increased and Supplemental Security Income was introduced for those older persons not covered by the existing Social Security programs; second, the Older Americans Act was passed in 1965 and was amended in 1973 resulting in greatly expanded social service programs for the elderly; and third, Medicare and Medicaid were introduced.

About ten percent of the population of the United States is 65 or older. Only about five percent of this elderly population resides in institutions (hospitals, nursing homes). Yet, for every person in an institution, there are two in the community who are homebound and one of every four of those homebound are bedridden (Shanas et al. 1968). The treatment and management of chronic illnesses is the major medical problem of America's elderly. About four older people in every five are afflicted to some degree by one or more chronic conditions (e.g., arthritis, rheumatism, heart disease, high blood pressure, impairment of hearing or vision). These chronic conditions severely limit the activities of about half of all Americans 65 and over (Manney 1974).

In addition, the severity of these illnesses increases dramatically with age. Between ages 65 and 74,40 percent experience some significant disability, above age 75, the prevalence of disability 
increases to 60 percent. Yet, older people are less often afflicted with acute illness--conditions lasting three months or less--and they are less likely to be injured than younger people. However, acute illness and injuries are more serious when they do strike older people. People 65 and older take twice as long to recuperate from an acute illness as those 45 to 64 . Similarly, older people take twice as long to recuperate from injuries. In all cases, older people with low incomes have more health problems and higher rates of disability and injuries than those with high incomes.

Inadequate or fixed incomes represent one of the most serious problems for elderly persons because so many social and health conditions are related or dependent on income. At least three of every ten elderly persons are likely to be in poverty as opposed to one of every eight younger persons. A 1972 report of the Bureau of the Census showed that 20 percent of all individuals 65 or over existed on incomes below the poverty level (Havighurst 1975). Thus, poverty, chronic illnesses, and the concomitant social isolation of the elderly result in one of every six elderiy persons not in institutions requiring one or more types of direct social services.

The elderly, due to their special circumstances and high dependency, consume a wide range of social and health related services; from special transportation programs to in-home nursing services, from nutrition programs to income maintenance programs, from special employment programs to senior centers. Therefore, the organizations delivering services to the elderly and the service 
providers working within those agencies are especially useful representatives of service organizations in which to examine the question of job satisfaction within human service organizations. 
CHAPTER II

DIMEISSIOINS OF ORGANIZATIONAL STRUCTURE

AND JOB SATISFACTION

\section{Introduction}

The dimensions of overall organizational structure have long been considered to have a major impact on the attitudes and behavior of individuals within organizations (James and Jones 1976). Early theories of social organization emphasized the conviction that the social structure "was the primary determinant of differential human characteristics" (Lichtman and Hunt 1971, p. 271). Classical organization theoriests proposed that these structural deterninants be utilized in the design of organizations to maximize efficiency. Twenty years later, neoclassical organization theorists proposed models based on the "more personalistic views of psychology" (Lichtman and Hunt 1971, p. 271). In reaction to traditional structural theorists, this school of thought rejected the importance of formal organizational structure in favor of the organization members. Finally modern structural theorists have attempted to integrate both the individual and the formal structure into a "unitary, systematic conceptual scheme" (Lichtman and Hunt 1971 , P. 271)

Modern organization theory proposes that human behavior in organizations is comprised of three elements: (1) the requirements 
of the organization, (2) the characteristics of people who populate the organization, and (3) the relations between them. Both classical structural theorists and modern structural theorists share a global theory of personality as a premise upon which the structure of the organization is designed. While traditional structuralists assume that man is lazy, untrustworthy, and works only for money, modern structural theorists argue that all men are interested in realizing their full potential. Both views share the assumption that "since people share certain important characteristics, differences in people or performance can best be explained in terms of differential positional occupancy in the organizational structure" (Lichtman and Hunt 1971, p. 272).

While individual characteristics tended to be ignored by traditional structural theorists, much of the modern structural theory has tended to focus on models such as Theory X-Theory $\mathrm{Y}$, mechanisticorganic, and bureaucratic-nonbureaucratic (James and Jones 1976). That is, these theories stress cognitive attributes, human experience, and individual differences as behavioral determinants. Thus, it appears that organizational research has fallen into two distinct categories: (1) studying organizational settings, i.e., studying the interrelationships among descriptive structural dimensions (classical organizational theory) and (2) studying individual differences within a single organizational context or a subsystem within a single organization (traditional organizational psychology). It has been stated elsewhere that the one approach looks at "organizations without people" while the other looks at "people apart from 
their organizational settings" (Herman and Hulin 1972, p. 85). Thus, the investigation of the influence of structure on attitudes has primanily been exploned within the areas of applied and social psychology. The next section of this chapter investigates organizational literature in terms of dimensions of organizational structure.

\section{Organizational Structure}

A literature review was undertaken in order to identify important aspects of organizational structure that could have an impact on the job satisfaction of onganizational members. A number of authors have presented taxonomic studies of organizational structure (Sells 1963, Porter and Lawler 1965, Indik 1968, Hall et al. 1967b, Prien and Ronan 1971, and Pugh et al. 1968).

Sells (1963) identified the following structural variables: (1) size, (2) differentiation by subgroup/levels, (3) autonomy, (4) control, reflecting degrees of centralization, controls on member behavior, span of control, sanctions, flexibility, communication channels, communication facilities, and openness of expression, and (5) role structure, reflecting degree of formalization, stratification by rank/status, hierarchical relations, permanence of boundaries and interpersonal distance. Porter and Lawler (1965), in analyzing organizational structure and individual behavior and attitudes, used both total organization properties and substructure properties. Total properties were: (1) size, (2) shape, tall or flat, (3) shape, centralized/decentralized. Substructure properties were: (1) organizational level, (2) line and staff hierarchies, 
(3) span of control, (4) size of subunits. Indik (1968) also used descriptive variables: (1) size, (2) span of control, (3) number of hierarchical levels, (4) authority structure, (5) communications structure, (6) degree of task specification, (7) degree of task interdependence, (8) task specialization, (9) stature and prestige structure, and (10) psychological distance between decision makers and operating levels in organization.

The above studies generally illustrate various opinions regarding what are considered to be the most relevant structural variables in relation to attitudes and behavior (James and Jones 1976). However, some of these variables appear to be interrelated. Several attempts have been made to develop a more parsimonious set of structural variables. Hall et al. (1967b) used judgment to categorize a number of structural measures: (l) complexity, including number of major activities, number of hierarchical levels, and number of subdivisions, (2) formalization, including centralization of authority and emphasis on written communication and going through channels, and (3) activities, including function and number of supportive departments.

Prien and Ronan (1971) factor analyzed 38 input and output organizational variables, including variables measuring organizational structure as well as organizational context (history, goals), organizational process (reward process), and organizational criteria. Factors which consistently appeared in three or more studies were: (1) organizational size, (2) formalization, (3) centralization of 
authority, (4) extent of technology, and (5) standardization with reference to skills and product complexity (James and Jones 1976 ). Dunteman (1966) factor analyzed responses to a questionnaire which included questions related to organizational characteristics, management attributes, incentive conditions, employee characteristics, and individual and organizational effectiveness. Factors which appeared to be primarily structural were: (1) size of onganization, (2) pay-skill level, (3) workforce reduction and job mechanization, (4) allocation of labor, and (5) technical personnel and controls versus protection against human liabilities.

Each of the above studies concerning dimensions of descriptive structure is subject to conceptual and/or methodological criticisms. For example, the dimensions presented by Sells (1963), Porter and Lawler (1965), and Hall et al. (1967b) are based on a priori categorizations lacking empirical verification. Secondly, it is questionable whether the three categories presented by Hall et al. (1967b) adequately encompassed all structural variance. The Prien and Ronan (1971) study would have been more informative if separate factor analyses had been conducted for separate domains for variables rather than a single factor analysis of a "hodgepodge" of heterogeneous measures (James and Jones 1976). Yet, it must be recognized that, in general, organizational analysis utilizes this kind of a priori approach in the selection of which variables to investigate. The state of the art of organizational analysis, particularly as it applies to the investigation of attitudes and behaviors, is such 
that very little else is available. There is, as yet, little empirical verification of organizational variables selected for study nor is there anything approaching consensus among organizational researchers as to which variables to look at and what those variables measure. The problem appears to be that there is no set of concepts concerning organizations and organizational structure that is agreed upon by even a small number of onganizational analysts. One of the most comprehensive attempts to identify dimensions of organizational structure was conducted by Pugh, Hickson, Hinings, and Turner (1968). Based on previous conceptual literature (Evan 1963, Hage 1965, Pugh, Hickson, Hinings, MacDonald, Turner, and Lupton 1963), Pugh et al. (1968) presented six "primary dimensions" of organizational structure: (1) specialization--division of labor according to functional specialization, (2) standardization--degree to which procedures (e.g., selection, advancement, workflow, control) are standardized, (3) formalization--the extent to which rules, procedures, instructions, and communications are written and the degree to which roles are defined, (4) centralization--measures of the "locus" of authority to make decisions affecting the organization, including decisions related to finances, evaluation, labor relations, and breadth of decisions, (5) configuration--shape of the role structure including subordinate ratios (span of control), height of workflow hierarchy and various percentage measures including percent of direct workers and non-workflow personnel, and 
(6) traditionalism--legitimized customs and bureaucratic procedures. The data gathered generated four dimensions of organizational structure: (1) structuring of activities, (2) concentration of authority, (3) line of control of workflow, and (4) size of supportive component .

While replications of the Pugh study (Inkson 1970a, 1970b) provide support for the majority of relationships, James and Jones (1976) criticize the study in that (1) cross validation measures are needed because of the limited sample size and (2) the emphasis on reasuring a priori structural characteristics might have provided common features of the set of a priori features rather than true dimension of organizational structure.

James and Jones (1976), using the Pugh et al. study as a basis, attempted a synthesis of the organizational structure studies. They proposed seven dimensions of organizational structure based on a compendium of studies including one, total organization size (Dunteman 1966, Indik 1968, Porter and Lawler 1965, Sells 1963, Prien and Ronan 1971). Two, centralization of decision making and authority, including locus of authority to make decisions (Pugh et al. 1968), centralization of authority (Hall et al. 1967a, Prien and Ronan 1971), shape--centralized or decentralized (Porter and Lawler 1965, Pugh et al. 1968, Sells 1963), differentiation by subgroups and levels (Sells 1963), shape--tall or flat (Porter and Lawler 1965 ), authority structure (Indik 1968), and "control" measures related to centralization (Sells 1963). Three, configuration, including the shape of the role structure (Pugh et al. 1968), span 
of control (Indik 1968, Porter and Lawler 1965, Pugh et al. 1968, Sells 1963), differentiation by subgroups and levels (Sells 1963), shape--tall or flat (Porter and Lawler 1965), number of hierarchical levels and subdivisions (Hall et al. 1967a, Indik 1968), and communication structure (Indik 1968). Four, formalization, including the degree of role definition and role structure (Pugh et al. 1968, Sells 1963), formalization of procedures (Prien and Ronan 1971), status and prestige structure (Indik 1968), emphasis on going through channels (Hall et al. 1967a), and extent of written communications (Hall et al. 1967a, Pugh et al. 1968). Five, specialization, division of labor according to functional specialization (Pugh et al. 1968, Sells 1963), line and staff hierarchies (Porter and Lawler 1965), and task specialization (Indik 1968). Six, standardization, degree to which procedures are standardized (Prien and Ronan 1971, Pugh et al. 1968), and degree of task specification (Indik 1968). And, finally, seven, interdependence of organizational components, degree of task interdependence (Indik 1968) and autonomy with respect to interorganizational functions (Sells 1963).

Again, the major criticism of this model is that the only measure of relevance to organizational structure is the fact that these dimensions have appeared in a number of studies in the literature. Thus, James and Jones' (1976) criticism of Pugh et al. is equally applicable here, i.e., all relevant dimensions of structure may not be encompassed. James and Jones (1976) acknowledge this point by saying that "the dimensions appeared to represent a consensus of current opinion and knowledge, although their relevance and 
construct validity await future research" (p. 83).

Organizational Structure and Attitudes

A review of the empirical work investigating the relationships between attitudes and organizational structure has revealed the following:

(1) For the most part, attitudes and behavior are considered separate and distinct categories. The literature which discusses the empirical research tends to evade the issue of distinguishing any relationship between the two variables, either when investigated together or separately. In general, attitude is translated to mean job satisfaction while behavior is translated to mean job performance. Numerous variables have been identified as part of these definitions, but they differ from study to study and result in a confusing array of conceptualizations.

(2) The empirical research tends to be methodologically diverse, as each study addresses a wide variety of differing aspects of both attitudes and behavion in organizations (especially when investigating the influence of the concept "structure" on the two variables). The research also varies from a within organization to a between organization comparison utilizing different types of samples. For example, comparisons of managers to subordinates that result in a sample dichotomy versus comparisons of differentiations among levels of management or workers. A frequently neglected area of investigation is the division of labor horizontally, as well as vertically, especially in the investigation of organizational attitudes and 
behaviors. Such sample dichotomization as managers versus workers tends to lead to problems of noncomparability in much of the empirical work.

(3) Most of the research designs used by structural researchers have not considered individual characteristics (e.g., age, education level, etc.) as part of the relationship between organizational structure and attitudes. As an exception, two studies (Bachman, Smith, and Slesinger 1966 and Tannenbaum and Smith 1964) have attempted to isolate attitude and behavior differences due to structural variables and individual differences. Herman and Hulin (1972) have criticised these studies because the methods used failed to distinguish between the effects of individual versus structural characteristics due to the operationalization of structure by composite "group perceptions." Since the method only ruled out individual differences from the group mean, it did not really test for the effects of individual as distinct from structural characteristics. Defining structural variables in terms of the perceptions of members has been used in empirical work as an attempt at translating objective organizational characteristics into terms meaningful to organizational members. This practice is problematic in that many of the empirical studies reviewed failed to specify how or why specific structure variables were chosen in the first place (Herman and Hulin 1972, Rousseau 1978).

In addition, these studies assumed that the objective dimensions of organizational structure chosen were isomorphic with the characteristics of the organization as perceived by the members. On the whole, 
there appears to be little effort made by researchers to determine if the a priori variables chosen are relevant to the organizational situation in which they were used.

(4) Researchers utilize a number of different types of methods to obtain their data. For example, Herman and Hulin (1972) used discriminate analysis to assess how attitude measures differentiated among technology measures, structural measures, and individual characteristics measures while Ghiselli and Siegel (1972) and Pugh et al. (1969) utilized factor analysis techniques. Still others-Pugh et al. (1968) and Inkson (1970a, 1970b)--used "personal judgment" in selecting their structural variables for comparison. This diversity of data generating and data analysis techniques contributes to the noncomparability of studies and confounds comparisons of findings.

(5) In addition, there is a prevalence of cross-sectional as opposed to longitudinal studies reported in the literature (as an exception, see Meyer 1972).

(6) Finally, Porter and Lawler (1965) demonstrated, in their review of this literature, that the research concerning these relationships generally encompassed only two sets of variables, namely organizational structure variables and attitude and/or behavior variables. Both Porter and Lawler (1965) and James and Jones (1976) hypothesized that these relationships could be influenced or moderated by still other sets of variables. This hypothesis should carry a great deal of weight when examined in the light of the evidence supporting attitude and/or behavior differences in 
the literature.

Another important element nissing from the empirical research is a recognition that the daily management activities of an organization (i.e., management techniques, leadership styles, decision making processes, etc.) may be as important in the influence of the organization on the attitudes and/or behavior of organizational members as is the structure of the organization.

Thus, when organizations differ in structure, that is, in the distribution of the units and positions within them, it is reasonable to conclude that the nature of the relationships among those units and positions and the leadership styles within those organizations may also be different. Even so, while the above statement appears obvious, there seems to be few adequate theoretical models yet established to address this issue. The empirical research is diverse, incorisistent, inconclusive, and the few "integrative" models that have been postulated (cf. Indik 1968, James and Jones 1976) need more empirical verification.

Empirical Work

Porter and Lawler (1965) postulated that attitudes and behavior would differ according to suborganizational properties, including organizational level, line and staff hierarchies, span of control, and size of subunits, and total organization properties, including size-total organization, shape--tall/flat, and shape--centralized/ decentralized. It was shown that five of the seven properties of organizational structure (span of control and centralization/ 
decentralization excepted) had some kind of significant relationship to either job attitudes or job behavior. Certain variables appeared to have stronger relationships to attitudes and behavior than others. The two properties of structure with the strongest relationships were organizational level and subunit size. Line/staff type of position total organizational size, and tall/flat shape (that is, a size by shape interaction) accounted for some significant relationships but the strength and clarity was not as great as level and group size. Herzberg (1957), in a review of the attitude-organization Iiterature up to that time, reported that job satisfaction increased monotonically with increasing levels within the organization. That is, middle management was more satisfied than workers but less satisfied than upper management. More recent studies (Porter 1962, 1964 , Rosen 1961, Handyside 1961) tend to support this conclusion. In addition, the research supports this conclusion for both nonmanagement and management levels.

Although the literature tends to support the importance of size as an influence on job attitudes, the effects of the size of one organizational unit may be moderated by the size of another organizational unit (e.g., Cummings and El Salmi 1970, England and Lee 1973, Mahoney et al. 1972, Porter and Lawler 1965). A number of attempts have been made to provide models for the relationship between size and behavior (Blau 1970, Meyer 1972, Indik 1968, Bass and Barrett 1972, Pheysey and Payne 1971, Ingham 1970). These studies support the conclusion that size, in and of itself, does not provide sufficient explanatory power concerning its effect on 
attitudes. Rather, size requires the inclusion of a number of other variables (e.g., formalization, specialization, differentiation, complexity, etc.) to which size is highly interrelated.

Talacchio (1960) postulated that with increasing organizational size, increased division of labor (affecting the nature of the job) and increased status differentiation (increasing the potential for interpersonal conflict) would result. He found that the larger the organization, the lower the satisfaction. Low job satisfaction was also related to absenteeism and interpersonal conflict.

However, Cummings and El Salmi (1970) found subunit and company size of less importance in determining managerial satisfaction than role diversity and job level. Role diversity and job level were found to be related to perceived need satisfaction and the possibility of need satisfaction. In terms of job level, the position one holds within the organization was found to have more influence upon one's attitudes than age, tenure, and education level (Herman and Hulin $1972)$.

Porter and Lawler (1965) reported no significant attitude differences associated with span of control. The majority of the job enlargement literature (management science) supports an opposite viewpoint. Research has shown that span of control is related to complexity of task. Thus, research on job enlargement has focused "directly on interactions between complexity of the job . . . and individual differences" (Herman and Hulin 1972, p. 87). This research tends to support the position that attitudes toward job 
enlargement are a function of both job variables and individual characteristics (Hackman and Lawler 1971, Hulin and Blood 1968, Blood and Hulin 1967, Turner and Lawrence 1965).

Porter and Lawler (1964) found a size-by-shape interaction accounting for different levels of job satisfaction in large/tall versus small/tall organizations, and small/flat versus large/flat organizations. This finding is confounded by the fact that Porter and Siegel (1965) testing the same hypothesis found no interaction.

Herman and Hulin (1972) in a review of the recent literature on organizational structure and job attitudes and behavior conclude that the evidence supports attitude differences as influenced by structure but not behavior differences. They state:

The evidence reported for attitude (especially job satisfaction) differentials by level in the hierarchy, functional division, group size, and perhaps an organizational size-shape interaction, is much more compelling than that for behavior differences. (p. 85)

The literature since the Herman and Hulin review has tended to focus on the relationships between hierarchical level and job satisfaction. The empirical support has been mixed. Heller and Yukl (1969) found levels to be related to differences in "perceived control" within the organization. Cummings and El Salmi (1970) reported differences in job satisfaction related to levels but Larson and Owens (1965), Jerdee (1966), and Graham (1969) did not. Berger and Cummings (1978) in a comprehensive review of the empirical literature conclude that occupational level and decentralization seem to be positively related to job satisfaction but that the 
relationships to span of control, organizational or subunit size, and line/staff distinctions were complex and difficult to determine. Locke (1976) reviewed the historical development of job satisfaction as a concept, the major theoretical orientations, and reviews of the empirical work and reports that the literature suggests that satisfaction is caused by challenging jobs (e.g., high autonomy, stimulation, responsibility, variety), high and equitable pay, good opportunities for promotion and good work conditions.

Adams et al. (1977) report positive relationships between satisfaction and occupational level and functional specialty. O'Connor and Cummings (1976) report that tension increases dissatisfaction while influence increases satisfaction. Katz and Van Maanen (1977) support Locke's (1976) contention that job satisfaction is caused by job properties (e.g., independence, challenge, variety), interaction features (leadership, feedback), and organizational policies (promotion, compensation). In addition, Dyer and Theriault (1976) report that job satisfaction was positively related to absolute level of pay, as well as some "fairness" measure of the degree to which it met expectations.

Most recently, integrative approaches have been advocated in which total organizational characteristics, subunit characteristics, and individual characteristics are to be investigated as they relate to job satisfaction (c.f., Rousseau 1978). As yet holistic approaches are few and far between and the evidence to support the hypotheses has yet to be widely sought. 
Conclusion

It becomes apparent after reviewing the literature that new models of organizational research are needed that encompass both individual and situational characteristics as antecedents of member attitudes and behaviors in organizations. While there are a few such models to be found in the literature, (James and Jones 1976, Indik 1968, Pugh, et al. 1968, 1969) only the Pugh et al. (1968, 1969) model has been empirically tested.

These models incorporate one unifying feature, that is, that organizational behavior and attitudes are seen as related to either the additive and linear aspects of individual and situational characteristics or to the interaction between the individual and situational characteristics (James and Jones 1976). This means that research investigating the effect of the organization on attitudes and behaviors must begin to assess both the micro and macro situational characteristics. This macro/nicro approach will necessitate a reconceptualization of the traditional descriptive and subsystems approaches used in organizational psychology. That is, this type of approach will require analysis of variables from all levels of the organization as well as the context (environment) in which the organization functions.

The micro level approach will aid in the understanding of the influence of individuals on the organization while the macro approach will aid in the understanding of how the characteristics of the organization (or workgroup) may influence member behavior and attitudes. Both appear necessary if we are to overcome the fragmentation of this area of organizational research and to allow us to clearly understand 
the relationship between onganizational situations and individual attitudes and behaviors.

Based on the literature review, it appears that of the many structural dimensions that have been cited or investigated in the influence of the organization on attitudes, size is the most important. While it is the most important, size in and of itself does not explain enough in relation to the effects of the organization. Rather, a number of other variables, some of which are highly interrelated to size, need to be included in the investigation. Thus, the relationships between the structural variables are complex and require the investigation of a multitude of interactions if they are to be of use in the assessment of member attitudes and behaviors.

\section{Job Satisfaction}

Despite the fact that job satisfaction is the most frequently researched job attitude and has been a topic of research for quite a long time, there still appears to be a serious lack of good theory within this empirical work. In general, job satisfaction has been of interest to social scientists concerned with the problems of work in industrial society, in particular organizational psychologists. A number of researchers have investigated job satisfaction as a result of a personal value system based on the assumption that work which enables the individual to fulfill his potential will be generally more satisfying than one that does not. Others have been interested in the concept in terms of the quality of one's life outside the work role (e.g., mental and physical health). While still others study job 
satisfaction in order to improve productivity and organizational functioning by improving the quality of the work experienced by employees.

There are a number of different conceptualizations of job satisfaction in the literature but they tend to fall into two distinct categories; (l) studies of overall job satisfaction (e.g., Brayfield and Rothe 1951), and (2) studies which deal with particular facets of an employee's job which are combined in some way to result in a total measure of job satisfaction (e.g., Alderfer 1969, Payne 1970, Porter and Lawler 1965, 1968, Smith, Kendall, and Hulin 1969). It appears that the majority of the research on job satisfaction is of the facetspecific type.

Within the facet-specific research one finds another dichotomy of viewpoint, that is, two views of facet-specific job satisfaction appear in the literature. One, the traditional point of view, assumes that the same dimensions of the job are capable of producing either satisfaction or dissatisfaction--a high amount of the dimension produces satisfaction whereas a low amount of the dimension produces dissatisfaction. Herzberg and his colleagues (1957, 1959) have challenged the traditional point of view with their "two-factor theory" of job satisfaction. They have argued that certain dimensions in the work situation (called satisfiers) are capable of producing satisfaction but play an extremely small part in producing dissatisfaction. On the other hand, other dimensions in the work environment (called dissatisfiers) are capable of producing dissatisfaction but do not generally (or necessarily) lead to satisfaction. Few studies have had the impact or 
generated such intense debate as has the two-factor theory. Numerous studies attempting to replicate the findings have since been published with conclusions ranging from close confirmation to totally divergent results.

Several authors have evaluated the empirical research on the "two-factor theory" as (1) a simplistic approach to motivation in the work context (Dunnette, Campbell, and Hakel 1967), (2) that it ignores individual differences in the determination of job satisfaction (Dunnette, et al. 1967), (3) that it is "shackled" to its data gathering method (retrospective storytelling) because many of the attempts which utilize this procedure do tend to support the theory while studies utilizing other data gathering procedures tend not to support the theory (Hinton 1968), (4) that static measures of job satisfaction were used (Hinton 1968), (5) that the authors used subjective coding of the interview material (Ewen 1966, Dunnette and Kirchner 1965), and (6) that the study may be a case of the individual projecting failure to external sources (Dunnette and Kirchner 1965). Support for the theory has been reported in the literature (Schwartz et al. 1963, Saleh 1964, Meyers 1964) but the studies all use the same data collection procedures as the original research and therefore may not be adequate tests of the theory itself.

Ewen, Hulin, Smith, and Locke (1966) attempted to replicate the Herzberg findings. A number of hypotheses for which Herzberg's theory and the traditional unidimensional theory make different predictions were tested on a sample of 793 male employees in industrial and business organizations. The "satisfiers" (or intrinsic facets) were defined as 
(1) the work itself, (2) promotions, and (3) responsibility. The "dissatisfiers" (or extrinsic facets) were defined as (I) company policy and administration, (2) supervision, (3) working conditions, and (4) pay. The data tended to support the traditional point of view in that the dissatisfaction with satisfiers (work, promotion, responsibility) did lead to dissatisfaction with the job. The results indicate that satisfiers are more strongly related to both overall satisfaction and overall dissatisfaction than the dissatisfiers (pay, etc.), thus suggesting that the extrinsic variables may depend on the level of satisfaction with the intrinsic variables. The authors conclude that the concepts of satisfiers and dissatisfiers do not accurately represent the manner in which job satisfaction variables operate.

Several reviews of the literature have attempted to evaluate the empirical evidence in support of and the evidence against the "twofactor theory" of job satisfaction. The conclusion advanced by Smith and Cranny (1968) seems dominant at the present time:

Herzberg must be given credit for highlighting the essential multidimensionality of satisfaction. The weight of the recent evidence, however, is against his two-factor oversimplification. (p. 471)

Three types of explanations historically have been suggested to account for the variation in the job satisfaction of workers; one, explanations in terms of the personalities of the individual workers (e.g., Vroom 1964). This line of reasoning is considered inadequate because it ignores the association of job satisfaction with job characteristics. Two, explanations in terms of differences in the nature of jobs people perform. These studies generally deal with two 
sets of variables, one a measure of work role characteristics and two, a measure of job satisfaction. For example, Porter and Lawler (1965) utilized characteristics of organizational structure such as size and span of control and Shepard (1970) used job content factors such as degree of specialization of task to measure their relationship to job satisfaction.

A widely tested theory of the determinants of this type of explanation is the "two-factor theory" of Herzberg et al. (1957, 1959) in which the variation in job satisfaction is characterized as a "structural" one because the attitudes of workers are seen as a direct reflection of the structure of the work place.

The "two-factor theory" approach raises theoretical problems in that it does not consider individual differences in the expressed satisfactions. These differences in satisfaction occur not only because people evaluate similar "objective" job characteristics differently but also because people seek different satisfactions from their work (Kallenberg 1977).

Derived from the criticism of the structure-satisfaction viewpoint, a third approach has been suggested by Goldthorpe and associates (1968). They postulated that satisfaction with work cannot be thoroughly understood without knowledge of the meanings that individuals impute to their work activity. Studies based on this perspective have attempted to establish "the ways in which the wants and expectations that people attach to their work activity shape the attitudinal and behavioral patterns..." (Kallenberg 1977). This "social action" frame of reference has not yet systematically or empirically established 
the ways in which meanings and the various satisfactions that work provides combine to determine job satisfaction.

Job satisfaction has often been discussed in terms of "morale," "identification," "job attitudes," "organizational climate," "organizational behavior," "cohesion," and "loyalty." It is interesting to note that while there is general agreement among job satisfaction researchers that satisfaction is determined by facets of the job situation, there is no consensus on which facets of the job are relevant in a particular setting. Despite the proliferation of empirical studies concerning job satisfaction, our understanding of its causes remains vague and confusing. Until very recently, conceptualizations of job satisfaction have been largely psychological and individualistic in orientation. There is another problem in that researchers do not agree whether the determinants of job satisfaction lie solely in the job itself (the intrinsic view), whether they reside solely in the worker's mind (the subjective view), or whether satisfaction is the result of an interaction between the worker and the work environment (Seashore and Tabor 1975, Locke 1969).

Locke (1976) has shown in a review of the literature that, in general, satisfied people are more satisfied with their life, have better physical and mental health, and tend to be on the job more frequently and leave the organization less frequently than those who are dissatisfied. There is as yet no theoretically compelling or empirically strong relationship between satisfaction and performance.

Recent studies continue to support these findings. London 
et al. (1977) Kavanaugh and Halpern (1977), and Ilgen and Hollenback (1977) report that job satisfaction is related to general life satisfaction and the degree to which one's job is important to one's life.

The job satisfaction/absenteeism/turnover relationships have had a great deal of attention but the results have been mixed. Smith (1977) and Ilgen and Hollenback (1977) both report studies where satisfaction was negatively related to absenteeism. However, Nicholson et al. (1976) in a review of 29 studies plus conducting one of their own showed that dissatisfaction had little impact on absenteeism.

Measurement of Job Satisfaction

Various measures have been constructed based on a wide variety of facets of job characteristics. For example, the Job Descriptive Index, the Minnesota Satisfaction Questionnaire, the General Motors Faces Scales, and the most recent, the Index of Organizational Reactions. Dunham et al. (1977) compared the Index of Organizational Reactions to the other three measures and results showed acceptable discriminant and convergent validity for all four measures. However, the dimensions did not always coincide and the construct validity of the dimensions and their relevance in the job situation are still. open to question.

Even now there is little agreement on the specific meanings of some terms (such as autonomy, motivation, supervision, participation), yet most of the research in the area is conducted with the assumption that we all know and agree on the meaning of these terms. And, as in the research on structural dimensions of organizations on job 
satisfaction, there have been few attempts to integrate or comparatively test theories. The research thus leaves us with little understanding of how job facets combine, their relative importance, and the changes that may occur in their importance due to individual differences, different settings, and over time.

The number of different conceptual distinctions of job satisfaction has led to it being measured in a variety of ways. It is not at all clear whether many of the measures are, in fact, measuring the same thing. Typically, it has been assumed that they do and thus data is collected with various approaches and has been "pooled" to reach conclusions about the relationship of satisfaction to a number of other variables. Since few studies have measured satisfaction in more than one way and compared the results, it is not clear that this is justified.

As stated previously, there are two primary measures of job satisfaction; one is overall measure of job satisfaction and, two is satisfaction with particular facets of one's job. Many of the ways job satisfaction has been defined specify different ways of measuring facet satisfaction and different ways of combining data in order to measure overall satisfaction. These satisfaction definitions also differ in the kinds of facets they include and in what they mean by a facet. Some measure satisfaction in different "need areas" (e.g., Porter 1961) while others measure satisfaction with concrete job factors as in pay and promotion (e.g., Smith, Kendall, and Hulin 1969). Finally, some of the definitions are direct "feelings" ratings while others are statements about the causation of satisfaction. All of 
these views share the important problem of specifying which facets are relevant in a given setting to a particular person and in defending their choice of facets (Wanous and Lawler 1972).

Typically, three procedures have been utilized when measuring facets of a job, particularly when combining those facets in an overall job satisfaction rating. One way to measure job satisfaction is to weight certain items of response based on the differential importance of the facets with the importance determined by the respondent, on theoretical or empirical importance, or upon empirically derived weights that maximize the correlation between the variables (Seashore and Tabor 1975, Wanous and Lawler 1972). Seashore and Tabor (1975) evaluate this type of procedure in the following way:

While the logic of weighting is impeccable and the operations are relatively simple, there is an emerging consensus that differential item weighting seldom offers a significant gain in construct validity, measurement reliability.; or. predictive power (p. 337 ).

Seashore and Tabor (1975) then cite plausible reasons for this result, (1) the weighting of facets in job satisfaction indexes has already been incorporated efficiently, perhaps unconsciously, by the individual in giving his responses to either descriptive or evaluative queries about his job, so that further weighting introduces little other than error, and (2) even powerful weights have little influence upon summative indexes when, as is usually the case, the component facets are numerous and the facet responses are positively correlated.

Another way to measure job satisfaction is to "hierarchically organize" the data into factors, indexes, or dimensions that may be based on either rational or empirical grounds (Seashore and Tabor 1975 , 
Wanous and Lawler 1972). Rational organizing of the data reflects the intentions or interpretations of the index author while empirical organization reflects statistical clustering. These procedures are useful in many ways but there is still the problem of the "correct" dimensioning of job satisfaction since there is little consensus in the literature as to what facets apply where and in what ways. The major issue still to be resolved here is that no definitive domain of relevant facets has yet to be established or agreed upon by a majority of organizational researchers.

Finally, a thind way that job satisfaction is measured is by utilizing discrepancy scores where measures of facet satisfaction are derived by subtracting the reported degree of facet fulfillment ("is now") from the respondents report of how much of the facet he would like to have ("would like") or how much he thinks there should be ("should be"), or the rating of importance. Seashore and Tabor (1975) describe this measure of satisfaction in this way:

While discrepancy scores have some conceptual elegance and provide a desirable linkage to psychological theory, there is little evidence that the resulting derived facet satisfaction measures are empirically more valid or more reliable than more direct estimates ( $p$. 339).

The arguments against the use of discrepancy scores are summarized by Seashore and Tabor (1975), (1) the units of measurement of derived scores (i.e., equivalence of scale intervals and "objective" reference of scale points) are ambiguous and make the scores less meaningful for descriptive purposes, (2) the errors of measurement and two bias components may be additive rather than randomly off-setting, and (3) the respondent's experience of discrepancy may be incorporated in his 
perception and report of degree of fulfillment (the "is now" rating) with the effect that the calculation of discrepancies is similar in its effect to differential weighting of doubtful effectiveness.

There is support for the use of discrepancy scores in the literature (Porter and Lawler 1968, Locke 1969, Wanous and Lawler 1972) in that their usefulness resides particularly in their empirical nature, that is, derived facet scores have been shown to work as representations of satisfaction in hypothesis testing and predictive schemes (Porter and Lawler 1968, Locke 1969). Wanous and Lawler 1972, in a study comparing the nine most popular methods of measuring job satisfaction showed that the discrepancy score worked better than the nondiscrepancy scores.

$\underline{\text { Summary }}$

Thus, after reviewing the literature on job satisfaction, it is apparent there is a dearth of good theory of job satisfaction to guide research; that there is little consensus upon what it is that should be investigated and in what particular settings; and that many of the operational definitions of job satisfaction imply different meanings of what it is to be satisfied. It is also apparent that there is a divergence of job satisfaction measures when correlated with facet specific or global satisfaction; that is, the operationalizations of job satisfaction measures diverge between additive, discrepancy, and weighted formulations. The literature has also shown that many of the scales or job satisfaction indices are not highly correlated and thus it is not safe to assume that, although indices reportedly measure satisfaction, they may not measure the same thing (Wanous and 
Lawler 1972).

What all this seems to say is that there is, as yet, no one best way to measure satisfaction. The best way depends on what independent or dependent variable the satisfaction measure is to be related to. In addition, the literature suggests that it is possible to measure satisfaction validly with different job facets since satisfaction with different facets has been shown to have differential correlations with various dependent variables. This all points out the need for adequate theory and methods in order to accurately delineate the various ways of measuring satisfaction, the various kinds of facet satisfaction, and the respective independent and dependent variables associated with satisfaction in particular settings. 
CHAPTER III

HYPOTHESES AND METHODOLOGY: INVESTIGATING JOB SATISFACTION WITHIN A SOCIAL SERVICE CONTEXT

\section{HYPOTHESES}

\section{Introduction}

While an integrated approach has been advocated in the literature, it is well beyond the scope of this project to examine this question in such detail. Here the concern is limited to a preliminary examination of organizational structure and job attitudes within a social service organizational context. Although it is possible, even probable, that other factors (e.g., environmental, individual) moderate or condition the relationships being addressed by this study, this initial step in the direction of a holistic approach is deemed important and necessary since the area of job satisfaction within social service organizations appears to be somewhat uncharted territory.

\section{Theoretical Framework}

An exception to the research limitations discussed in the previous section is a study by Ghiselli and Siegel (1972) in which they suggest a research model where dimensions of organization in relation to attitudes and behavior can be compared. In their model the organization is divided into its structure, its activities, and the interaction of the structure and activities as shown in a criterion of 
effectiveness (see Figure 3 ).

According to the authors, organizational structure can be compared in terms of (1) people (size), (2) groups (functional divisions, line or staff), or (3) levels of management and shape (centralized or decentralized, tall versus flat). Organizations can also be compared according to the "coordinative relationships among the organizational structure; such as "integrative processes," for example, decisionmaking processes, communication patterns, control mechanisms, or leadership styles (p. 617). Finally, organizations can be studied by comparing the interaction of structure and the coordinative processes through some criterion of effectiveness, such as job satisfaction (e.g., Porter and Lawler 1965) or job performance (e.g., Meltzer and Salteri 1960, Carzo and Yanouzas 1969).

\begin{tabular}{|c|c|c|}
\hline $\begin{array}{l}\text { Organizational } \\
\text { Structure: }\end{array}$ & $\begin{array}{l}\text { Integrative } \\
\text { Processes: }\end{array}$ & $\begin{array}{l}\text { Criterion of } \\
\text { Effectiveness: }\end{array}$ \\
\hline $\begin{array}{r}\text { e.g., size } \\
\text { groups } \\
\text { levels }\end{array}$ & $\begin{array}{c}\text { e.g., decision- } \\
\text { making } \\
\text { communications } \\
\text { control }\end{array}$ & $\begin{array}{r}\text { e.g., job satisfaction } \\
\text { job performance }\end{array}$ \\
\hline
\end{tabular}

Figure 3. Organizational dimensions. (Model from Ghiselli and Siegel 1972)

This model appears to have the most utility for the examination of the question of the influence of the organization on attitudes (job satisfaction) or organizational members. Thus, the social service organizations investigated in this study will be compared on structure, integrative processes, and on the influence of structure and 
processes on job satisfaction.

Based on the review of the literature and the model presented by Ghiselli and Siegel (1972), a model of organizations was designed in order to guide the investigation of structural and situational characteristics of organizations as they influence individual attitudes toward the job.

Organizations were divided into three dimensions: the formal structure of the organization, that is, the enduring characteristics of organizational structure; the daily management-activity of the organization, that is, the day-to-day management procedures in order to achieve organizational goals; and a job criterion of job satisfaction, that is, the feelings a worker has toward his job (see Figure 4).

\begin{tabular}{|c|c|c|}
\hline $\begin{array}{c}\text { Formal Structure } \\
\text { (Organizational } \\
\text { Structure) }\end{array}$ & $\begin{array}{c}\text { Management-Activity } \\
\text { (Integrative } \\
\text { Processes) }\end{array}$ & $\begin{array}{l}\text { Job Satisfaction } \\
\text { (Job Criterion) }\end{array}$ \\
\hline
\end{tabular}

Figure 4. Organization component of theoretical model.

Structural Variables

Based on a review of the literature, the structural variables postualted.to have an influence on member attitudes were: (1) size, (2) formalization, (3) complexity, and (4) external dependence. Size. Of the many organizational variables examined in relation to member attitudes, organizational and subunit size are utilized 
most frequently. Both the theories and the research regarding the effects of size on various dependent variables have been contradictory. For example, Blau (1970) has theorized that the larger the organization, the greater the structural differentiation. This increased differentiation in turn resulted in an enlarged administrative component and staff to effect coordination, communications and control due to increased complexity. The point Blau is trying to make is that as size increases, the problems associated with increased differentiation also increase and thus, a greater need for control. mechanisms within the organization arises. This need for greater control results in the implementation of general and impersonal rules and procedures (formalization, standardization) in order to achieve organizational goals. A conclusion to be drawn from the above theory is that many of the structural characteristics of organizations (e.g., size, formalization, configuration, specialization, standardization, centralization, etc.) may all be positively, and highly, correlated with one another.

For example, in a study by Pugh et al. (1968), specialization, formalization, and standardization were all found to be highly related to one another and to size. Also, Hage (1965) found that centralization was highly related to formalization. Chapin (1951) and Tsouderos (1955) suggest that increased size is related to an increased degree of bureaucratization. Hall (1963), in contrast, found that size was not a major factor in determining the degree of bureaucratization in organizations. Terrien and Mills (1955) suggest that the administrative component increases disproportionately in 
size as organizational size increases. Anderson and Warkov (1961) found that larger organizations contained a smaller proportion of personnel engaged in administration. Haas et al. (1963) suggest that the relationship between size and administrative component may be curvilinear, with the administrative component at first increasing disproportionately in size and then decreasing with further organizational growth. Pugh et al. (1969) concluded that organizational structure was largely determined by size, in addition to dependence on a parent organization and, what they termed, a "charter-technologynexus." Studies by Inkson et al. (1970a, 1970b) supported conclusions that organizational size and technology provided the major influence for structuring of activities within the organization.

However, Pondy (1969) and Holdaway and Bowers (1971) found inverse relationships between size and span of control. Hall et al. (1967a)also found few relationships between organizational size and other structural variables. Hall et al. (1967a) point out the following :

It is commonly noted that the size of an organization somehow 'makes a difference' in other structural variables. Caplow (1957) and Grusky (1961), among others, have assumed that large organizations are, by definition, more complex and formalized than small organizations, while Blau and Scott (1962)...have argued that size may not be such a critical factor... In short, there is agreement that size affects structure, but there is no agreement on the relative importance of size vis-a-vis other aspects of organizational structure (p. 904).

Thus, while the evidence is somewhat mixed, there is little doubt that size is an important organizational variable, not only for its postulated influence on member attitudes, but also because it is often 
related to many other structural characteristics of organizations. Size is defined as "the scale of operations of an organization as determined by the number of employees," based on Price (1972), Pugh et al. (1969).

Hypothesis Number 1. The langer the organization, the lower the job satisfaction of organizational members with the organization. Formalization. For the most part, the terms used to describe formalization in the organizational literature refer to the use of writeen norms (Pugh, Hickson, Hinings, and Turner 1968). Hage and Aiken (1970) have stated that organizations need daily guidelines for their operations and that these guidelines are fuenished by rules (the repository of past experience). An organization which compiles its norms in written form is more formalized than one which does not. In addition, organizations which compile their norms in written form will generally have more explicit norms than organizations that do not (Price 1972). Similarly, an organization that bases its day-today operating procedures on written rules and regulations can also be thought of as more formalized than one that does not.

Many investigators have examined the concept of formalization. For example, Hage and Aiken (1969), Pugh et al. (1968), Prien and Ronan (1971), and Hall et al. (1967). Hage and Aiken (1969) investigated the determinants of routine technology utilizing interview techniques with the directors or supervisory personnel of 16 social welfare and health organizations. They predicted a positive relationship between routine work and formalization, that is, the more routine the work, the greater the formalization. Significant 
relationships were found between routine work, on the one hand, and rule manual, job description, and specificity of job description, on the other. They concluded that an organization in which the rules are important is probably an organization in which the rules are explicitly stated.

In relation to the hypotheses concerning formalization, studies have shown that a highly formalized organization is also one that is more routinized (Hage and Aiken 1969). Routine work may thus become dull, mechanical, nonchallenging, or boring. Thus, a highly formalized organization may produce tasks that do not challenge an organization member's talents, abilities, or intellect. A highly formalized organization may thus create job dissatisfaction for the organization member, through routinized work tasks and strict procedural guidelines that allow little individual initiative or creativity in the daily discharge of work.

As is the case with organizational size, many variables are considered to be interrelated with formalization, e.g., centralization (Hage \& Aiken 1967), specialization, standardization and centralization (Pugh et al. 1968), and configuration (tall versus flat) and administrative centralization (Ghiselli and Siegel 1972). In addition, formalization and standardization are often confounded in the literature (cf. Prien and Ronan 1971) in that they are operationalized to measure the same thing. Further, specialization, a structural variable closely related to formalization, has been considered to increase as the complexity within an organization increases. Thus, increasing the number of events in the organization leads to increased 
division of lator, task specialization, and often more elaborated line and staff hierarchies (James and Jones 1976).

As can be seen from the literature, formalization is an important aspect of structuring of the activities of an organization. The degree to which this structuring is explicit is one measure of the degree of formalization of an organization and the degree to which activities are structured may have an impact on member attitudes. Formalization is here defined as "the importance of written rules within an organization," based on Hage and Aiken (1969).

Hypothesis Number 2. The greater the formalization within an organization, the lower the job satisfaction of members within an organization.

Complexity. A highly complex organization is characterized by structures with many levels of authority, or a large number of occupational roles, or many subunits (division or departments), etc. Vertical and horizontal complexity may be distinguished from a global concept of complexity. For example, the number of levels of authority illustrates vertical complexity whereas the number of occupational roles and the number of subunits illustrates horizontal complexity (Price 1972, Blau 1966, 1968).

Vertical complexity is often discussed in terms of "flatnesstallness," and the "configuration" of organizational structure. Horizontal complexity is discussed in terms of "division of labor," "specialization," "role differentiation," "segmentation," and "functional differentiation." It is important to note that the different dimensions of complexity are often treated as separate concepts in 
the literature. There appears to be little agreement among organizational researchers on conceptualizing complexity either as a single concept with a series of dimensions or as a series of separate concepts (Price 1972). Complexity is also referred to or discussed in terms of "importance of skills in a social system" (Price 1972). When defined in this manner, complexity is measured by indicators such as the number of occupational specialties, professionalism, and the time required for training to fill the occupational roles.

Based on the literature, it can be postulated that a highly complex organization will have a greater number of hierarchical levels, occupational roles, and subunits than an organization of low complexity. In relation to vertical complexity, a more complex organization would have a high degree of specialization (e.g., a high number of job titles) and this higher specialization could imply less varied job content (cf. Indik 1965) which might be associated with lower job satisfaction for its members. For this thesis, it can be postulated that the greater the complexity of an organization, the greater the demands placed on the organizational member due to complicated management procedures designed to meet.organizational goals. Increased complexity, at least theoretically, thus may lead to an increase in the impersonality of personal relations within an organization, formalization of management procedures, and increased supervision measures to control productivity. In this way, increased complexity may lead to job dissatisfaction.

As previously noted, Blau (1970) proposed that increased organizational size generated a greater structural differentiation, 
increased differentiation led to increased efforts at coordination, communication, and control within the organization. Thus, complexity may be seen as being highly correlated with size, that is, the larger the organization, the greater the complexity (e.g., increased structural differentiation). Blau further proposed that the greater the complexity, the larger the administrative component needed to handle the increase in efforts to coordinate various functions within the organization. This is accomplished through increasingly formalized communication systems and the increase in efforts at control (supervision). Thus, complexity is also highly correlated with size, degree of coordination, communications, and supervision. The larger the organization, the more complex. The more complex, the more formal the operating procedures. The more formal the organizational operating procedures, the more impersonal the organization becomes for the organization member.

Gouldner (1954) viewed increased size and bureaucracy as leading to greater needs for control which resulted in the implementation of general and impersonal rules within the organization. Various authors have examined the dysfunctional results of increased bureaucracy for the organizational member, including (a) failure to allow for the growth and development of personalities, (b) encouragement of conformity and group think, (c) disregard of the formal organization, (d) no adequate judicial processes, (e) lack of adequate means for resolving organizational conflict, (f) outdated authority and control systems, (g) failure to easily assimilate new technology and personnel, and (h) conditioning that leads to the "organizationa man" (Bennis 1969, and 
cited in James and Jones 1976), (i) reliance on depersonalized relations and strict enforcement of rules resulting in rigid behavior (Merton 1957), (j) presence of individuals attracted to supervisory positions who are monocratic and who tend to reinforce insecurity in subordinates (Thompson 1967), (k) reliance on impersonal rules resulting in low productivity (Gouldner 1954), (1) productivity effects such as wasted time, higher maintenance costs, low morale, impaired labor recruitment, etc. (Jasinski 1956), and (m) increased departmentalization and differences in goals and interests between departments, leading to departmental conflict (Selznick 1949).

Thus, complexity can be seen as interrelated to the previously selected variables, formalization and size. Complexity is defined as "the degree of structural differentiation within an organization." based on Price 1972.

Hypothesis Number 3. The greater the complexity of an organization, the lower the job satisfaction of members within the organization. External Dependence. While many studies have investigated interorganizational relationships within the organization's environment (e.g., Emery and Trist 1965, Terryberry 1968, Evan 1966), few have examined the impact of the environment on internal organizational processes. There are studies that have attempted to describe the nature of organizational environments in terms of the degree of turbulence (Emery and Trist 1965, Terryberry 1968) and in terms of organizational sets (Evan 1966). Others have emphasized transactional interdependencies among organizations (e.g., Guetzkow 1966, Litwak and Hylton 1962). While others have investigated the importance of 
interorganizational relationships (Perrow 1967).

However, our understanding of the influence of the environment on internal organizational processes remains an important, unanswered question. The few exceptions to this rule include Thompson and McEwen (1958), who showed how the organizational environment can affect goal-setting in organizations; Simpson and Gulley (1962) found that voluntary organizations with diffuse pressures form the environment were more likely to have decentralized structures, high internal communications, and high membership involvement, while those having more restricted pressures from the environment had the opposite characteristics; Terryberry (1968) hypothesized that organizational change is largely induced by forces in the environment; and Yuchtman and Seashore (1967) defined organizational effectiveness in terms of the organization's success in obtaining resources from the environment.

One important study, conducted by Aiken and Hage (1968), investigated the relationships between organizational interdependence and influenced internal organizational behavior on 16 health and welfare organizations. Organizational interdependence was operationalized as the number of joint cooperative programs with other organizations. Aiken and Hage postulated that the greater the number of joint programs, the more organizational decision-making is constrained through obligations, commitments, or contracts with other organizations, and thus the greater the degree of organizational interdependence. It was found that organizations with many joint programs tended to be more complex, more innovative, have more active internal communications channels, and somewhat more decentralized decision-making structures. 
No relationship was found between number of joint programs and degree of formalization. Aiken and Hage (1968) conclude that with increased division of labor, organizations become more complex (i.e., more occupational diversity and greater professionalism of staff) and more innovative and that the need for resources to support such innovations promotes interdependent relations with other organizations and the greater integration of the organization in a community structure.

Aiken and Hage (1968) examined joint programs but involvement with other organizations implies many forms of dependence. The sources of funding or of clients is also an important form of dependence. Dependence on an external organization for funding can have far reaching effect on internal organizational processes, whether the external organization is a parent compnay or local or federal government. This mechanism for gaining resources for the organization may in fact result in a loss of autonomy over many intraorganizational processes.

This form of dependence is particularly evident in social service organizations who are dependent on local organizations for funding (e.g., community chest or community human resources money) or on the federal government (e.g., OEO and the Community Action Programs of the late 60 's). At a minimum, this kind of dependence can result in a greater need for internal coordination and external relations with the funding source. This may mean contractual commitments to outside organizations that result in constraints on organizational behavior. A prime example of this form of dependence to external agencies are the agencies and organizations serving elderly clients. Through an act of Congress, the 1973 Amended Older Americans Act 
established funding for social service organizations to establish programs for elderly clients. Along with this funding came requirements and stipulations as to who the agency could serve with the money (e.g., only those 65 or older) and the kinds of services that could be paid for (nursing home payments as opposed to community services such as in home nursing). In addition, the funded agencies had to be officially "coordinated" and monitored by a regional agent, the Area Agencies on Aging. Thus, dependence on outside agencies for resources has the potential to greatly influence intraorganizational procedures and policies. External dependence is defined for this thesis as "the degree to which outside organizations influence intraorganizational decisions and procedures."

Hypothesis Number 4. The greater the external dependence of an organization, the lower the job satisfaction of organizational members.

Activity Variables

Based on the literature review, three activity variables are hypothesized to influence attitudes of organizational members. These activity variables are: (1) vertical communications, (2) supervision, and (3) participation.

Vertical communications. Communications are processes in which the transmission and reception of ideas, emotions, and attitudes (verbally and nonverbally) produces responses for the purpose of eliciting actions to accomplish organizational goals and objectives. This transmission of information assumes many forms in organizations; formal discussions between superordinates and subordinates, informal conferences among subordinates, publication of newsletters, media, etc. 
Communications is often discussed under the labels of "socialization," "feedback," "ambiguity," "acculturation," "assimilation," "education," etc.

Four types of communications have been distinguished by Price (1972). The first and most common distinction is made between formal and informal communication. The basis of this distinction is whether or not the information is officially or unofficially transmitted. Formal communication refers to officially transmitted information. The sanctions and structure of the organization are used to support and maintain a formal system of communication while informal communication systems have no such institutionalized supports. A second distinction between vertical and horizontal communication is also commonly distinguished in the literature. Vertical communication refers to the transmission of information in the superordinate-subordinate relationship, whether from superordinate to subordinate or from subordinate to superordinate. Horizontal communication refers to the transmission of information among peers. A third type is the distinction made between personal and impersonal communications, and overlaps the first category. The basis of this distinction is whether or not the information is transmitted in situations where mutual influence is possible during the transmission event. Personal conversations and telephone calls are examples of personal communication in contrast to the use of mass media to transmit information (impersonal). Fourth, instrumental and expressive communication may be distinguished. The distinction here is between the transmission of cognitive information (instrumental) and the transmission of 
normative and affective information (expressive).

Measurements of communications systems within organizations ane important in that a system of communication which only informs members about impersonal, instrumental, or job-related events in a formal manner, and does not furnish information about performance-related rationale and ideology would tend to have a negative impact on the operations and members of an organization, especially if those members are more prone to communication styles that are informal, expressive, and personalized.

of interest to this study as the aspect of communications which are included in upward/downward (vertical) communications and the degree of formalization with which these communications take place. Vertical communications are defined as "the degree to which information is transmitted to members personally (informally) or impersonally (formally) within the organization."

Hypothesis Number 5. The more formal the vertical communications within the organization, the lower the job satisfaction of members. Supervision. There are three basic elements within the concept of "control" within an onganization: (1) the setting of standards and objectives to serve as a guide for performance, (2) measuring and evaluating performance according to the standards and objectives, and (3) taking corrective action. Newman, Summer and Warren (1967) cite major issues involved in controlling the level of performance that management must address:

1. When and where should a review of performance take place?

2. Who should make the appraisals? 
3. What standard should be used for evaluation?

4. To whom should the results of evaluation be reported?

5. How may the entire process be completed promptly, fairly, and at reasonable expense ( $\mathrm{p}$. 676)?

A major assumption on which this model of management supervision is based, indeed most behavioral models of management, is the assumption the people react negatively to supervisory standards. Even so, rules, objectives, and standards are necessary to the survival of the organization. Sisk (1969) explains why there may be negative reactions to set rules and standards in organizations.

There may be a lack of understanding of standards because they are imposed without any accompanying explanation of their need and value. (In addition) regardless of how carefully standards have been set and flexibility built in, unexpected conditions may make accomplishing the standard difficult or impossible but the person or persons involved get blamed for the poor performance (p. 608).

It is evident that rules, objectives and standards are necessary parts of the management process, for the mere survival of an organization may depend upon how they are formed, adapted and implemented. In addition, the "climate" within the organization, particularly between management and workers, will be heavily influenced by the kinds of rules and standards and the manner in which they are implemented within the organization.

Supervision is often discussed in terms of "span of control" and refers to the number of members managed by the average administrator. The nature of this management will vary greatly for different types of occupations and for different types of organizations. The terms "superordinates" and "subordinates" are typically used to define span of control (Price 1972). Span of control can be distinguished 
from administrative staff and centralization. Administrative staff refers to the full-time career members of a social system who basically perform the activities that indirectly contribute to its primary output. Centralization refers to the degree to which power is concentrated among the members of a social system. For example, an organization may be highly centralized with a low span of control, that is, with a small number of members managed by the average administrator. On the other hand, an organization may be lowly centralized with a high span of control. The problem with this definition of supervison is that it may not apply to professional and non-professional organizations (Price 1972). Of particular interest to this study is the conceptualization of supervision in terms of power and influence.

Power (legitimate authority) and influence (illegitimate authority) refer to the degree to which an individual has the capacity to obtain performance from other individuals. Supervision for this thesis is concerned with control of service provider behavior within the service delivery setting. A situation in which a supervisor continually monitors a service provider or one in which a service provider has no authority to make service delivery decisions with clients tend to create dissatisfaction. Thus, the amount and quality of supervision of service providers is an important element of job satisfaction. Supervision is defined as "the degree of supervison providing direction for member conformance to the defined goals of the organization."

Hypothesis Number 6 . The greater the supervision in an organization, the lower the job satisfaction of members. 
Participation. Participation in decision making is often considered a part of centralization. In this view, a high degree of participation in decisions affecting the organization implies a low degree of centralized authority within an organization. Conversely, a low degree of participation in decision-making implies a high degree of centralization.

In this thesis, the degree to which the members of a social system believe their behavion can determine the outcomes they seek (participation) is distinguished from the degree to which power is distributed in a social system (centralization). Participation in a sense refers to the manner in which the members of a social system perceive a particular type of patterned social interaction whereas the second definition refers to an objective situation. Participation thus refers to a subjective variable. For example, an individual may have a self-perception of relative powerlessness when, objectively, the individual may exercise considerable power. Conversely, an individual may have a self-perception of powerfulness while, objectively, exercising relatively little power.

The influence of structure on participation has not systematically been attempted in the literature. When participation is discussed, it is usually within the context of centralization of decision-making. For example, in a study investigating onganizational interdependence on intraorganizational structure, Aiken and Hage (1968) examined the influence of dependence on external organizations on centralization. Dependence on external organizations was operationalized as the number of joint programs with other organizations an 
organization was involved in. Centralization was defined as staff participation in decision-making over such organizational practices as hiring of personnel, promotions of staff, adoption of new organizational policies, and adoption of new programs or services. Also in the definition of centralizations was an index of the degree of staff participation in decision-making concerning work.

The authors hypothesized that a high degree of centralization varies inversely with the number of joint programs. The findings indicate that while highly interdependent organizations have slightly more decentralized decision-making practices concerning organizational resources, there is slightly less control by staff over the work they do. The results also show that degree of participation appears to be a function of other variables, such as the degree of professionalization of staff and number of committees within an organization, rather than the dependent variable of number of joint programs. Thus, participation in decisions over work and organizational resources appears to be important in organizations with a professional staff. Since many of the organizations in this study's sample are of a professional nature, the investigation of participation is relevant. Participation is defined as "the degree of participation of members in the organization in the decision-making processes affecting them and their job."

Hypothesis Number 7. The greater the participation in decisionmaking by staff, the greater the job satisfaction of members with the organization. 
Job Satisfaction

Job satisfaction is defined as the degree to which the members of a social system have a positive affective orientation toward their job. Members who have a positive affective orientation are satisfied, whereas, members who have a negative affective orientation are dissatisfied.

The organizational literature commonly distinguishes various dimensions of satisfaction, such as work, supervision, pay, promotion, co-workers, etc. Thus, it is possible to have different degrees of satisfaction for different dimensions of a job and have a global degree of satisfaction for all elements that make up a person's job. There are two kinds of primary data utilized in the job satisfaction literature: facet-free and facet-specific (Seashore and Tabor 1975). Facet-free primary data are obtined when the respondent is asked to indicate his global satisfaction with his job. Facetspecific primary data are obtained when the respondent is asked to represent his satisfaction with respect to some specific facet or facets of his job or job environment. Both kinds of primary data will be utilized in this study.

In addition, many job satisfaction scales and indexes have some form of cognition of job elements included, that is, elements of a job are first recognized as "being there" or not; or are considered important to the individual for need satisfaction; or how'much of an element "should be there" versus how much "there is" (Wanous and Lawler 1972). Thus, the satisfaction scales to be used in this study will include a cognition as well as an affective component. The next section will 
describe the data gathering procedures used for this project.

\section{METHODOLOGY}

\section{Data Source}

The data for this project are derived from the client Relations Research Project* conducted by the Institute on Aging, 1976 to 1979. There are two types of samples utilized in this thesis, (1) samples of social service agencies, and (2) samples of service providing personnel.**

\section{Introduction}

Sampling is taking any portion of a population or universe and considering it to be representative of that universe or population. Random sampling is a method of drawing a sample of a population so that each member of the population has an equal chance of being selected.

For the most part, representative means to be typical of a population, that is to "exemplify the characteristics of a population" (Kerlinger 1973). However, in research, a representative sample means that the sample has approximately the characteristic of the population "relevant to the research question" (Kerlinger 1973).

Samples can be broadly classifed into one of two categories: Probability and non-probability samples. Probability samples use some form of random sampling in one or more of the stages of the research.

*Attitudes Toward Older Persons on the Part of Service Delivery Professionals, Administration on Aging Grant \#90-A-1006.

**The term "service provider" refers to those personnel in social service agencies who directly provide services to older clients. 
Non-probability samples do not use random samples. Thus, while nonprobability samples lack the virtues of random sampling, they are sometimes necessary and unavoidable. The weaknesses of non-probability samples can be mitigated by using care, knowledge, and expertise in selecting samples and by replicating studies with different samples. For this thesis, both a random and a non-probability sample were used.

\section{Sample Frame}

The sample was identified utilizing a "kind of service" structure, based on the importance of particular services to elderly clients. The "kind of service" structure was grounded in a review of the gerontological literature and a general survey of the kinds of services currently being delivered to older clients within the sample area. Thus, the organizations used in this study were drawn from a pool of social and health agencies currently delivering services to clients within the Portland-Multnomah County area of Oregon, an urban area with a population of about 550,000 .

These social service organizations were arranged according to six service-type categories identified from the literature and which form the basis of the sample frame. These six service categories are:

1. Health/Mental Health services

2. Income Maintenance services

3. Nutrition services

4. Housing services

5. Transportation services

6. Interaction services 
Table VIII presents the kinds and number of social service agencies and organizations included in each service category .

\section{TABLE VIII}

SOCIAL SERVICE TYPES*

Types/Number of Agencies

Examples

health/mental health (15)

income (5)

nutrition (1)

transportation (5)

housing (5)

interaction (11) hospitals, nursing homes, in-home nursing agencies, mental health clinics

Social Security, senior employment agencies

congregate meal programs, homedelivered meal programs

mass transit, escort programs, special needs transportation programs

public housing, retirement housing projects

senior centers, information and referral services, senior volunteer opportunities, recreational programs, friendly visitor programs, telephone reassurance programs

*Adapted from a table from the Client Relations Project.

Table IX presents the types of service providers sampled from all of the six service type categories to be included in the survey portion of this study. In all, a total of 530 service providers were included in the sample. 
TABLE IX

SERVICE PROVIDER SAMPLE AND RETURN RATE**

\begin{tabular}{|c|c|c|c|}
\hline Cells & Type of service provider & Number sampled & Return rate \\
\hline 1 & hospital doctors & 48 & $26 / 48=48 \%$ \\
\hline 2 & hospital nurses & 50 & $43 / 50=86 \%$ \\
\hline 3 & hospital nurses aides & 47 & $34 / 47=72 \%$ \\
\hline \multirow[t]{2}{*}{4} & in-home nursing nurses & 22 & $18 / 22=82 \%$ \\
\hline & in home nurses aides & 24 & $18 / 24=75 \%$ \\
\hline \multirow[t]{2}{*}{5} & nursing home nurses & 24 & $19 / 24=79 \%$ \\
\hline & nursing home nurses aides & 26 & $17 / 26=65 \%$ \\
\hline 6 & mental health practitioners & 49 & $47 / 49=96 \%$ \\
\hline 7 & income personnel & 48 & $43 / 48=90 \%$ \\
\hline 8 & nutrition personnel & 48 & $42 / 48=88 \%$ \\
\hline 9 & transportation personnel & 48 & $31 / 48=65 \%$ \\
\hline 10 & housing personnel & 48 & $44 / 48=92 \%$ \\
\hline \multirow[t]{2}{*}{11} & interaction personnel & $\underline{48}$ & $46 / 48=96 \%$ \\
\hline & TOTAL & 530 & $428 / 530=81 \%$ \\
\hline
\end{tabular}

*Adapted from a table from the client Relations Project.

Two samples were used in this study, one of social service organizations and one of direct service providers within those organizations.

Organizational Sample

The organizational sample is made up of 42 social service 
organizations and their directors within the Portland-Mulnomah County area. The data gathered from these agency directors were designed to identify characteristics of the service-providing agency which might influence job satisfaction. The director of the agency was used as the respondent for information concerning the organization based on the assumption that, as the individual in charge of the total operations of the agency, the director would have a holistic perspective and understanding of the structure and functioning of the organization that on-line service providers might not. Thus, the agency directors were utilized as the major information source for the organizational characteristics data. Except for one agency which was added at a later date, the data for the organizations were gathered between August and October of 1977.*

Selection of Agencies

Social service agencies which delivered services to at least some elderly clients were classified into one of the six service-type categories as listed in Table VIII. Agencies serving elderly clients were identified on the basis of:

1. the "Inventory of Resources" from the Area Plan for Programs on Aging of the Portland-Multnomah County Area Agency on Aging, 1975-76;

2. the Directory of Community Services in Clackamas, Multnomah, and Washington Counties of Oregon and Clark County of Washington,

*The director of the one agency added to the sample was interviewed in May, 1978. 
published by Tri-County Community Council, Portland, Oregon, 1972 and 1974 editions;

3. the Directory of Programs and Services for Older Adults, State of Oregon, published by the Institute on Aging, Portland State University, Portland, Oregon, 1971;

4. the Portland telephone directory for 1975-76;

5. personal communications with members of the PortlandMultnomah County social service network; and

6. prior research conducted by the Institute on Aging, Portland State University, Portland, Oregon.

From the total number of agencies identified as part of the preliminary sample, 49 were selected to be included in the study. These 49 agencies were selected as a "purposive" sample on the basis of three organizational characteristics important in agencies delivering services to the elderly. A "purposive" sample is a non-probability sample and is characterized by the use of judgment and a deliberate effort to obtain representativeness in samples by including presumably typical areas, groups, or characteristics within the sampling frame (Kerlinger 1973). Three organizational characteristics typical of agencies serving elderly clients formed the basis for the purposive sample of organizations. The three characteristics are:

1. Size of agency (small to large)

2. Auspice of agency (public on private, profit or non-profit), and

3. Age of clientele (elderly only or mixed age clientele. 
Thus, the 49 agencies selected were chosen on the basis of their representativeness.

Data Gathering Procedure: Organizational Data

The data gathering procedures used for the organizational sample are as follows. During Phase I (August 10, 1977) of the data gathering, the directors of the 49 selected agencies were mailed a personalized letter introducing the study and requesting the agency's participation. During Phase II (August 15-21, 1977), the directors were contacted by telephone to confirm their agencies' participation in the study.

Participation in the study meant that the director of the agency agreed to:

1. participate in an interview with a staff member concerning the characteristics of the agency itself,

2. provide a personnel list of all personnel who deliver direct services to at least some elderly clients, and

3. give permission for the project to mail survey questionnaires to a sample of their personnel at their place of work.

Of the 49 agencies originally selected to be in the study, 43 agreed to participate. Of the 43 agencies who agreed to participate, 41 agencies participated in all stages of the data gathering. Two agencies decided to limit their participation to a completed interview only. The two agencies, a nursing home and a retirement housing project, refused to permit the agency's personnel lists to be provided to the study. Thus, it is these 41 agencies, plus one agency added 
later in the study that comprise the organizational sample.

During Phase III of the data gathering (August 22 to October 22, 1977), interviews were conducted with the agency director (or next level of management designated by the director) at the agency utilizing the Organizational Fact Sheet. The Fact Sheet is a formalized interview schedule, measuring information regarding the characteristics to the organization. At the time of the interview, personnel lists of direct service providers who worked with at least some elderly clients were collected (where possible). In some cases, the requested information could not be supplied at the time of the interview, thus, the appropriate information was then mailed to the interviewer in a self-addressed, stamped envelope provided by the study. Following the receipt of the personnel lists, the agency directors were mailed a personalized thank you letter. Forty-three interviews were completed by the project's staff with 42 utilized as the basis for the organizational sample.

Data Gathering: Service Provider Data

During phase IV of the data gathering procedure, the service provider sample was constructed. The service providers to be surveyed for the project were randomly selected from all possible service providers working with at least some elderly clients in each agency. The selection of subjects was made through the use of a table of random numbers. Each service provider category (see Table VIII) was used in each appropriate service type to compile a service provider random sample of 530 (see Table IX). Approximately 48 
service providers were selected from each sample category.

Phase $V$ of the data collection for the service provider survey was conducted between November 25, 1977 and January 30, 1978. A multi-step mailed survey and follow-up procedures were utilized at one week intervals to generate as high a return rate as possible to ensure generalization to the larger population.

On November 25, 1977, a letter was mailed to all selected service providers introducing the study and requesting their participation. On December 2, 1977, A General Attitude Survey Questionnaire was mailed to each subject at their place of work along with a cover letter that included instructions for completion of the questionnaire instrument. On December 9, 1977, a reminder postcard was mailed to all respondents who had not yet returned a completed questionnaire. A personalized thank you letter was mailed to each respondent whenever a completed questionnaire was returned to the study. On December 16, 1977, a follow-up letter urging subjects to complete their questionnaire was mailed to those respondents who had not returned a completed questionnaire. Finally, on December 23, 1977, a replacement questionnaire and cover letter were mailed to all subjects who had yet to complete and return a questionnaire to that date. These standardized follow-up procedures were completed as of December 30, 1977. A total of 63 percent of the questionnaires had been returned to the study by that time.

During January, 1978 to May, 1978, unstandardized follow-up procedures were instituted to increase the response rate. These 
procedures included personal phone calls to all non-respondents, personal interviews where necessary, and personal retrieval of completed questionnaires. These procedures increased the total response rate to 81 percent (see Table IX).

Thirty-seven subjects were replaced during the course of data gathering. These replacements were added due to sampling errors in the original sample or due to illness at the time of the survey. All replacements were selected on a random sample basis, as in the original sample. The data collection for this study was terminated as of June, 1978.

Description of Samples: Organizations

A frequency distribution of the data generated from the Organizational Fact Sheet reveals the following about the organizations included in the sample. Table $X$ presents this data in summary form. As can be seen in Table $X$, the 42 agencies varied on a number of organizational characteristics.

Of the 42 sample agencies, 15 were categorized as Health/Mental Health agencies, including two hospitals, three in-home nursing organizations, six nursing homes, and four mental health agencies. Of the 27 non-medical organizations, five were income maintenance or employment agencies, five were housing projects (including public housing), five were transportation organizations (including public transportation), one was a nutrition program, and eleven agencies were classified as "interaction" and included senior centers and neighborhood community organizations. 


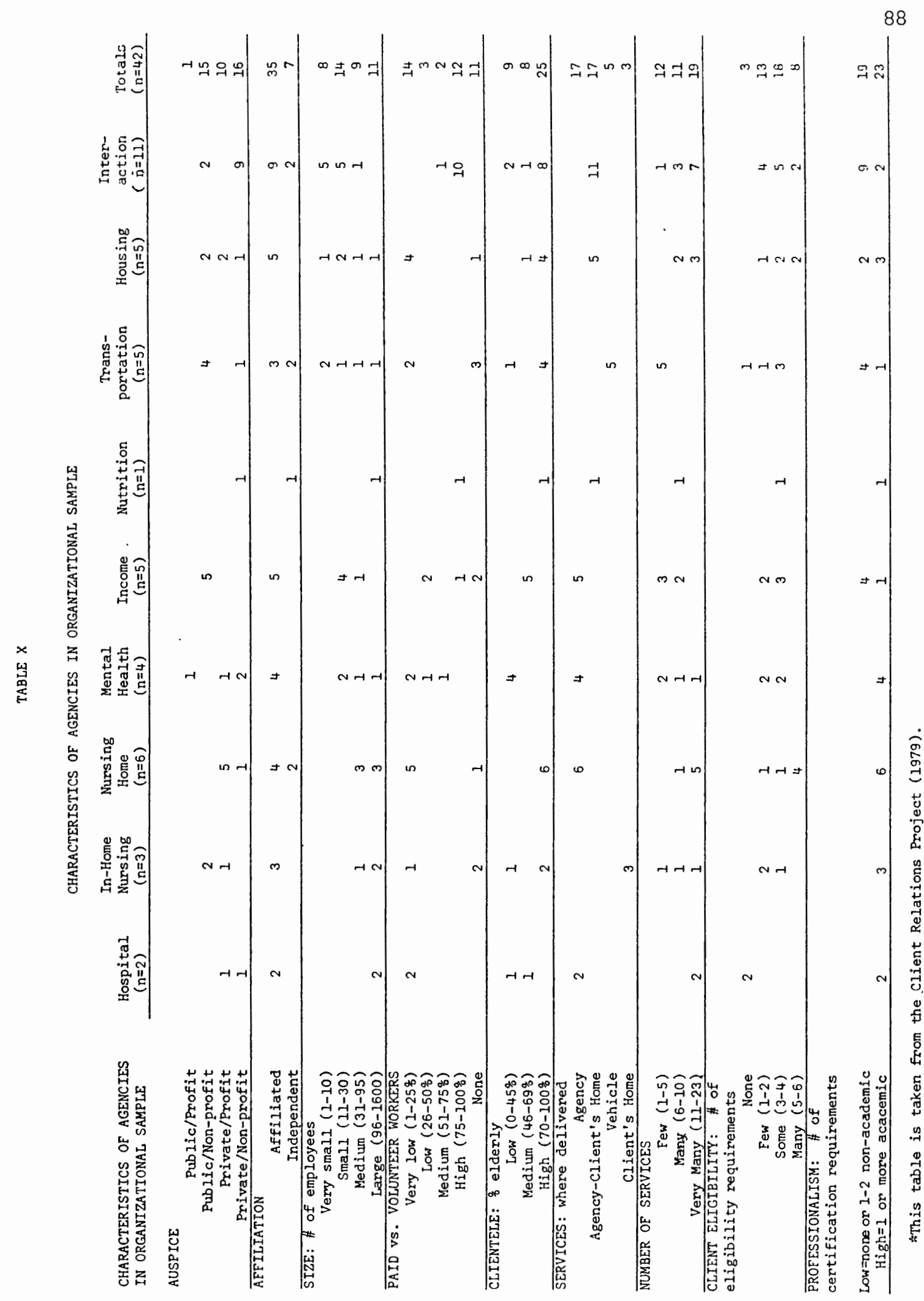


Auspice. Included in the sample were 26 private and 16 public onganizations; 31 were non-profit while 11 were profit-oriented. Affiliation. Thirty-five of the 42 organizations included in the sample were affiliated with at least one other organization, usually a parent organization or a funding agency. Of the health/ mental health agencies, 13 were affiliated and two defined themselves as independent $(n=15)$. Of the non-medical agencies in the sample, 22 were affiliated with other onganizations while five defined themselves as independent $(n=27)$.

$\underline{\text { Size }}$ is an important element in many organizational interactions. Size was operationalized as total number of paid employees. The number of employees ranged from a low of two to a high of 1600 . The mean number of employees for all agencies was 125 while the median was 25 employees.

Volunteers are an important part of human service delivery. Thirty-one of the 42 agencies in the sample utilized volunteers in the service delivery. The number of volunteers for all agencies ranged from a low of one to a high of 4000 . The mean number of volunteers for the 31 agencies was 125, while the median number of volunteers was 10 .

Services. The number of services an agency delivers to its clients influences its organizational practices just as the type of services delivered. The number of services delivered by all agencies ranged from a low of one service delivered to a high of 23 different services. The mean number of services delivered was 10 . 
Client Eligibility is an important aspect of human service delivery and determines who receives services. Of the 42 sample agencies, 39 had at least one eligibility requirement for service delivery. The number of eligibility requirements ranged from one to a high of six. The mean number of eligibility requirements for all 39 agencies was 3.21 .

Services were delivered in a variety of settings in the sample. of the 42 sample agencies, 17 delivered their services within their agency, five delivered their services in a vehicle, 17 delivered their services in both their agency and the clients' homes, and three delivered their services in the clients' homes only.

Finally, the number of elderly clients served was considered an important element to be examined. The percentage of elderly clients served by each agency in the sample ranged from a low of only 2 percent of the client population to a high of 100 percent. The mean was 70 percent while the median was 88 percent of the total client population.

Descriptions of Samples: Service Providers

Table XI presents descriptive data on the service provider sample. In terms of service provider characteristics; the service providers ranged in age from under 20 to 89 years of age. The mean age for the service providers was 44. Sex of the service providers included 136 males and 292 females.

Education. In regard to education level, the range was less than 8th grade to graduate degrees. The mean level of education was defined 
TABLE XI

CHARACTERISTICS OF SERVICE PROVIDER IN GEINERAL ATTITUDE SURVEY SAHFLE*:

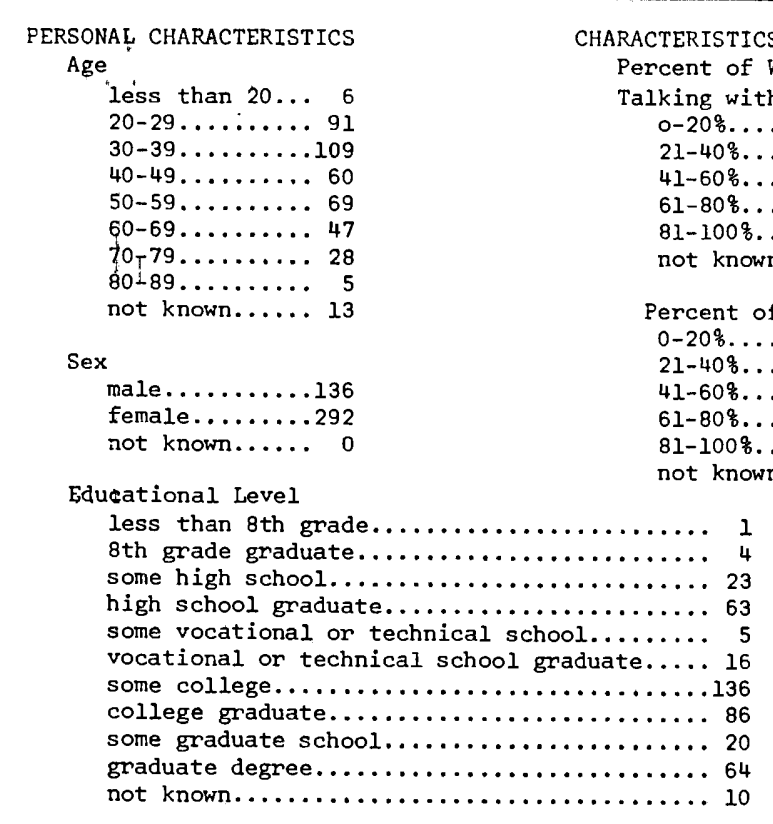

JOB-RELATED CHARACTERISTICS

Hours Worked Per Week

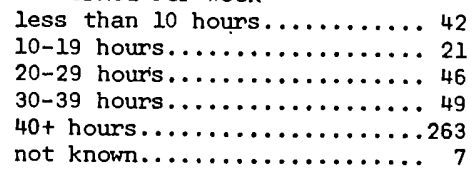

Paid or Volunteer

paid.................... 383

volunteer................... 39

other..................... 2

not known................. 4

Years on Job

less than 1 year........... 28

$1-3$ years $\ldots \ldots \ldots \ldots \ldots \ldots \ldots 196$

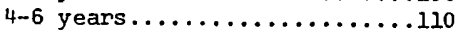

7-9 years................ 39

$10-12$ years................. 20

$13-15$ years............... 11

$16-18$ years............... 4

$19-21$ years.............. 4

$22-24$ years................ 2

$25-27$ years................ 2

$28-30$ years $\ldots \ldots \ldots \ldots \ldots \ldots . \ldots \ldots$

not known.................. II
Sex of Elderly Clients

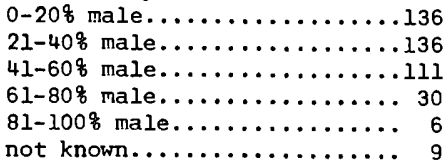

Frequency of Contact with Same Elderly client

one time only................. 33

less than once a year.............. 7

yearly ........................ 7

twice a year.................. 30

monthly ....................... 56

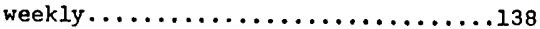

daily..........................

not known..................... 13

Note. Numbers following each response option indicate the number of service providers who made that response. Total sample size equals 428 ,

*The author is grateful to Marilyn Petersen for the use of this table from the Client Relations Project (1979). 
as "some college."

Hours per Week. The average number of hours worked per week by service providens was 35 hours with a range of less than 10 hours to over 40 hours per week. The majority of the sample are paid workers rather than volunteers and the average service provider has worked in his/her agency for about four years. The years spent on the job ranged from less than one year to 30 years on the job.

Interaction with clients. On the average, the sample members spend from 4I-60 percent of their work time being with or talking to clients and have a clientele that is from 61-80 percent elderly. The average number of clients seen per day is 23 and ranges from fewer than 10 to over 100. The sex of clientele is predominately female with 21-40 percent of elderly clients being male. The average amount of time a service provider sees the same client is weekly.

Description of Samples: Agency Directors

Information gathered by the study concerning characteristics of the directors themselves includes, (1) years on the job, and (2) sex. At the time of the interview, directors had been with their agencies for from three months to 23 years, with a median tenure of four years. The sample of directors was approximately balanced for sex, with 22 directors being male and 20 being female.

Instruments

The data to test the hypotheses of this study were gathered from two questionnaires; (1) a self-report measure consisting primarily of sets of closed ended items with seven-step response alternatives 
called the General Attitude Questionnaire a survey instrument, and (2) an interview instrument consisting of both closed-ended items with seven-step response alternatives and open-ended items called the Organizational Fact Sheet.

General Attitude Questionnaire

On the basis of a review of the attitudinal literature, an attitudinal model was developed by Petersen (1977) in order to guide the assessment of attitudes of social service and health providers toward working with older clients.

For the purposes of the Client Relations Project, attitude was defined as "an attitude in any concept held by an individual to which affect (i.e., feeling) is attached and from which behavioral predispositions result." (Petersen 1977). In the Petersen model (1977), an attitude is composed of three parts: a cognitive component (i.e., the concept), that is, the definition of the target to which the attitude is addressed. This component can include both a description and an evaluation and can vary in its composition from a single concept to a complex organization of concepts. Attitudes also include an affective component, which is the feeling (positive or negative) directed toward the attitude target.

Finally, attitudes include a behavioral component, consisting of approach and avoidance tendencies or "predispositions." Such predispositions result in preferential behavior, positive affect generates approach tendencies and negative affect generates avoidance tendencies. A wide variety of other variables may influence the content and 
the expression of individual attitudes, such as, the object itself, the situation on context in which the object is encountered; past experience with similar objects, etc. All these variables and more contribute to the environment in which the object or situation is encountered which then influences attitudes.

On the basis of the conceptual model, General Attitude Questionnaire items were generated from interviews with service providers in order to identify relevant aspects of service providers' cognitions, affect, and behavioral predispositions towards (1) older clients and providing services to older clients, and (2) the situation in which the service provider works (the organization). The interview schedule was administered to twenty-two service providers, two from each of the sampling categories. In response to the interview questions, the service providers were requested to speak not only for themselves but, for and about, their co-workers as well. Based on a content analysis of the interviews, a questionnaire was developed and pretested by mail in Vancouver, Washington on a sample of service providers as representative of the final sample as possible ( $n=92$, return rate-52 percent). Analyses of the pretest resulted in the survey version of the General Attitude Questionnaire.

Items of cognition of older client included questions such as, "On my job: I have too little information about my elderly clients, my elderly clients are hard to communicate with;" "On the whole, the elderly clients I serve: have a positive outlook on life, are uncooperative, have a wealth of experience, refuse to help themselves, are considerate, are hostile," and "On the whole: my elderly clients' 
problems have been brought on by forces beyond their control, my elderly clients hold the same attitudes and values as I do."

Items of cognition of situation include "The services which my agency provides to its elderly clients are: very worthwhile for the client, provided effectively for the client, of high priority to my agency;" "On my job: effective teamwork helps me to do my work, I get credit for using my own initiative, I have ample opportunity to air complaints, staff turnover at my agency makes my work harder, I get recognized by management for doing good work, staff absenteeism makes my work harder, enough training is available to me, etc."

Items of affect toward older client include, "On my job: my elderly clients are especially interesting to me," "How enjoyable do you find the following things you do at work, being with or talking to clients," and "On the whole, I enjoy working with older people as clients."

Items of affect toward situation include: "On my job: I enjoy the work on which I spend my time, my work is an expression of my beliefs," and "On the whole: my job is very rewanding to me."

Finally, behavioral predispositions toward older clients included items such as: "On my job: my elderly clients and I laugh together, I have to be especially careful about what I say to my elderly clients, I can just be myself with my elderly clients, I try not to get personally involved with my clients, I am very warm toward elderly clients, I prefer to act in a businesslike way with my elderly clients, and elderly clients tire me out quickly." 
Thus, as can be seen by the examples of General Attitude Questionnaire items, the three components of attitudes towards clients and job situation were addressed in this questionnaire.

Three scales of job satisfaction, derived from the three dimensions of attitudes, were constructed from items on the General Attitude Questionnaire. The finst scale of job satisfaction is recognition of DISCONTENT aspects towards job, measuring negative elements within the job situation (i.e., the organization) and of service provision to elderly clients that could lead to discontent with job. Items included in this scale encompassed staff and staff relations (e.g., absenteeism, turnover, incompentent staff), red tape (e.g., forms, rules, and regulations that interfere with service provision), status of job, disagreements with management concerning the way to deliver services, and negative characteristics of elderly clients that might interfere with delivering service (e.g., elderly clients who do follow their advice). The second scale was recognition of CONTENT aspects of one's job, measuring the positive elements of the job situation and of elderly clients that might lead to content with one's job. The scale included such items as service provider participation in decision-making concerning their job and service delivery, recognition by management of the service provider's work and suggestions concerning their jobs, the pay they receive, co-worker relations (e.g., effective teamwork makes my job easier), management trusts them to work independently, and positive characteristics of elderly clients and service delivery to elderly clients that might lead to contentment in their work (e.g., my elderly clients have a wealth of experience, my elderly clients 
appreciate my services).

The thind scale was overall feelings concerning one's job and included items concerned with job situation, older clients, and working with older clients.

Organizational Fact Sheet

Based on a review of the literature concerning organizational structure and its influence on attitudes and behaviors, a model of organizations was designed, based on a model presented by Ghiselli and Siegel (1972) (see Chapter 3), to be used to identify relevant aspects of the work situation that might influence job satisfaction.

In accordance with the conceptual model, organizations were separated conceptually into two primary dimensions, a structural dimension and a management-activity dimension. Within each dimension, relevant characteristics of organizations in terms of the effects on organization members were generated based on the literature review. These relevant characteristics were then utilized in the design of the Organizational Fact Sheet.

Within the structural dimension, characteristics of organizations generated the following types of items: size of organization, as determined by size of budget, number of personnel in organization, number of departments, and number of services delivered, the organization's goals and objectives, the auspice of the organization (that is, public-private/profit-non-profit), whether the organization was affiliated with external agencies, the configuration of the organization as determined by the number of personnel between the director 
and the on-line service providers, the degree of formalization of procedures in the organization, the degree of professionalization of the staff in the agency, as determined by the number of certification requirements demanded of personnel, organizational age, and any major organizational changes that had taken place within the last five years. Management-activity dimension variables attempted to assess the dynamic and processual qualities of the organizations within the sample, that is, questions were open-ended and included the type and frequency of supervision of on-line service providers within the organization, the frequency and quality of staff meetings with on-line staff involved, the kinds and frequency of training offered to on-line staff by the agency, the degree of participation in decision-making in which on-line staff are involved, and the frequency and quality of communication procedures utilized within the organization.

While a great deal of information was collected about the sample agencies and how they function, the emphasis of the Organizational Fact Sheet lay in the determination and generation of the seven organizational scales on which the hypotheses of this study will be tested. The majority of items from the Organizational Fact Sheet were utilized in building the scales which were identified in the Hypothesis section of this thesis.

The Fact Sheet was constructed and pretested on nine management level personnel, six were within a university setting and were program directors or department heads and three were conducted in community service agencies and in a regional governmental agency with management 
personnel. Assessment of the pretests resulted in minor changes of the Fact Sheet consisting of wording changes or question format changes.

Reliability of Instruments

Internal consistency for the scales contructed from the Organizational Fact Sheet data will be presented using item/total correlations (see Chapter 4). Because the Organizational Fact Sheet scales were intended to measure relatively homogeneous dimensions, this item/total correlation approach would reflect internal consistency of the scales.

Cronbach's Alpha was used to demonstrate reliability for the General Attitude Questionnaire and is presented in the final report of the Client Relations Project, entitled, "Attitudes Towards Older Persons on the Part of Service Delivery Professionals," Administration on Aging grant number 90-A-1006. Copies may be obtained through the Institute on Aging, Portland State University. 
CHAPTER IV

A DISCUSSION OF THE RELATIONSHIPS BETWEEN ORGANIZATIONAL STRUCTURE AND JOB SATISFACTION

Administration of Instruments: Organizational

Fact Sheet

The Organizational Fact Sheet $(n=42)$, an interview instrument, was read to the subject by an interviewer. Responses were written on the instrument by the interviewer. In all cases where the response set was closed-ended, subjects were handed a checklist exhibiting the sets of responses for each question after it was read aloud by the interviewer. The subject then answered the question by checking off his/her answers on each checklist.

The Organizational Fact Sheet was comprised of 39 items with 12 corresponding checklists. Interviewers were in possession of the only copy of the interview instrument; the subjects saw only the closed-ended response set checklists.

The instructions to the interviewer for reading the questionnaire items were listed on the interview instrument itself. Instructions for answering the checklists were printed, along with the exact wording of the verbal question from the interview schedule, on the corresponding checklists given to the respondent. 
Administration of Instruments: General

Attitude Questionnaire

The General Attitude Questionnaire $(n=423)$, a survey instrument, was mailed to the sample at the agencies where they worked along with a cover letter explaining the processes of filling out the questionnaire. Items were closed-ended seven-step response alternatives ranging from 1 (never) to 7 (always). Items were to be answered by the respondent in terms of the never-to-always response set accompanying each section of the questionnaire.

The following section discusses the contents of each scale used in this study. Items for each scale and item/total correlations are presented in Table XII for the scales derived from the Organizational Fact Sheet. When scales are constructed with less than six items, the reported item/total correlation are total scores with the item removed.* All items used from the General Attitude Questionnaire are presented in Table XII.

Scale Construction and Scoring: Organizational Fact Sheet

Seven scales measuring various dimensions of organizational structure were generated from the Organizational Fact Sheet including:

(1) SIZE, a two item additive scale measuring the number of employees and number of part-time employees as an indicator of scale

"While the sample size for the organization section of this study is 42 , item/total correlations are calculated for 43 organizations due to the inclusion of one organization utilized in another phase of the Client Relations Project. At no other time is this organization included in any statistical analysis in this study. 
TABLE XII

ORGANIZATIOINAL SCALE ITEMIS WITH ITEM TOTAL CORRELATIONS

SCALE ITEMS

ITEM/TOTAL CORRELATIONS

Scale 1: SIZE (Range $=.5$ to $4.0 ; \bar{x}=2.13$; sd $=1.15$ )

(a) number of employees

(b) number of part-time employees

Items intercorrelated at $(r=.53)$

Scale 2: FORMALIZATION (Range $=1$ to 7 ; $\overline{\mathrm{x}}=4.76 ; \mathrm{sd}=1.23$ )

Checklist \#5 items:

(a) budgeting

(b) hiring/firing

(c) service provision to clients

(d) promotions/pay

(e) interactions with other agencies

(f) staff meetings

(g) vacations

$(r=.62)$

$(r=.62)$

$(r=.52)$

$(r=.56)$

$(r=.70)$

$(r=.68)$

$(r=.50)$

Checklist \#8 items:

(h) the day-to-day management decisions of my agency are based on the written rules and regulations

(i) policy or program changes suggested by service providers must be presented to management through formal, standardized procedures 
TABLE XII (Continued)

SCALE ITEMS

ITEM/TOTAL CORRELATIONS

Scale 3: COMPLEXITY* (Range=1, to 2.25; $\overline{\mathrm{x}}=2.11 ; \mathrm{sd}=.93)$

(a) number of departments within organization

(b) number of levels from director to on-line staff

(c) number of supervisors in agency

(d) number of criteria used to differentiate departments

$$
\begin{aligned}
& (r=.65) \\
& (r=.86) \\
& (r=.66) \\
& (r=.77)
\end{aligned}
$$

Scale 4: EXTERINAL DEPENDENCE (Range=0 to 10;

$$
\overline{\mathrm{x}}=4.31 ; \mathrm{sd}-3.46)
$$

Checklist \#l:

(a) budgeting/expenditures of funds

(b) regulations/rules

(c) specification of the services/tasks your

$(r=.43)$

$(r=.68)$ agency performs

(d) clients; that is, who your agency can serve

$(r=.60)$

$(r=.69)$

$(r=.68)$

$(r=.69)$

$(r=.53)$

$(r=.62)$

$(r=.49)$

$(r=.69)$

Scale 5: VERTICAL COMMUNICATIONS (Range $=0$ to 3 ;

$$
\overline{\mathrm{x}}=1.25 ; \mathrm{sd}=.76)
$$

(a) technical assistance techniques

(b) special training sessions

(c) action abstracts: short articles diagnosing problems and offering alternative solutions

(d) short media articles: audio-visual presenta-. tions, magazine and journal articles analyzing specific problems

$$
\begin{aligned}
& (r=.40) \\
& (r=.43) \\
& (r=.63) \\
& (r=.27)
\end{aligned}
$$

*Item total correlations calculated with all items included. Total scores are somewhat inflated. 
TABLE XII (Continued)

SCALE ITEMS

ITEM/TOTAL CORRELATIONS

Scale 5 (Continued)

(e) draft legislative bills: models bills designed for possible use in an organization in problem solving $(r=.36)$ with public funds

(f) consulting by multi-disciplinary teams: group of specialists created to solve particular organizational proìlems

Scale 6: SUPERVISION (Range $=2$ to 7; $\bar{x}=4.65 ; \quad s d=1.22$ )

Checklist \#7 items:

(a) because rules or regulations require a supervisor's involvement

(b) to deal with problem clients

(c) to evaluate service providers

$(r=.70)$

$(r=.67)$

(d) at the request of clients

$(r=.66)$

(e) to deal with technical decisions related to $(r=.56)$ professional standards

$(r=.76)$

Checklist $¥ 8$ items:

(a) service providers are closely monitored by their supervisors

(b) service providers are checked to ensure that they are following procedures

(c) even small matters in the service delivery encounter are referred to a supervisor for final approval

Scale 7: PARTICIPATION (Range=2 to 6.25; $\overline{\mathrm{x}}=5.16 ; \mathrm{sd}=1.09$ )

Checklist \#8 items:

(a) service providers make the decisions about how they serve their clients

(b) service providers are encouraged to be creative in solving service delivery problems 
TABLE XII (Continued)

Scale 7 (Continued)

(c) service providers participate in making the agency decisions which affect them and their work

(d) service provider suggestions are put into practice by my agency

(e) service providers are involved in the planning and establishment of new programs

(f) non-professional personnel participate in the day-to-day decisions concerning the provision of service to clients

$$
(r=.61)
$$$$
(r=.69)
$$$$
(r=.64)
$$$$
(r=.73)
$$ 
of operations. Items were open-ended absolute numbers and were scored by adding the items together and dividing them by the number of items on the scale (2). The larger the score, the larger the organization $(n=42)$.

(2) FORMALIZATION, a nine-item additive scale designed to assess the degree to which written rules were used as a basis for intraorganizational decisions and activities. Items included in the formalization scale were to be answered with a seven step response alternative ranging from 1 (never) to 7 (always). Items were scored by adding the responses together and dividing the total number of items on the scale (9). The larger the resulting score, the more formalized the organization. Seven of the nine items included in the scale were derived from Checklist \#5 of the Organizational Fact Sheet, the last two items included were derived from checklist \#8. Checklist \#5 items were answered in terms of the question: "How often are the following day-to-day management activities governed by the written rules and regulations of your organization?" Items derived from Checklist $\$ 8$ were answered in terms of the question, "In terms of an average face-to-face encounter between clients and service providers, please indicate how often each of the following occurs within your agency" $(n=42)$.

(3) COMPLEXITY, a four-item additive scale measuring the degree of structural differentiation within an organization. Items included in the formalization scale were open-ended questions concerning number of departments within the organization, never of levels from the director to on-line service providers, the number of supervisors in 
the agency, and the number of criteria that departments are differentiated from one another within the organization. The items were scored as absolute numbers, added and then divided by the number of items on the scale (4). The larger the number the more complex the organization.

(4) EXTERNAL DEPENDENCE, a ten-item additive scale measuring the degree to which outside organizations influence intraorganizational decisions and procedures. The iterns for the scale are derived from Checklist \#l of the Organizational Fact Sheet and were answered by checking the items that applied to the organization and leaving the items that did not apply blank. Items were added to a total score by the number of checks on the checklist. The scores ranged from 0 (none) to 10 (all). The larger the number of checks, the more externally dependent the organization.

The items on the External Dependence scale were produced by the question, "Over which of the following procedures does the larger (external) organization exercise control within your agency?" $(n=32)$.

(5) VERTICAL COMMUNICATIONS, a six-item additive scale measuring the degree to which information is transmitted to members formally or informally within the organization. The items for this scale are derived from Checklist \#6 of the Organizational Fact Sheet. Item/ total correlations are totals minus each item. Six items of the nineitem scale were designed as formal communication procedures. The respondent was asked to answer the question by checking "all of the following techniques you use within your agency." The checks for the six formal communications procedures were then tallied and divided 
by the number of items on the scale (6). The result was the agency Vertical Communications score. The larger the score, the more formal the communications procedures used within the organization $(n=42)$.

(6) SUPERVISION, an eight-item additive scale measuring the frequency of supervision practices within an organization. The items for the Supervision scale were derived from Checklist \#7 and three items of the total eight from Checklist \#8. All items were answered in terms of a seven-step response set ranging from 1 (never) to 7 (always). Items from Checklist \#7 were generated by the question, "Please indicate the frequency with which each of the following criteria influences a supervisor's involvement in the service delivery encounter," and items from Checklist \#8 that were generated by a stimulus question concerning how often various organizational circumstances occurred in the agency $(n=42)$.

(7) PARTICIPATION, a six-item additive scale measuring the degree of participation of members in the decision making process affecting them and their jobs. Item/total correlations are reported with the items removed from each total score. The six items were all derived from Checklist \#8. All items were answered in terms of a seven-step response set ranging from 1 (never) to 7 (always). Items from Checklist \#8 represent responses to the instruction: "In terms of an average face-to-face encounter between clients and service providers, please indicate how often each of the following occurs within your agency." Responses were added and then divided by the number 
of items on the scale (6), which resulted in the Participation score for each agency. The higher the score, the more participation.

Measurement of Job Satisfaction: The General Attitude Questionnaire

The overall job satisfaction score was derived from three scales measuring various dimensions of job satisfaction presented in Table XIII.

\section{(1) Recognition of Discontent Aspects of Job Situation, a} 33 item additive scale measuring the aspects of one's job that lead to discontent. Items for this scale were derived from various sections of the General Attitude Questionnaire, including 14 items from Section $B$ with a seven-step response alternative 1 (never) to 7 (always). In addition, eight items from section $C$ were included and answered on a seven-step response alternative scale from I (not at all) to 7 (very strongly), based on the question, "I disagree with the following people on how I should provide services to my elderly clients." Also, one item was taken from Section D, a 1 (never) to 7 (always) scale with the question, "On the whole, my elderly clients" problems have been brought on by themselves." Nine items were derived from Section E utilizing a (1) never to (7) always scale. A last item was taken from Section $H$ with a 1 (never) to 7 (always) response set to the question, "On my job the requests my elderly clients make of me are inappropriate."

The items were added and divided by the number of items of the scale (33) for a DISCOIJENT score. The higher the score, the more 
TABLE XIII

GENERAL ATTITUDE QUESTIONNAIRE ITEMS SEGREGATED

BY SECTION OF JOB SATISFACTION DIMENSIOIS:*

Scale 1: Recognition of Discontent aspects of one's job (Discontent

Cognitions) (Range: 1 to $5.5 ; \bar{x}=2.90 ; s d=.74$ )

Discontent Cognitions of Job SITUATION

Section B:

(2) my agency's rules interfere with my providing services to elderly clients

(3) providing services to my elderly clients is made harder by incompetent people in my agency's staff

(10) I am bogged down in paperwork in providing services to my elderly clients

(12) staff turnover at my agency makes my work harder

(15) staff absenteeism makes my work harder

(23) I have to deal with a lot of red tape in providing services to my elderly clients

(24) the requirements of governmental regulatory agencies interfere with my providing services to elderly clients

(27) I get blamed when things don't go right

Section C:

(1) the public

(2) my coworkers

(3) my agency's parent organization

(4) the administrators of my agency

(5) my supervisors

(7) governmental regulatory agencies

(8) funding services

*Item numbers correspond to questionnaire numbers on General Attitude Questionnaire. 
TABLE XIII (Continued)

Scale 1 (Continued)

Section D:

(9) my elderly clients' problems have been brought on by themselves

Discontent Cognitions of CLIElTS

Section B:

(5) I have too little information about my elderly clients

(8) my elderly clients are hard to communicate with

(14) my own personality interferes with my providing services to elderly clients

(20) the public looks down on people who do the work I do

(21) my elderly clients' physical conditions limit what I can do for them

Section C:

my elderly clients refuse to follow my advice

Section $E$ :

(4) are uncooperative

(6) refuse to help themselves

(7) are ungrateful

(10) are hostile

(11) have given up on life

(13) are angry

(16) are overly demanding

(1.8) have serious emotional problems

(21) are chronic complainers

Section $H$ :

(22) the requests my elderly clients make of me are inappropriate 
TABLE XIII (Continued)

Scale 2: Recognition of Content Aspects of One's Job (Content Cognition)* (Range $=3.4 ; \bar{x}=5 ;$ sd $=.66$ )

Content Cognitions of SITUATION

Section A:

(1) very worthwhile for the client

(2) provided effectively for the client

(3) of high priority to my agency

Section B:

(1) effective teamwork helps me do my work

(4) I get credit for using my own initiative

(6) the pay I receive enables me to live comfortably

(9) I have ample opportunity to air complaints concerning my job

(11) I get recognized by management for doing good work

(13) I participate in making the agency decisions which affect me and my work

(16) enough training is available to me

(17) I am paid as much as I am worth

(18) I make the decisions about how I serve my elderly clients

(22) my suggestions are put into practice by my agency

(28) my supervisor trusts me to work independently

Content Cognitions of CLIENTS

Section D:

(2) my elderly clients problems have been brought on by forces beyond their control

(3) my elderly clients hold the same attitudes and values as I do

Section E:

(1) have a positive outlook on life

(5) have a wealth of experience

(9) are considerate

(12) are at peace with themselves

(15) appreciate my services 
TABLE XIII (Continued)

Scale 2 (Continued)

Section E: (Continued)

(17) have interesting stories to tell

(19) are dependable

(20) have a sense of humor

(22) are warm

Scale 3: Overall Feelings Toward Job (Affect)* (Range=1.7 to 7; $\bar{x}=5.8 ; s d=.87$ )

Affect Toward SITUATION

Section B:

(7) I enjoy the work I do

(25) my work is an expression of my beliefs

Section $\mathrm{J}$ :

(1) my job is very rewarding to me

Affect Toward CLIENTS

Section $\mathrm{H}$ :

(29) my elderly clients are especially interesting to me Section I:

(l) being with or talking to clients

Section $\mathrm{J}$;

(2) I enjoy working with older people as clients 
discontent was recognized by an organizational member. Scores ranged from 1 to 55 with a mean and a median of 2.90 and a standard deviation of $.74 \quad(n=4.15)$

(2) Recognition of Content Aspects of Job Situation, a 27item additive scale measuring the aspects of one's job that one recognizes as leading to contentment. Items for this scale were derived from various sections of the General Attitude Questionnaire. Included were items from Section A, with a seven step response set of 1 (never) to 7 (always). In addition, 11 items came from Section B, also utilizing a 1 (never) to 7 (always) response set. The CONTENT scale also included two items from section D, answered on a continuum from 1 (never) to 7 (always). Nine items were derived from section $E$, also using a 1 (never) to 7 (always) response set. The items were added together and divided by the number of items of the scale (27) for a CONTENT score. The higher the score, the more contentment was recognized by an organizational member about the job. Scores ranged from 3.2 to 6.6 with a mean and median of 5 and a standard deviation of .66 $(n=420)$.

(3) Affective Orientation Toward One's Job, a six-item scale measuring a member's overall feelings toward the job. Included in the scale were items from Section B, using a I (never) to 7 (always) response set and items from section $H$ using the same scale. Items from. Section I used a (1) not at all enjoyable to (7) very enjoyable response set. Section $J$ included items again with a (1) never to 7 (always) response set. 
Items were added and divided by the number of items (6) for an overall affective orientation toward one's job. The higher one's score, the more positive the feelings one holds toward one's job. The s'cores ranged from 1.7 to 7 , the mean and median were 5.8 with a standard deviation of $.87 \quad(n=425)$.

Intericorrelations of Scales

The seven scales from the Organizational Fact Sheet and the three scales from the General Attitude Questionnaire were separately correlated in order to determine the degree of interdependence of the scales. Table XIV presents the intercorrelations of the organizational structure dimension scales.

As can be seen from the table, size is the most highly correlated dimension of organizational structure. This is not an unexpected result in that size has been both theoretically postulated and empirically shown to be highly related to other structural dimensions within organizations (see for example, Blau 1970 for a theoretical treatment, Porter and Lawler 1965, Prien and Ronan 1971 for empirical studies and Porter and Lawler 1965 and James and Jones 1976 for reviews of the literature).

Size has been shown to be interrelated to job level (Porter and Lawler 1965), complexity (Pugh, Hickson and Hinings 1969), centralization (Ghiselli and Siegel 1972, Hage 1965), specialization (Pugh et al. 1968) and many other structural variables, particularly those encompassed in the concept of bureaucracy. In addition, all of these variables have been found to be highly correlated with one another 

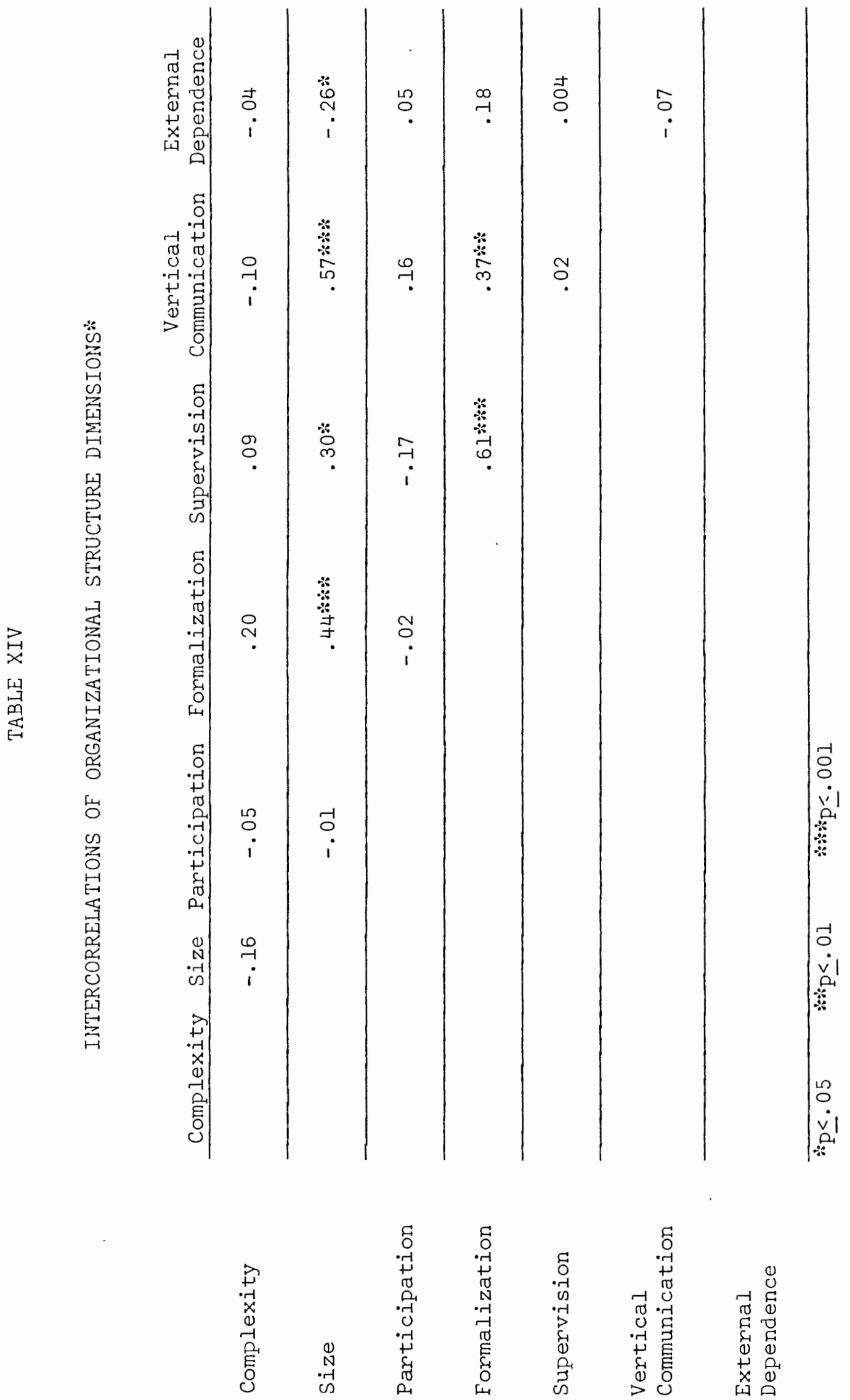
(James and Jones 1976).

As can be seen in Table XIV, size is most highly correlated with vertical communications $(r=.57, p \leq .001)$ and with formalization $(r=.44$, $\mathrm{p} \leq$.001). This can easily be understood in that both scales attempt to measure different aspects of the same organizational dimension, that is, more formalized and standard operating procedures (Hage, Aiken and Marrett. 1971, Lawler, Porter and Tannenbaum 1968, Haas and Collen 1963, Terrien and Mills 1955, Tsouderos 1955). Thus, with increasing size, the need to coordinate internal organizational procedures may also increase.

In addition, size is positively correlated with degree of supervision $(r=.30, p \leq .05)$. Again, size has been shown to be related to various measures of supervision (often called span of control) in numerous studies in the literature. For example, Blau (1970) theorized that increased size resulted in greater differentiation within the organization which then resulted in a larger administrative component in order to effect coordination. It follows then that the larger the organization, the larger the span of control. Pugh et al. (1969) supported this hypothesis in their study of 52 organizations, though the effects of size were somewhat indirect.

In contrast, Pondy (1969) and Holdaway and Bowers (1971) found inverse relationships between organizational size and supervision and Anderson and Warkov (1961) found that larger organizations contained smaller administrative units than had been postulated. Thus, as Haas and Collen (1963) have suggested, the relationship between size and 
supervision (and size with many other organizational dimensions) may, in fact, be curvilinear.

In addition to being correlated with size, formalization is also correlated with supervision $(r=.61, \mathrm{p} \leq .001)$ and with vertical communications $(r=.37, p \leq .01)$. As previously discussed, this theoretically follows in that a larger span of control may increase the degree to which formal and standardized procedures are imposed in an organization and has often been empirically shown (e.g., Hage and Aiken 1965, 1967, 1969, Pugh et al. 1969, Hall 1967, Prien and Ronan 1971) to occur.

Also of interest to this discussion is the fact that complexity was negatively, but not significantly, related to size $(r=-.16)$. This finding is somewhat in opposition to the organizational literature where size and complexity are positively and highly correlated (Pugh et al. 1968, 1969, Blau 1970, Gouldner 1954). Rushing (1967) also found some negative relationships between complexity and size. One explanation for this negative correlation might be that the effects of size diminish after a certain point in organizational growth. Another possible explanation might be that large organizations require proportionately fewer administrative personnel than small organizations. Still, if the assumption that the number of administrative personnel increases in response to problems of increased coordination is valid, the finding of a negative correlation between size and complexity appears to suggest that coordinative difficulties decrease with organizational size. This conclusion is not very likely. What may occur, 
however, is that coordination problems resulting from increased size are qualitatively different from those resulting from increased division of labor (complexity).

Increased size may imply, as Rushing (1967) suggests, an increase in the number of personnel that are just like the personnel already in the organization. While this increase may in fact necessitate increases in coordination efforts, the increase will be of the same type as that already in existence. The kind of coordination procedures may not necessarily increase along with increases in size, thus, complexity may not be lineraly related to size. It is also possible that increased division of labor and increased size may have opposite effects on the organization (e.g., numbers of administrative personnel) because the coordination difficulties associated with each of them may be qualitatively different.

Finally, size was negatively correlated with the external dependence scale $(r=-.26, p \leq .05)$. While the relationships between organizational size and dependence on external organizations has not been extensively documented, there are a few exceptions. In addition to those listed in the hypothesis section of this thesis are Aiken and Hage (1968) and Boland (in Heydebrand 1973). Aiken and Hage concluded in their study of 16 social welfare and health organizations that increased division of labor (complexity--greater occupational diversity and greater professionalization of staff) leads to increased innovation within the organization and this increased innovation increases the need for resources to support the innovation. Thus, increased dependence on outside organizations results from increased 
division of labor. Increased size, as discussed above, may not have the same impact on an organization as increased complexity thus the question of increased size and external dependence is still unanswered. Aiken and Hage (1968) found that more occupational diversity and greater professionalization of staff in organizations that were dependent and that the size relationships were positive but only moderate. Thus, larger organizations were only slightly more dependent than small organizations.

Boland (1973) investigated the effects of size on centralization (both internal relations and external relations). It was hypothesized that as size increases (number of faculty at universities), so too would a centralized administrative component designed specifically to deal with external relations. In addition, as size increased, another centralized body would emerge specifically to deal with internal relations.

Boland's findings concerning the relationship of size to external relations is similar to those of Haas and Collen (1963), that is, that the effects of size hit an apparent "threshold:" This means that increased size leads to an increased external relations component only up to a certain point. After this increase in size, the effects diminish. The effects of size on internal relations however remained constant, larger organizations develop and maintain a body within the organization (universities) designed to deal with internal relations whereas smaller organizations do not. Thus while size appears to influence internal organization relations, it may affect external 
relations in a curvilinear manner.

\section{Summary}

The relationships between increased SIZE and FORMALIZATION, increased SIZE and SUPERVISION, and increased FORMALIZATION and SUPERVISION are confounded by the fact that these variables are also highly interrelated to other structural dimensions of organizations (James and Jones, 1976). These interrelationships may moderate the effects one variable might have on another and the possible effects one might have on attitudes and/or behavior of members of the organizations. What has been demonstrated is that the relationships between many structural dimensions are not clear nor are they always linear. For example, increased size had been thought to increase the size of the administrative component within organizations (e.g., Terrien and Mills 1955) yet Anderson and Warkov (1961) found that the size of the administrative component of an organization actually diminished after a certain point in the growth of an organization.

Nor is the relationship of SIZE to EXTERNAL DEPENDENCE clear. Adding to the confusion concerning the relationships of external dependence and structure variables is the fact that theoperationalizations of dependence are quite different in the few studies thathave examined these characteristics (e.g., Hage, Aiken and Marrett 1971; Rushing 1967). Thus, conclusions cannot easily be drawn. It tentatively appears that size is associated with many organizational variables, including dependence on external organizations, but that this 
relationship exists only up to a certain point. After a certain point, it appears that the relation of size to structure within and outside the organization is moderated or diminished. That is, the effects of size appear to be curvilinear in many instances.

What these interrelationships point out is that there can be no precise understanding of the influence of organizational structure on any organizational behavior without taking into account the interdependencies of structural variables and until these interdependencies are clearly explicated.

Intercorrelation of Job Satisfaction Scale

Table XV presents the intercorrelations of the three dimensions of job satisfaction. As can be seen, recognition of DISCONTENT aspects of one's job correlates significantly with lower AFFECT toward one's job while recognition of CONTENT aspects of one's job correlates significantly with higher AFFECT. These relationships are what one would expect if the job satisfaction scales are internally consistent and thus follow the predicted pattern of the hypotheses concerning job satisfaction.

TABLE XV

INTERCORRELATION OF JOB SATISFACTION DIMENSIONS

\begin{tabular}{l|c} 
& Affect \\
DISCONTENT & $-.21 *$ \\
\hline CONTENT & $.35 \%$
\end{tabular}

$\therefore \mathrm{P} \leq .001$ 
Data Analysis

Table XVI presents the correlational data used to test the hypotheses of this study concerning the influence of organizational. structure on member job satisfaction. It should be remembered that this study is only a preliminary step in a' much needed holistic approach to the study of the effects of organizational structure on member attitudes and behaviors. The analyses presented here attempt only to address the possible correlates between organizational structure and job satisfaction.

The analysis of the data show that, overall, recognition of DISCONTENT aspects concerning one's job (DISCONTENT COGNITIONS) are more highly associated with structural dimensions of organizations than either recognition of CONTENT aspects of one's job (CONTENT COGNITIONS) or feelings toward one's job (AFFECT). That is, five of the seven scales (SIZE, FORMALIZATION, COMPLEXITY, SUPERVISION, and PARTICIPATION) correlated significantly with DISCONTENT COGNITIONS concerning one's job. However, the PARTICIPATION correlation was in the opposite direction to the stated hypothesis and the size of the correlations, in all cases, are extremely low. Thus, much caution will be exercised in the discussion concerning dimensions of organizational STRUCTURE and JOB SATISFACTION.

The analysis concerning CONTENT COGNITIONS of one's job shows that none of the organizational dimensions correlated well with the CONTENT scale. Thus, at least in this instance, structural dimensions of organizations do not appear to aid in our understanding of 


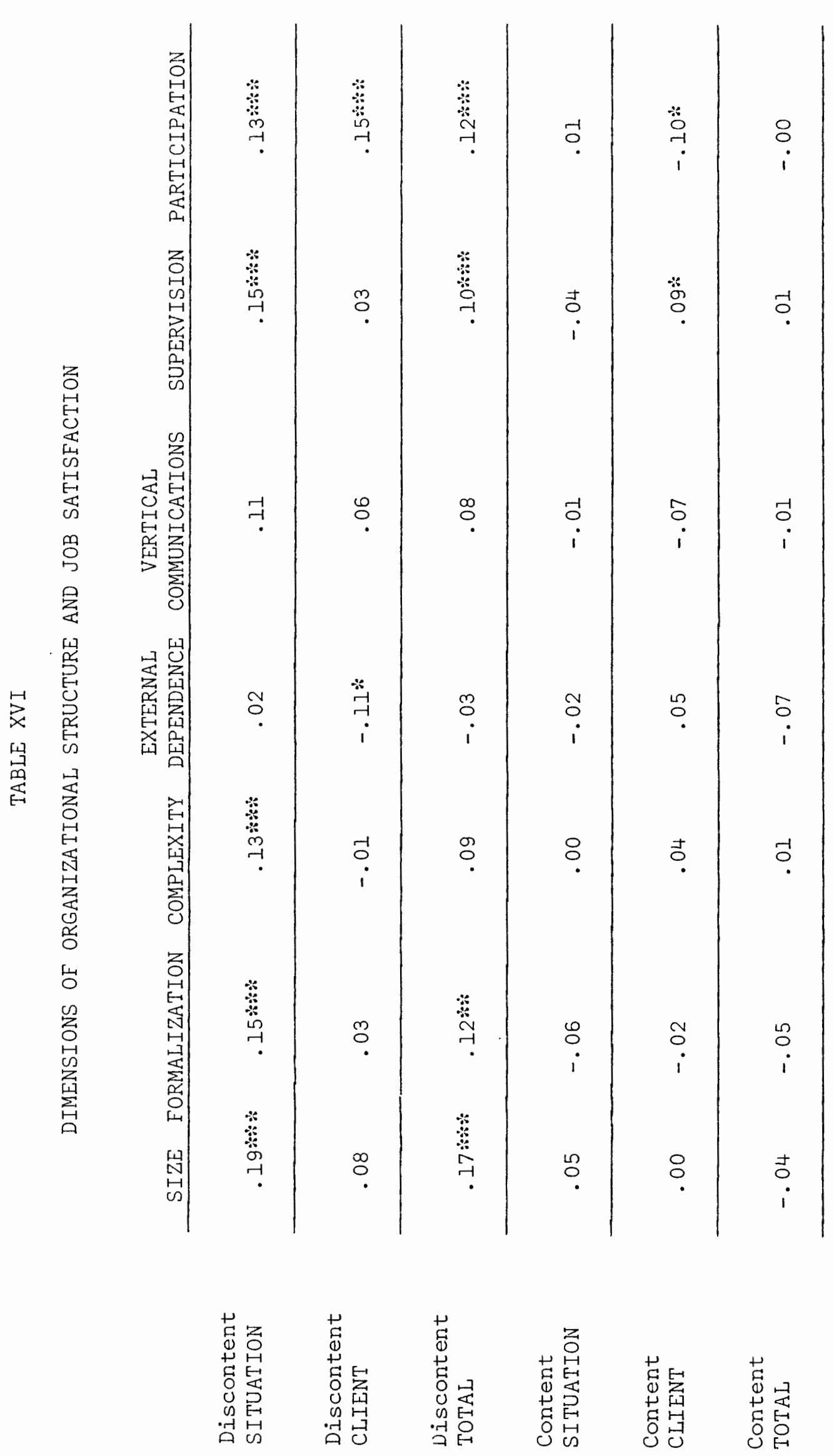




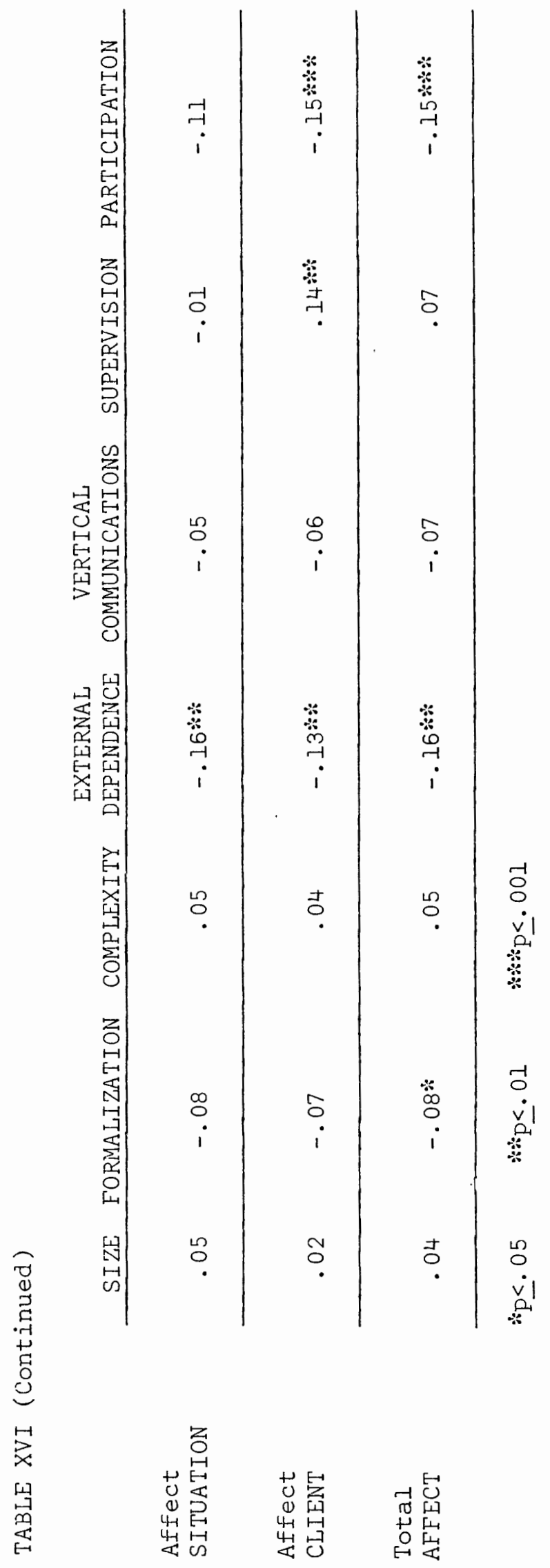

125 
what it is about the organization that may lead to recognition by the number of elements of the job that may lead to CONTENT COGNITIONS. In addition, the data concerning CONTENT COGNITIONS does not appear to be negatively related to dimensions of organizational STRUCTURE. This finding is in direct opposition to the stated hypotheses of this study.

Finally, of the seven STRUCTURE dimensions measured, only three correlated significantly with feelings toward job (AFFECT). Those scales were FORMALIZATION, EXTERNAL DEPENDENCE, and PARTICIPATION. However, of those three significant findings, only two were in the predicted direction (FORMALIZATION and EXTERNAL DEPENDENCE) and the size of the correlations were extremely low.

Therefore, due to the low and inconsistent findings of this study, all hypotheses proposed by this project are rejected. Organizational structural dimensions, in the ways they were operationalized and/or the way they were measured, do not appear to be associated with the job satisfaction of members of social service organizations as measured in this study. As can be seen in Table XVI, while there is some support for the contention that organizational structure is indeed associated with DISCONTENT COGNITIONS concerning one's job, the associations are not consistent across all three dimensions of job satisfaction. Thus, what may be associated with CONTENT COGNITIONS concerning one's job and AFFECT toward one's job, does not appear to be addressed by this study. 
Hypothesis Testing

Hypothesis Number 1. The larger the size of an organization, the lower the job satisfaction of members within the organization. As can be seen in Table XVI, SIZE correlates positively and significantly with DISCONTENT COGNITIONS concerning one's job $(r=.17$, $\mathrm{P} \leq .001)$. But, SIZE does not show a relationship with CONTENT COGNITIONS of one's job nor with AFFECT toward one's job. What appears to be happening is that organizational SIZE is recogninzed by members as contributing to DISCONTENT COGNITIONS but does not appear to be associated with either CONTENT COGNITIONS or feelings concerning the job (AFFECT). This is somewhat surprising in that the relevant literature emphasizes the influence of organizational size on member job satisfaction. While there is a small relationship between DISCONTENT COGNITIONS and SIZE, the relationships are not consistent across all dimensions of job satisfaction. Therefore, the hypothesis is rejected. The exact nature of the influence of size must be explicated more precisely before the specific ways size might influence job satisfaction are to be understood.

Hypothesis Number 2. The greater the formalization of an organization, the lower the job satisfaction of members within the organization.

As can be seen in Table XVI, the FORMALIZATION scale significantly correltated with DISCONTENT COGNITIONS of one's job ( $r=.12$, $\mathrm{p} \leq .01)$ but was not associated with CONTENT COGNITIONS of one's job. In addition, FORMALIZATION of organizational procedures correlated 
negatively with member AFFECT toward job $(r=-.08, p \leq .05)$. Both correlations, while significant, are extremely weak. Therefore, while it appears that formalized organizational procedures is associated with member DISCONTENT COGNITIONS and member AFFECT, the fact there there is no apparent association between FORMALIZATION and CONTENT COGNITIONS when a negative relationship was postulated leads to a rejection of the hypothesis concerning FORMALIZATION. Hypothesis Number 3 . The greater the complexity of an organization, the lower the job satisfaction of members within the organization.

The COMPLEXITY scale significantly correlated with member DISCONTEIT COGNITIONS of ones job $(\mathrm{r}=.09, \mathrm{p} \leq .05)$ though the size of the correlation is extremely weak. This finding is confounded by the fact that no relationships were found between COMPLEXITY and member CONTENT COGNITIONS or member AFFECT. It appears that the structural dimension of COMPLEXITY is more associated with member DISCONTENT COGNITIONS than either of the other two job satisfaction components. Due to the inconsistent findings concenning COMPLEXITY, the hypothesis is rejected.

Hypothesis Number 4. The greater the external dependence of an organization, the lower the job satisfaction of members within the organization.

EXTERNAL DEPENDENCE, unlike the other structural dimensions of organizations does not correlate with member DISCONENT COGNITIONS. In addition, there was no relationship between EXTERNAL DEPENDENCE 
and member CONTENT COGNITIONS. But, in accordance with the hypothesis, there was a significant and negative correlation between EXTERNAL DEPENDENCE and member AFFECT $(r=-.16, p \leq .01)$. Thus, while dependence on outside organizations influencing intraorganizational decisions and procedures does not appear to be associated with either member recognition of DISCONTENT or CONTENT elements of the job situation, there is a weak relationship to a member's feelings toward his job.

Again, while there was a significant correlation between structure and affect, the size of the correlation was weak and not consistent across all three dimensions of job satisfaction. Therefore, the hypothesis concerning EXTERNAL DEPENDENCE and job satisfaction is rejected.

Hypothesis Inmber 5. The greater the formalization of vertical communications, the lower the job satisfaction of members within the organization.

While formalized VERTICAL COMMUNICATION procedures within the organization would logically impact on the frequency and quality of communication patterns within the organization, the data suggest that there is in fact little evidence of such association. The data, presented in Table XVI show that formalization of information disseminating procedures of an organization is not associated with any of the three job satisfaction dimensions measured. While logic and other research would dictate otherwise, the lack of relationships preclude acceptance of the hypothesis. Therefore, the hypothesis 
concerning the relationship of formalized VERTICAL COMMUNICATION procedures with job satisfaction is rejected.

Hypothesis Number 6 . The greater the supervision of service. providers, the lower the job satisfaction of members within an organization.

As can be seen in Table $X \mathrm{VI}$, the correlations between SUPERVISION and the three dimensions of job satisfaction are either extremely weak or nonexistent. While SUPERVISION and member DISCONTENT COGNITIONS of job correlates significantly $(r=.10, p \leq .05)$, the size of the relationship is extremely small. Frequency of SUPERVISION does not appear to have any relationship to member CONTENT COGNITIONS nor member AFFECT toward job. Thus, again it appears that structural dimensions of the organization (SUPERVISION) appears to have a greater association with nember DISCONTENT COGNITION than with other job satisfaction dimensions. But, since the correlation is so small, it is difficult to have any confidence in the relationship. Thus, due to the inconsistent findings concerning the relationship between frequency of SUPERVISION and member job satisfaction, the hypothesis is rejected.

Hypothesis Number 7. The greater the participation in decisionmaking concerning them and their job, the greater the job satisfaction of members within the organization.

The most surprising findings of this study are found in the relationships between the degree of member PARTICIPATION in decisionmaking and the degree of job satisfaction. Contrary to much empirical work, the data indicate that greater PARTICIPATION is associated with member DISCONTENT COGNITIONS of one's job $(r=.12, \mathrm{p} \leq .01)$ and lower 
AFFECT toward job $(r=-.15, p \leq .001)$. PARTICIPATION did not show any relationship, positive as expected or negative, with member CONTENT COGNITIONS. These findings are in direct opposition to the stated hypothesis of this study and are very puzzling in light of much of the theoretical and empirical work concerning job satisfaction. Therefore, due to the significance of the negative correlations, though low, and the lack of a relationship between PARTICIPATION and CONTENT COGNITIONS, the hypothesis is rejected.

\section{Summary}

In looking at the data, it appears that organizational STRUCTURE dimensions are primarily associated with job satisfaction in terms of member DISCONTENT COGNITIONS of one's job. That is, of the seven hypothesized relationships, four significant correlations in the predicted direction were found, though they were all extremely low. DISCONTENT COGINITIONS positively and significantly correlated with SIZE $(r=.17, p \leq .001)$, FORMALIZATION $(r=.12, p \leq .01)$, COMPLEXITY $(r=.09, p \leq .05)$, and SUPERVISION $(r=.10, \mathrm{p} \leq .05)$.

of the three scales that did not correlate in the predicted direction, the PARTICIPATION scale positively and significantly correlated with DISCONTENT $(r=.12, \mathrm{p} \leq .01)$, contrary to the hypothesis. While VERTICAL COMMUNICATIONS correlated positively, and in the predicted direction, the size of the correlation was negligible. Finally, EXTERNAL DEPENDENCE did not correlate at all with member recognition of DISCONTENT.

These data are confounded by the inconsistent and contradictory findings concerning recognition of CONTENT aspects of one's job 
(CONTENT COGNITIONS) and AFFECT toward one's job. The hypotheses of this study postualted negative and significant relationships between organizational STRUCTURE dimensions and member CONTENT COGNITIONS. No relationships were found, that is, the correlations were so low as to be considered nonexistent. Thus, while organizational STRUCTURE tentatively appears to be associated with member recognition of DISCONTENT COGNITIONS concerning one's job, it does not appear to be associated with member recognition of CONTENT COGNITIONS, either negatively or positively.

Finally, the relationships between organizational structure and member AFFECT are a hodgepodge of results. Of the seven postulated negative relationships between structural dimensions and member feelings toward job, only two were found to be significant and in the predicted direction. The scales were FORMALIZATION $(r=-.08, p \leq .05)$ and EXTERNAL DEPENDENCE $(r=-.16, p \leq .01)$. However, the size of these correlations is extremely low and thus, tentative.

Most surprising are the relationships between PARTICIPATION and member AFFECT toward job. PARTICIPATION correlated significantly, but negatively, with member AFFECT $(r=-.15, p \leq .001)$ as well as with member DISCONTENT COGNITIONS. These data are in direct opposition to the hypothesis of this study concerning PARTICIPATION. What these relationships appear to show is that greater PARTICIPATION in decision-making is associated with negative aspects of job satisfaction, that is, greater DISCONTENT COGNITIONS and lower AFFECT. This conclusion is contradictory to much job satisfaction theory and research concerning the importance of member participation in relationship to higher 
member job satisfaction.

One possible explanation for this surprising finding may be the way PARTICIPATION is defined for the members of an onganization. On the one hand, for the director of the agency, higher participation could logically mean members were involved in the processes and procedures of management of the organization and therefore, should lead to job satisfaction. On the other hand, for members of client serving organizations, the definition or meaning of participation may be different. Additionally, the importance of recognizing that the organizations in this sample serve elderly clients, the most resource deprived and emotionally charged client population in this society, cannot be understated. Thus, service providers to elderly clients, who may in fact be a "special" population of people in the first place, may define particiaption in management procedures as taking precious time away from their most important function, that of delivering services to their clients. Thus, instead of seeing PARTICIPATION as an opportunity to provide input to the management processes of the organization, PARTICIPATION may be viewed as part of the bureaucratic rules of the organization that take time away from clients. Thus, a negative evaluation of PARTICIPATION by a service provider would be the result.

The question arises as to why inconsistent relationships were found across the three dimensions of job satisfaction and why the relationships were so low. While STRUCTURAL dimensions of organizations appear to be associated with member DISCONTENT COGNITIONS, they do not appear to be associated with member CONTENT COGNITIONS. In addition, the relationships between organizational STRUCTURE dimensions and 
member AFFECT toward job are inconsistent and extremely low.

One possible explanation may be that because job satisfaction research has primarily been conducted on business and industrial organizations, the power to discern relevant relationships between STRUCTURE and JOB SATISFACTION within social service organizations may yet be limited. Many organizational researchers have suggested that organizational structure is derived or generated from the basic goal or function the organization is designed to achieve. Since the organizations in this study were of a social or health service type, that is, they are client serving organizations, it is plausible that client interaction may be an important element distinguishing social service organizational STRUCTURE from business or industrial organizational structure.

Since a social on health service organization is designed to deliver services, it may be that the client-service provider interaction in the delivery of the services enhances or detracts from the relationship between organizational structure and member job satisfaction. For example, individuals who work in social service agencies may be predisposed in some way to like working with the public. That is, service delivery is primarily a people-to-people task. It is plausible to assume that people who become service providers must enjoy the interperonal rewards of the interaction with clients that is involved in the delivery of services

It may also be that the kind of client being served is an important element in the STRUCTURE-JOB SATISFACTION relationship. That is, since working with older clients is not a financially lucrative nor 
status oriented occupation, something else must be operating in order to attract people into these jobs. It may be that the interpersonal rewards that come from helping elderly clients is the bottom line as to why one would work at a low paying, status job.

In order to explore the possible importance of the older client and client-service provider interaction in the relationship between organizational STRUCTURE and JOB SATISFACTION, the job satisfaction scales were segregated into two additional dimensions. These dimensions were a component measuring job satisfaction in terms of the job situation only (called SITUATION) and a component measuring job satisfaction in terms of the older client-service provider interaction only (called CLIENT) (see Table XVI).

Table XVI presents the data concerning the correlations between member DISCONTENT COGNITIONS of SITUATION and CLIENT and the onganizational STRUCTURE dimensions. As can be seen, all but two of the STRUCTURE dimensions correlated significantly and in the predicted direction with member DISCONTENT COGNITIONS of SITUATION (EXTERNAL DEPENDEINCE and PARTICIPATION excepted). Only two relationships appeared between STRUCTURE dimensions and DISCONTENT COGNITIONS of CLIENT. One, EXTERNAL DEPENDENCE, was in the predicted direction $(r=-.11, p \leq .05)$. The second, PARTICIPATION, correlated positively with member DISCONTENT COGNITIONS of CLIENT, in opposition to the hypothesis concerning PARTICIPATION. In addition, PARTICIPATION correlated significantly, and in the predicted direction, with member DISCONTENT COGNITIONS of SITUATION $(r=.13, \mathrm{p} \leq .001)$. Thus, while most STRUCTURE dimensions appear to be more highly associated with member DISCONTENT 
COGNITIONS of SITUATION (though the correlations are low) than the member DISCONTENT COGNITIONS of CLIENT. DISCONTENT COGNITIONS of SITUATION appear to contribute more to the TOTAL DISCONTENT correlations than DISCONTENT COGNITIONS of CLIENT.

Two significant relationships appear to be contributing to the TOTAL AFFECT correlations. SUPERVISION correlates significantly, but in the opposite direction to the hypothesis, with member AFFECT toward CLIENT $(r=.14, p \leq .01)$. That is, treater SUPERVISION appears to be associated with higher AFFECT toward CLIENT. This is an interesting finding. It may be that positive AFFECT toward CLIENT is indeed important to the relationship between organizational STRUCTURE and member AFFECT. However, due to the fact the correlation between AFFECT toward CLIENT and SUPERVISION is low, this conclusion is tentative. There are too many other possible intervening or moderating variables (e.g., individual service provider characteristics) that were not controlled in this study to come to any definitive conclusion concerning the importance of clients or client-service provider interaction in the possible relationship of organization STRUCTURE and JOB SATISFACTION.

Since SUPERVISION on the Organizational Fact Sheet was operationalized as the frequency of supervisor involvement in the service delivery encounter, it may be that because a supervisor is frequently there, final decisions concerning service delivery to clients can be made right away. Since the final decision to provide a service is vital to the client who requests the service, the fact that the decision can be made immediately may lead to client satisfaction and thereby lead 
to service provider satistaction. Again, the organizational variables used in this study may have difterent meanings for participants in service delivery organizations. This possible explanation for the unexpected finding concerning SUPERVISION is certainly tentative since there are many elements in the question of the relationship between STRUCTURE and JOB SATISFACTION that were not addressed by this study. Table XVI presents the correlational data between the dimensions of organizational STRUCTURE and member CONTENT COGNITIONS. As can be seen in the table, there were few significant relationships to be found between the dimensions of member CONTENT COGNITIONS and organizational STRUCTURE dimensions.

It appears that structural dimensions, as operationalized by this study, are not associated by service providers in social service organizations with recognition of elements of the job situation relating to CONTENT of the job. In addition, only two dimensions of organizational STRUCTURE correlated significantly with member CONTENT COGNITION of CLIENT. SUPERVISION correlated positively, though the correlation is low $(r=.09, p \leq .05)$, with CONTENT COGNITION of CLIENT while PARTICIPATION correlated negatively $(r=-.10, p \leq .05)$. It is difficult to have any confidence in correlations this low. It seems that organizational STRUCTURE has little or no relationship to member CONTENT COGNITIONS of either the CLIENT or the SITUATION. This conclusion is in direct opposition to the postulated intervention of the client and clientservice provider interaction on the relationship between organizational structure and job satisfaction. 
The correlations between member AFFECT dimensions and organizational STRUCTURE show that there are few significant correlations found. OnIy EXTERINAL DEPENDENCE correlated significantly in the predicted direction with member AFFECT toward SITUATION ( $r=-.16, p \leq .01)$. In addition, EXTERINAL DEPENDENCE correlated significantly and in the predicted direction with member AFFECT toward CLIENT ( $r=-.13, \mathrm{p} \leq .01)$. Lower AFFECT towand both CLIENT and SITUATION appears to be significantly associated with the degree of EXTERNAL DEPENDEINCE of an organization, though the correlations are low. AFFECT toward CLIENT does not appear to be important in the negative relationship between EXTERNAL DEPENDENCE and member AFFECT.

Finally, the correlation between PARTICIPATION and the dimensions of member AFFECT toward job are surprising. Both AFFECT toward SITUATION and AFFECT toward CLIENT correlate significantly, but negatively, with member PARTICIPATION. The findings are in direct opposition to the stated hypothesis concerning PARTICIPATION. It appears that PARTICIPATION in organizational decision making is associated with lower AFFECT towand SITUATION $(r=-.11, p \leq .05)$ and CLIENT $(r=-.15, p \leq .001)$. Just why this would occur is difficult to explain.

Overall, both AFEECT toward SITUATION and AFFECT toward CLIENT contribute to the TOTAL AFFECT toward job correlation ( $r=-.15$, $\mathrm{P} \leq .001)$. Only in terms of SUPERVISION does one dimension of AFFECT appear to have a greater association (AFFECT toward CLIENT) and thus, contributes more to the total score. Thus, only three dimensions of 
STRUCTURE appear to be associated with member AFFECT (PARTICIPATION, FORMA'LIZATION, and EXTERNAL DEPENDENCE). Of the three significant findings between STRUCTURE and TOTAL AFFECT, PARTICIPATION is in the wrong direction to the hypothesis and FORMALIZATION did not have any significant relationships among the dimensions of SITUATION or CLIENT. Only in the case of EXTERNAL DEPENDENCE did the correlations support the hypothesis of this study. Therefore, greater FORMALIZATION and EXTERNAL DEPENDENCE appear to be negatively associated with lower AFFECT towards job, although the correlations are low. Additionally, greater PARTICIPATION appears to be associated with lower AFFECT toward job, contrary to expectations.

\section{Conclusions}

Table XVI has presented all the correlational data from the dimensions of organizational STRUCTURE related to the dimensions of JOB SATISFACTION (DISCONTENT, CONTENT, and AFFECT with SITUATION and CLIENT). As can be seen, organizational STRUCTURE dimensions are the most strongly associated with member DISCONTENT COGNITIONS based primarily on DISCONTENT COGNITIONS of SITUATION. There are few relationships to be found among the STRUCTURE dimensions and member CONTENT COGNITIONS of SITUATION and CLIENT and no relationships between organizational STRUCTURE and TOTAL CONTENT COGNITIONS. Finallỳ, while there are two consistent findings among the dimensions of AFFECT toward job (EXTERNAL DEPENDENCE and PARTICIPATION), the data do not support the hypothesis concerning the negative relationships between dimensions of organizational STRUCTURE and JOB 
SATISFACTION. In addition, the data do not support the alternative postulation that CLIENT or client-service provider interaction may moderate the influence of STRUCTURE on member attitudes.

While there were no consistent relationships to be found across all dimensions of job satisfaction, and the relationships that were found were extremely low. Separating out the dimensions of SITUATION versus CLIENT provided interesting insights into the possible ways dimensions of organizational STRUCTURE may be operating or interacting with JOB SATISFACTION. It appears that DISCONTENT COGNITIONS of SITUATION contribute more to our understanding of TOTAL DISCONTENT COGNITIONS. Additionally, neither dimensions of CONTENT COGNITIONS aided in our understanding of the relationship being investigated since no relationships were found for this dimension of job satisfaction.

A possible explanation for this may be that relevant dimensions of organizational structure have yet to be identified that will in fact lead to member CONTENT COGNITIONS. It is interesting to note that most of the literature concerning the influence of organizational structure on member attitudes assumes that the influence will be negative. That is, for example, the greater the FORMALIZATION, the lesser the job satisfaction. If this assumption were correct, significant and negative relationships should have been found between member CONTENT COGNITIONS of SITUATION and organizational STRUCTURE dimensions. The data from this study tend to suggest that this may 
not always be the case. Thus, the assumption of the negative relationship of STRUCTURE to JOB SATISFACTION must be reexamined if we are to adequately address this issue. A few studies have found an opposite relationship between some dimensions of STRUCTURE and member attitudes. For example, studies have shown that low FORMALIZATION and low STANDARDIZATION can lead to role conflict and role ambiguity and lower job satisfaction (House 1971, House and Rizzo 1972) just as high formalization and standardization, while providing for less role ambiguity, conflict, and anxiety, may lead to low task complexity, high group formality, and low job satisfaction (e.g., Pheysey et al. 1971, Corwin 1969, Hulin and Blood 1968). Thus, the influence of STRUCTURE on member attitudes may in fact not be linear (e.g., the effects of size on an organization) and may not always be negative. Therefore, an emportant question has emerged from this study. It appears future research ought to try to identify the elements of organizational STRUCTURE that lead to member CONTENT COGNITIONS and try to explain their relationship to, all three dimensions of job satisfaction.

Finally, the relationship of organizational STRUCTURE and member AFFECT show few significant correlations between them. While EXTERNAL DEPENDENCE was consistent across both dimensions of member AFFECT, there were no relationships to be found between EXTERNAL DEPENDENCE and either member DISCONTENT COGNITIONS or member CONTENT COGNITIONS; the relationships concerning PARTICIPATION were in the wrong direction; and, finally, the only other significant correlation was with FORMALIZATION. FORMALIZATION and DISCONTENT COGNITIONS also 
correlated significantly, but there was no relationship to CONTENT COGINITIONS. Thus, the contradictory and equivocal nature of the data show that the relationships of organizational structure to job satisfaction needs much work if we are to ever clearly understand the nonlinear and interactive relationships that may be operating. 


\section{CHAPTER V}

\section{A REVIEW OF THE FINDINGS AND A PLEA FOR FUTURE RESEARCH}

Research on the relationship of organizational settings and individual responses has primarily been empirical in nature and has lacked a theoretical framework. There is evidence that the job situation influences attitudes, and at times, behavion, but the reasons for this and the processes by which this happens are still unclear. Added to this is the fact that job satisfaction and job performance research traditionally has been conducted on business and industrial organizations. Shifts in the nature of the economy have resulted in changing forms of work (from industrial to service) and changing composition of the workforce. With the rise of the "welfare state" and with it the proliferation of social service organizations has come a challenge for organizational researchers. The organizations and the people involved in client service may or may not be structurally or psychologically the same as those in organizations processing non-human products. In addition, the kind of client being served may contribute something to the structure of the organization and thus its impact on organizational members.

Answers to the questions of what differences and similarities exist between the two types of organizational settings are vital if we are to modify, if necessary, our approach to investigating the relationships of the organization to member attitudes and behavior. 
The exact influence that the "client" and that the client-to-service provider interaction has upon the delivery of service must be clearly delineated before we can realistically attempt to map the relationship of organizational structure to member attitudes and behavior. Theoretical and empirical frameworks for research investigating the influence of organizational settings on member attitudes and performance that are applicable in a industrial organization may not be of equal value in a social service setting.

Six criteria have been suggested as ways which distinguish human service organizations from business and industry: (1) their work force composition, (2) labor intensity, (3) closeness to the consumer, (4) lack of a tangible product, (5) recipient oriented human service, and (6) the relational, interpersonal, and humane human services. These distinguishing characteristics might logically affect the basic structures of the organization itself and perhaps even on the management procedures utilized to accomplish the goals of the organization.

This study represents a preliminary examination of the relationship of traidtional organizational structure concepts to job satisfaction where important job task element involved within these organizational contexts is that of delivery of services to clients. Four hundred and twenty-eight social and health service providers from 42 social service organizations serving elderly clients were surveyed concerning their attitudes toward their job and their clients. Data were analyzed in terms of examining the relationships between a number of organizational structure variables and member job satisfaction were examined. 
The data show that, overall, recognition of DISCONTENT aspects concerning one's job (DISCONTENT COGNITIONS) are more highly associated with the STRUCTURAL dimensions of organizations than either recognition of CONTENT aspects of one's job (CONTENT COGNITIONS) or feelings toward one's job (AFFECT). That is, four of the seven organizational STRUCTURE dimensions correlated significantly with DISCONTENT COGNITIONS (SIZE, FORMALIZATION, COMPLEXITY, and SUPERVISION). However, the size of the correlations were, in all cases, extremely low. There were no relationships found between CONTENT COGNITIONS and the dimensions of organizational STRUCTURE. This finding is in direct opposition to the expectation of significant negative relationships between STRUCTURE and member recognition of CONTENT aspects of their job. Finally, two STRUCTURE dimensions correlated significantly with member AFFECT toward job in the predicted direction (FORMALIZATION and EXTERNAL DEPENDENCE).

When the contributions of the job SITUATION and CLIENT interaction elements of job satisfaction were separated out and analyzed, the findings remained essentially the same. The data show that the relationships between organizationaI STRUCTURE and DISCONTENT COGNITIONS are based primarily on the member recognition of DISCONTENT with SITUATION rather than of DISCONTENT with CLIENT. Thus, the associations found between STRUCTURE and DISCONTENT COGNITIONS appear to be contributed to most by the organizational situation aspects of the job. Only EXTERNAL DEPENDENCE and PARTICIPATION significantly correlated with member DISCONTENT COGNITIONS of CLIENT. While six STRUCTURE variables correlated significantly, although at a low level with DISCONTENT 
COGNITIONS of SITUATION, only four significant relationships resulted between TOTAL, DISCONTENT COGNITIONS and STRUCTURE. Obviously, a more precise operationalization distinction of both STRUCTURE and JOB SATISFACTION in client serving organizational settings are needed in order to address the complex interactions of job situation, client service, and member attitudes.

There were few significant relationships found between nember recognition of CONTENT aspects of one's job and organizational STRUCTURE. The hypotheses of this study postulated a significant and negative relationship between CONTENT COGNITIONS and onganizational STRUCTURE. The fact that few relationships were found suggests the need for a reconceptualization of the traditional approach to organizational research. That is, if the traditional assumption that organizational structure leads to negative job attitudes by organizational members is correct, negative relationships should have been found between STRUCTURE and member CONTENT COGNITIONS of jOb SITUATION. Since few significantly negative relationships were found (SUPERVISION and PARTICIPATION excepted), perhaps the STRUCTURE of an organization can promote development of positive COGNITIONS and AFFECT of workers. Fon example, while high FORMALIZATION and high STANDARDIZATION have been found to lead to low task complexity, high group formality, and low job satisfaction (e.g., Pheysey et al. 1971, Corwin 1969, Hulin and Blood 1968) it has also been found that low FORMALIZATION and low STANDARDIZATION can lead to role conflict and role amibguity and lower job satisfaction (House and Rizzo 1972, House 1971). In addition, the effects of SIZE on many organizational procedures (e. g., the 
administrative components) have been shown to be curvilinear (e.g., Rushing 1967). The traditional assumption of the negative associations between organizational structure and member attitudes and behaviors may need to be revised in light of new evidence suggesting either a curvilinear or independent association between organizational structure and member attitudes.

Alternatively, because this study was limited in scope, it may not have measured the dimensions of onganizational STRUCTURE that are in fact associated with member CONTENT COGNITIONS and member AFFECT. There were a number of elements within the onganizational environment that were not controlled in this study that need further work to delineate thein contribution to the influence of the organization on the job satisfaction of members. Other organizational elements might include: One, the impact that service-provider client interaction has on organizational structure, that is, since the goal of the organization is client service, this may determine the kinds of structure developed by the onganization members to achieve organizational goals. Logically, different goals would generate different kinds of structure which may then have a differential impact on organizational members. Thus, the delineation of how client serving organizations differ structurally from business or industrial organizations needs to be assessed. Two, in addition, the kind of client served by a service organization may impact on the kinds of structure generated to achieve organizational goals. Since the agencies in this sample primarily served elderly clients, a particularly resource-deprived client population, the influence this might have on structure and on service 
provider perceptions of the organization is a vital and unanswered question. What contributions do elderly clients make to the organizational context and in what ways is this related to member attitudes and behaviors was an important question that this study was unable to address. Three, the kind of client is additionally important in the selection process that may go on with the kinds of people who work in service organizations serving elderly clients. Is there a self-selection process going on in which only certain kinds of people end up serving elderly clients? What personal characteristics do they bring to the service setting that may then interact with elderly clients and contribute to the relationship of structure and job satisfaction? Finally, does the experience of service providerclient interaction alter the perceptions and/on behavior of the service provider in any way, that is, does interaction with elderly clients make a service provider more or less onganizationally oriented or more or less client oriented?

These questions are of major significance for both organizational researchers, in a society characterized by social service organizations, and to gerontologists where a large number of elderly are highly dependent upon the social services provided by these organizations. The delineation of the characteristics and relationships between social service organizations, the individuals who provide services, and the kinds of clients served are a potential bridge between two areas of research traditionally separate, that is, organizational research and the field of gerontology. These elements must be understood before we can adequately address the question of the 
relationship of social service onganizational structure and member job satisfaction.

In addition, the fact that some contradictory relationships were found could be an artifact of the study's operationalization of organizational STRUCTURE. The definition of what organizational structure actually means in a social service setting, as opposed to the traditional operationalization for business and industrial organizations, may have been missed by this study. For instance, the traditional operationalization of PARTICIPATION in an industrial on business setting is usually measured by the member participation in organizational decision-making affecting him and his job. It is assumed that this participation will enhance the member's involvement in the management of the organization, will provide added social control of member behavior, and will in fact lead to greater job satisfaction due to the member's involvement in decision-making. The data, however, tentatively suggest that PARTICIPATION is defined differently in a client serving organizational setting. PARTICIPATION correlated positively on both dimensions of member DISCONTENT COGNITIONS (SITUATION and CIIENT): That is, greater participation was associated with greater DISCONTENT COGNITIONS of SITUATION and CLIENT. In addition, PARTICIPATION correlated significantly, though the correlation was low, and negatively with member CONTENT COGNITIONS of CLIENT. FinaIIy, PARTICIPATION correlated negatively and significantly on both dimensions of member AFFECT toward job (SITUATION and CLIENT), providing support for the assertion that greater PARTICIPATION is associated with lower member AFFECT 
toward SITUATION and CLIENT. These data, though the correlations were low, suggest a different conceptualization of PARTICIPATION being utilized by social service workers.

One possible explanation for this finding was suggested in the data analysis chapter of this thesis, that is, because the sample of workers are service providers and because they serve a resourcedeprived population of clients, the elderly, the time needed for the organizational participation may be viewed as an imposition of organizational red tape on bureaucratic procedures upon them. They may feel that their primary purpose within the organization is to provide services, particularly to those in great need like elderly clients. Thus, the time taken for management decision-making is time taken from needy clients.

The fact that opposite relationships to the hypotheses of this study were found, does suggest a needed reconceptualization of organizational STRUCTURE variables within social service and client service settings. One way this may be accomplished is to utilize qualitative data-gathering procedures in the development of an organizational structure questionnaire examining social service organizations. That is, it may be necessary to find out the meaning of STRUCTURE dimensions for the members of service delivery organizations before attempting to address the larger question of the relationship of organizational STRUCTURE to member ATTITUDES and BEHAVIOR.

The equivocal and contradictory findings of this study suggest a number of conclusions and directions for future research. I. The consistency with which organizational STRUCTURE was 
shown to be related to member DISCONTENT COGNITIONS, particularly in regard to job SITUATION, while at the same time being unrelated to member CONTENT COGNITIONS of SITUATION suggests the possibility that separate dimentions of organizations are associated with CONTENT and DISCONTENT COGNITIONS. That is, STRUCTURE appears to be more important as a source of member DISCONTENT COGNITIONS and lower AFFECT, though the size of the relationships provides only minimal support for this suggestion, than of member CONTENT COGNITIONS. Just what dimensions of the organization are associated with member CONTENT COGNITIONS remains an unanswered question.

Traditional job satisfaction theory assumes that more of a particular dimension of the job situation will lead to member job satisfaction (e.g., pay) while less of the same dimension will lead to an increase of member dissatisfaction or vice versa. The data suggest that STRUCTURAL dimensions of organizations are related to DISCONTENT COGNITIONS and negative AFFECT toward the job but have little relationship to member CONTENT COGNITIONS and positive member AFFECT. Thus, CONTENT and DISCONTENT COGNITIONS and eventually, AFFECT, appear to be associated with separate and distinct dimensions of the job situation. Thus, the data tend to support the traditional theory of job satisfaction.

2. It has become apparent that relevant dimensions of organizational structure that are associated with member CONTENT COGNITIONS and positive AFFECT toward job may not have been adequately addressed by this study. That is, the operationalizations of the structural 
dimensions or the way they were measured may have confounded the influence STRUCTURE may have on member CONTENT COGNITIONS and positive AFFECT. Definitions of organizational dimensions operationalized on an a priori basis with little grounding in the organizational setting may be an important limitation to this study. As in the case of PARTICIPATION and SUPERVISION, what may be a relevant definition in one setting (industrial organizations) may not be as relevant in another (client service organizations).

The question whether STRUCTURAL dimensions of organizations are indeed associated with member CONTENT COGNITIONS and positive member AFFECT, or if STRUCTURE is primarily associated with member DISCONTENT COGNITIONS and negative member AFFECT, is unclear; and is an important future research question generated by this study. What is clear is the need to rethink our traditional assumptions concerning the negative and linear relationship between organizational STRUCTURE and member attitudes and behavior. This is a necessary first step in the explication of the impact of the organization on the members within it.

3. The identification and the delineation and identification of what particular elements in the organizational setting, whether structural or nonstructural, are associated with member CONTENT COGNITIONS and thus positive AFFECT need to be examined. While neither the SITUATION nor the CLIENT elements of the job situation appear to be assoicated with member CONTENT COGNITIONS, some other variables must be operating within the relationship. What these variables are and what their relationships are to STRUCTURE and to member ATTITUDES are important elements in the organizational context not addressed by 
this research. It is possible that nonstructural aspects of the job situation, such as the informal organizational network, the characteristics of the service providers, or the characteristics of the clients served may be interacting or moderating the relationships investigated here. There is a great need to examine the whole organizational environment, including interorganizational relationships, if we are to begin to get at the complex relationships of organization, individual, and the social service setting.

4. A major question that should lead to future research is the much needed exploration of the differences and similarities between social service organizations and their industrial and business counterparts. While this major question has been theoretically addressed in this study, comparisons between such organizations will be necessary to examine the significance and meaning many organizational variables hold in the two settings; for example, the implications that processing a human object has for those members of the organization responsible for those tasks; and the distinctions, if any, of management procedures in organizations that boast a professional staff. There are endless questions to be answered in this area; undoubtedly, the contrasts will become increasingly important as the significance of the "service society" becomes recognized.

5. Finally, the potential for answering these questions insocial service organizational research can be found in integrative models. The advent of integrating models for organizational analysis will require the development of new rationales and methodologies for the 
identification and measurement of macro, micro, and individual components within the organizational setting.

What must be recognized by organizational researchers is the fact that meaningful onganizational research requires the investigation of a large number of variables from many domains within the organization. Additionally, the relationships between the variables are often complex and require the investigation of a number of interactions, particularly where variables intervening between the micro, macro and individual components are involved. Lastly, it should also be recognized that organizational life is a dynamic process, the dynamic nature of many integrating models necessitates longitudinal experimental paradigms and the study of feedback processes occurring in ghe organizational environment.

While this study could not address many of the above-mentioned elements that need to be addressed to investigate adequately the complex relationships occurring between individuals and organizations, the preliminary nature of this research has tentatively identified a number of important aspects of job satisfaction in a client-serving context. The identification of a possible "two-factor" component operating within the organizational setting has enormous potential for future investigations in the service provider-client relationship. The provisional challenge to traditional organizational researchers' assumptions about the negative relationship of structure to organizational members' attitudes toward their jobs, offers another area for future research. And, finally, the delineation and explication of 
elements in the job setting of social service onganizations that may influence positive cognitions and positive affect for organizationa members is a third area for research. It is hoped that these suggestions will provide a strong impetus for organizational researchers to adopt integrating models for research, with the accompanying need for more thorough and explanatory investigations of organizational structure and its association with job satisfaction, as reflected by attitudes of members of the organization. 


\section{BIBLIOGRAPHY}

Adams, E. F., Laker, D. R., E Hulin, C. L. An investigation of the influence of job level and functional specialty on job attitudes and perceptions. Journal of Applied Psychology, 1977, 62, 335-343.

Aiken, M., \& Hage, J. Organizational interdependence and intraorganizational structure. American Sociological Review, $1968,33,912-930$.

Alderfer, C. P. An empirical test of a new theory of human needs. Organizational Behavior and Human Performance, 1969, 4, 142-175.

Alderfer, C. P. Existence, relatedness and growth: Human Needs in organizational settings. New York: Free Press, 1972.

Anderson, T. R., \& Warkov, S. Onganizational size and functional complexity: A study of administration in hospitals. American Sociological Review, 1961, 26, 23-28.

Bachman, J. C., Smith, C. G., E Slesinger, J. A. Control, performance, and satisfaction: An analysis of structural and individual effects. Jounnal of Personality and Social Psychology, $1966, \underline{4}, 127-13 \overline{6}$.

Bass, B. M., \& Barrett, G. V. Man, work and organizations: An introduction to industrial and organizational psychology. Boston: Aliyn \& Bacon Press, 1972.

Beauregard, R. A. From isolation to organizations: Structural barriers to client-induced accountability in the human services. Journal of Sociology and Social Welfare, 1977, 4 , 1109-1121.

Bell, D. Labor in the post-industrial society. Dissent, 1972, 19, 166- 173 .

Bell, D. The coming of the post-industrial society: A venture in social forecasting. iNew York: Basic Books, 1973.

Bennis, W. C. Organizational developments and the fate of bureaucracy. In L. I. Cummings $\&$ W. E. Scott (Eds.), Organizational behavior and human performance. Homewood, IL: Irwin-Dorsey, 1969. 
Berger, C. J., \& Cummings, L. L. Onganizational structure, attitudes and behaviors. In B. Staw (Ed.), Research in organizational behavior (Vol. 1). Greenwich, CiN: JAI Press, 1978.

Blau, P. A formal theory of differentiation in organizations. American Sociological Review, 1970, 35, 201-219.

Blau, P. M. The hierarchy of authority in onganizations. American Journal of Sociology, 1968, 73, 453-467.

Blau, P. M., Heydebrand, W. V., \& Stauffer, R. E. The structure of small bureaucracies. American Sociological Review, 1966, 31, 179-191.

Blau, P. M., E Scott, R. W. Formal organizations. San Francisco: Chandler Publishing Co., 1962.

Blood, M. R., E Hulin, C. L. Alienation, environmental characteristics, and worker responses. Journal of Applied Psychology, $1967, \underline{51}, 284-290$.

Brayfield, A. H., \& Rothe, H. F. An index of job satisfaction. Journal of Applied Psychology, 1951, 35, 397-4ll.

Brinkerhoff, M. B., E Kunz, P. R. (Eds.). Complex organizations and their environments. Dubuque: Wm. C. Brown Company, Publishers, 1972 .

Buck, V. E. Working under pressure. New York: Crane, Russak and Company, Inc., 1972 .

Burke, R. J. Are Herzberg's motivators and hygienes unidimensional? Journal of Applied Psychology, 1966, 50, 317-321.

Campbell, J. P., Dunnette, M. D., Lawler, E. E., $\varepsilon$ Weick, K. E., Jr. Managerial behavior, performance, and effectiveness. New York: McGraw-Hill, 1970.

Caplow, T. Organizational size. Administrative Science Quarterly, 1957, I, 484-505.

Carzo, R., \& Yanouzas, J. N. Effects of flat and tall organization structure. Administrative Science Quarterly, 1969, 14, 178-191.

Chapin, F. S. The Growth of Bureaucracy: An hypothesis. American Sociological Review, 1951, 16, 835-836.

Corwin, R. G. Patterns of organizational conflict. Administrative Science Quarterly, 1969, 14, 507-519. 
Crozien, M. The bureaucratic phenomenon. Chicago: University of Chicago Press, 1964.

Cumming, E. Systems of social regulation. New York: Atherton Press, 1968.

Cummings, L. L., $E$ El Salmi, A. M. The impact of role diversity, job level, and onganizational size on managerial satisfaction. Administrative Science Quarterly, 1970, 15, 1-10.

Dachler, H. P., E Mobley, W. H. Construct validation of an instrumentality-expectancy-task-goal model of work motivation: Some theoretical boundary conditions. Journal of Applied Psychology Monograph, 1973, 58, 397-418.

Damone, H. W., \& Harshbarger, D. (Eds.). Handbook of human service organizations. New York Behavioral Publications, 1974.

Dunham, R. G., Smith, F. J., $\varepsilon$ Blackburn, R. S. Validation of the Index of Organizational Reactions with the JDI, the MSQ, and Faces Scale. Academy of Management Journal, 1977, 20, 420-432.

Dunnette, M. D., Campbell, J. P., $\varepsilon$ Hakel, M. D. Factors contributing to job satisfaction and job dissatisfaction in six occupational groups. Organizational Behavior and Human Performance, 1967, 2, $143-174$.

Dunnette, M. D., \& Kirchner, W. R. Psychology applied to industry. New York: Appleton-Century-Crofts, 1965.

Dunteman, G. H. Organizational conditions and behavior in 234 industrial manufacturing organizations. Journal of Applied Psychology, $1966,50,300-305$.

Dyer, L, $\varepsilon$ Theriault, R. Determinants of pay satisfaction. Journal of Applied Psychology, 1976, 61, 596-604.

Emery, F. E., E Trist, E. L. The causal texture of organizational environments. Human Relations, 1965, 18, 309-324.

England, G. W., $\varepsilon$. Lee, R. Onganization size or an influence on perceived organizational goals: A comparative study among American, Japanese, and Korean managers. Organizational Behavior and Human Performance, 1973, 9 , 48-58.

Evan, W. M. Indices of the hierarchical structure of industrial organizations. Management Science, 1963, 9, 468-477. 
Evan, W. M. The onganization-set: Toward a theory of interorganizational relations. In M. B. Brinkerhoff \& P. R. Kunz (Eds.), Complex organizations and their environments. Dubuque: Wm. C. Brown, Co., Publishers, 1972.

Evans, M. G. Conceptual and operational problems in the measurement of various aspects of job satisfaction. Journal of Applied Psychology, 1969, 53, 93-101.

Evans, M. G. Extensions of a path-goal theory of motivation. Jounnal of Applied Psychology, 1974, 59, 172-178.

Ewen, R. G. Some determinants of job satisfaction: A study of the generality of Herzberg's theory. Journal of Applied Psychology, $1964,48,161-163$.

Ewen, R. G. Weighting components of job satisfaction. Jounnal of Applied Psychology, 1967, 5I, 68-73.

Ewen, R. G. Smith, P. C., Hulin, C. L., E Locke, E. A. An empirical test of the Herzberg two-factor theory." Journal of Applied Psychology, 1966, 50, 544-550.

Federico, R. C. The social welfare institution: An introduction. Lexington, $\overline{M A:}$ D. C. Heath and Company, 1973.

Freidson, E. Dominant Professions, bureaucracy, and client services." In W. Rosengren $\&$ iN. Lefton (Eds.), Organizations and clients: Essays in the sociology of service. Columbus, $\mathrm{OH}$ : Charles E. Merrill Publishing Co., 1970.

Freidson, E. (Ed.). Professions and thein prospects. Beverly Hills: Sage Publications, 1973.

Friedlander, F. Job characteristics as satisfiers and dissatisfiers. Journal of Applied Psychology, 1964, 48, 388-392.

Fuchs, V. Service economy. New York: Columbia University Press, 1968.

Gans, H. More equality. New. York: Pantheon Books, 1973.

Gartner, A., E Riessman, F. Service society and the consumer vanguard. New York: Harper and Row, Publishers, 1974.

Ghiselli, E. E., E Siegel, J. P. Leadership and managerial success in tall versus flat organizational structures. Personnel Psychology, 1972, 25, 617-624. 
Goldthorpe, J. H., Lockwood, D., Bechofer, F., \& Platt, J. Affluent worker: Industrial attitudes and behavior. Cambridge: Cambridge University Press, 1968.

Gouldner, A. W. Patterns of industrial bureaucracy. New York: Free Press, 1957.

Graen, G. G., $\varepsilon$ Hulin, C. L. Addendum to an empirical investigation of two implications of the two-factor theory of job satisfaction. Journal of Applied Psychology, 1968, 52, 341-342.

Graham, W. K. Comparison of job attitude components across three organizational levels. Personnel Psychology, 1969, 22, 33-40.

Greenwood, E. Attributes of a profession. Social Work, 1957, 2, 45-55.

Gross, E. Work, organization, and stress. In S. Levine $\varepsilon$ N. Scotch (Eds.), Social stress. Chicago: Aldine Publishing Company, 1970.

Grusky, 0. Corporate size, bureaucratization, and managerial succession. American Sociological Review, 1961, 67, 269-274.

Guetzkow, H. Relations among organizations. In R. V. Bowers (Ed.), Studies on behavior in organizations. Athens, GA: University of Georgia Press, 1969.

Haas, J. E., \& Collen, L. Administrative practices in university departments. Administrative Science Quarterly, 1963, 8, 44-60.

Haas, J. E., E Drabek, T. E. Complex organizations: A sociological perspective. New York: Macmillan Company, 1973.

Haas, J. E., Hall, R., $E$ Johnson, N. Size of the supportive component in organizations: A multi-organizational analysis. Social Eorces, 1963, 42, 9-17.

Hackman, J. R., E Lawler, E. E. Employee reactions to job characteristics. Administrative Science Quarterly, 1971, 55, 259-286.

Hackman, J. R., E Oldham, G. R. Development of the job diagnostic survey. Journal of Applied Psychology, 1975, 60, 159-170.

Hage, J. An axiomatic theory of organizations. Administrative Science Quarterly, 1965, 10, 289-321.

Hage, J., \& Aiken, M. Relationship of centralization to other structural properties. Administrative Science Quarterly, 1967, 14, 73-92. 
Hage, J., E Aiken, M. Routine technology, social structure, and organizational goals. Administrative Science Quarterly, $1969,14,366-377$.

Hage, J., Aiken, M., \& Marrett, C. B. Organization structure and communications. American Sociological Review, 1971, 36, 860-871.

Hall, R. H. Intraorganizational structural variation: Application of the bureaucratic model. Administrative Science Quarterly, $1962, \underline{7}, 295-308$.

Hall, R. H. Bureaucracy and small organizations. Sociology and Social Research, 1963, 48, 38-46.

Hall, R. H., Haas, J. E., E Johnson, N. J. Organizational size, complexity, and formalization. American Sociological Review, $1967,32,903-912$. (a)

Hall, R. H., Haas, J. E., E Johnson, I. J. An examination of the Blau-Scott and Etzioni typologies. Administrative Science Quarterly, 1967, 12, 118-139. (b)

Hall, R. H., E Tittle, C. R. A note on bureaucracy and its correlates. American Journal of Sociology, 1963, 49, 32-40.

Halpern, G. Relative contributions of motivator and hygiene factors to overall job satisfaction. Journal of Applied Psychology, 1966, 50, 198-200.

Handyside, J. D. Satisfactions and aspirations. Occupational Psychology, 1961, 35, 213-244.

Haug, M. R., E Sussman, M. Professional autonomy and the revolt of the client. Social Problems, 1969, 17, 153-161.

Havighurst, R. J. Future aged: The use of time and money. Gerontologist, February 1975, 15 (Pt. II), Pp. 10-15.

Heller, R., E Yukl, G. A. Participation in decision making and situational variables. Organizational behavior and human performance, 1971, 16, 485-500.

Herman, J. B., Dunham, R. D., E Hulin, C. L. Organizational structure, demographic characteristics and employee responses. Organizational behavior and human performance, 1975, 13, 20 $\overline{6-232}$.

Herman, J. B., E Hulin, C. L. Studying organizational attitudes from individual and organizational frames of reference. Organizational Behavion and Human Performance, 1972, 8, 84-108. 
Herman, J. B., E Hulin, C. L. Managerial satisfactions and organizational roles: An investigation of Porter's need deficiency scales. Journal of Applied Psychology, 1973, 57, 118-124.

Herzberg, F., Mausner, B., Peterson, R. 0., E Capwell, D. F. Job attitudes: Review of research and opinion. Pittsburgh: Psychological Service of Pittsburgh, 1957.

Herzberg, F., Mausner, B., E Snyderman, B. Motivation to work. lNew York: Wiley Press, 1959.

Heydebrand, W. V. Comparative organizations: Results of empirical research. Englewood Cliffs, New Jersey: Prentice-Hall, Inc., 1973.

Hickson, I. J. Convergence in organization theory. Administrative Science Quarterly, 1966, 11, 229-237.

Hickson, D. J., Pugh, D. S., E Pheysey, D. C. Operations technology and organization structure. Administrative Science Quarterly, 1969, I7, 378-397.

Hinton, B. L. An empirical investigation of the Herzberg methodology and two-factor theory. Onganizational Behavior and Human Performance, $1968, \underline{3}, 286-309$.

Holdaway, E. A., E Bowers, T. A. Administrative ratios and organization size: A longitudinal examination. American Sociological Review, 1971, 36, 278-286.

House, R. J. A path goal theory of leader effectiveness. Administrative Science Quarterly, 1971, 16, 485-500.

House, R. J., $\xi$ Rizzo, J. R. Role conflict and ambiguity as critical variables in a model of organizational behavior. Organizational Behavior and Human Performance, 1972, 7, 467-505.

Hulin, C. L., E Blood, M. J. Job englargement, individual differences, and worker responses. Psychological bulletin, 1968, I, 41-55.

Hulin, C. L., E Smith, P. C. A Iinear model of job satisfaction. Journal of Applied Psychology, 1965, 49, 209-216.

Ilgen, D. R. Satisfaction with performance as a function of the initial level of expected performance and the deviation from expectations. Organizational Behavior and Human Performance, $1971, \underline{6}, 345-36 \overline{1}$. 
Ilgen, D. R., \& Hollenback, J. H. The role of job satisfaction in absence behavion. Organizational Behavior and Human Performance, $1977,19,148-161$.

Indik, B. P. The scope of the problem and some suggestions toward a solution. In B. P. Indik \& F. K. Berrien (Eds.), People, groups and organizations, New York: Teachers College Press, 1968.

Ingham, G. Size of industrial organization and worker behavior. Cambridge: Cambridge University Press, 1970.

Inkson, J. H. K., Pugh, D. S., \& Hickson, D. J. Organization context and structure: An abbreviated replication. Administrative Science Quarterly, 1970, 5, 318-329.

Inkson, J. H. K., Schwitter, J. P., Pheysey, D. C., E Hickson, D. J. Comparison of organizational structure and managerial roles. Journal of Management Studies, 1970, 7, 347-363.

James, L. R., \& Jones, A. P. Onganizational structure: A review of structural dimensions and their conceptual relationships with individual attitudes and behavior. Organizational Behavion and Human Performance, 1976,6 , 74-113.

Jasinski, F. J. Use and misuse of efficiency controls. Harvard Business Review, 1956, 34, 105-112.

Jerdee, T. H. Work group versus individual differences in attitude. Journal of Applied Psychology, 1966, $\underline{5}, 431-433$.

Kahn, R. L., Katz, D., \& Gutek, B. Bureaucratic encounters: An evaluation of government services. Journal of Applied Behavional Science, 1976, 12, 178-198.

Kahn, R. L., Wolfe, D., Quinn, R., Snoek, J., \& Rosenthal, R. Onganizational stress: Studies in role conflict and ambiguity. New York: Wiley Press, 1964.

Kallenberg, A. L. Work values and job rewards: A theory of job satisfaction. American Sociological Review, 1977, 42, 124-143.

Katz, D. The motivational basis of organizational behavior. Behavioral Science, 1964, 9, 131-146.

Katz, D., \& Kahn, R. L. The social psychology of organizations. New York: John Wiley, 1966. 
Katz, E., E Danet, B. Petitions and persuasive appeals: A study of official-client relations. American Sociological Review, $1977,30,469-486$.

Katz, R. The influence of group conflict on leadership effectiveness. Organizational Behavior and Human Performance, 1977, 20, 265-286.

Katz, R., E Van Maanen, J. V. The loci of work satisfaction, job interaction and policy. Human Relations, 1977, 30, 469-486.

Larson, J. M., E Owens, W. A., Jr. Worker satisfaction as a criterion. Personnel Psychology, 1965, 18, 39-47.

Lawler, E. E. Job attitudes and employee motivation: Theory, research, and practice. Personnel Psychology, 1970, 23, 223-237.

Lawler, E. E. Pay and organizational effectiveness: A Psychological view. Hew York: McGraw-Hill, 1971.

Lawler, E. E., Porter, L. W., E Tannenbaum, A. Managers' attitudes toward interaction episodes. Journal of Applied Psychology, $1968, \underline{52}, 432-439$.

Lewis, L. S., E Ryan, M. N. Professionalization and the professoriate. Social Problems, $1976,24,282-287$.

Lichtman, C. M., E Hunt, R. G. Personality and organization theory: A review of some conceptual literature. Psychological Bulletin, 1971, 76, 27I-294.

Litwak, E. Models of bureaucracy which permit conflict. American Journal of Sociology, 1961, 67, 177-184.

Litwak, E., $\varepsilon$ Hylton, L. F. Interorganizational analysis: A hypothesis on coordinating agencies. Administrative Science Quarterly, $1962, \underline{6}, 395-426$.

Locke, E. A. What is job satisfaction? Onganizational Behavior and Human Performance, 1969, 4, 309-336.

Locke, E. A. Personnel attitudes and motivation. Annual Review of Psychology, 1975, 26, 457-480.

Locke, E. A. The nature and causes of job satisfaction. In M. E. Dunnette (Ed.), Handbook of industrial and organizational psychology. Chicago: Rand McNally, 1976.

Lyon, H. L., \& Ivancevich, J. M. An exploratory investigation of onganizational climate and job satisfaction in a hospital. Academy of Management Journal, 1974, 635-648. 
Macarov, D. Social welfare as a by-product: The effect of neomercantilism. Journal of Sociology and Social Welfare, 1977, 4, $1135-1144$.

Mahoney, T. A., Frost, P., Crandall, N. F., \& Weitzel, W. The conditioning influence of organizational size upon managerial practice. Organizational Behavior and Human Performance, 1972, $\underline{8}, 230-241$.

Manney, J. D. Aging in American society. Ann Arbor: University of Michigan Press, 1974.

March, J. G., E Simon, H. A. Organizations. New York: Wiley, 1958.

Marx, K. Selected writings in sociology and social philosophy

(T. B. Bottomore \& M. Rubel, Eds. and trans.). New York: McGraw-Hill, 1964.

Meltzer, L., E Salteri, J. Organizational structure and the performance and job satisfactions of physiologists. American Sociological Reviews 1960, 27, 351-362.

Mennerick, L. A. Client typologies: A method of coping with conflict in the service worker-client relationships. Sociology of Work and Occupations, 1974, I, 396-418.

Merton, R. K. Bureaucratic structure and personality. Social Forces, $1940,18,560-568$.

Merton, R. K. Social theory and social structure. Hew York: Free Press, 1957.

Meyer, N. W. Size and the structure of organizations: A causal analysis. American Sociological Review, 1972, 37, 434-441.

Meyers, M. S. Who are your motivated workers? Harvard Business Review, 1964, 42, 73-78.

Mitchell, T. R. Organizational behavior. Annual Review of Psychology, $1979,30,246-281$.

Hewman, W. H., Summer, C. E., $\varepsilon$ Warren, K. E. The process of management (2nd ed.). Englewood Cliffs, New Jersey: PrenticeHall, Inc., 1967.

Nicholson, N., Brown, C. A., \& Chadwick-Jones, J. K. Absence from work and job satisfaction. Journal of Applied Psychology, 1976, 61, 728-737. 
O'Connel, M. J., \& Cummings, L. L. The moderating effects of environment and structure on the satisfaction-tension-influence network. Organizational Behavior and Human Performance, 1976, 17, 351-366.

Parsons, T. How are clients integrated into service organizations. In W. Rosengren $\varepsilon$ M. Lefton (Eds.), Organizations and clients: Essays in the sociology of service, Columbus, OH: Charles E. Merrill Publishing Company, 1970.

Payne, R. L. Factor analysis of a Maslow-type need satisfaction questionnaire. Personnel Psychology, 1970, 23, 251-268.

Payne, R. L., E Pheysey, D. C. G. G. Stern's Organizational Climate Index: A reconceptualization and application to business organizations. Organizational Behavior and Human Performance, $1971, \underline{6}, 77-98$.

Perrow, C. A framework for the comparative analysis of organizations. American Sociological Review, 1967, 14, 444-459.

Petersen, M. Overview progress report: Client relations research project. Portland, OR: Institute on Aging, Portland State University, 1977.

Pheysey, D. C., Payne, R. L., $\varepsilon$ Pugh, D. S. Influence of structure at organization and group levels. Administrative Science Quarterly, $1971, \underline{6}, 215,234$.

Pondy, L. R. Effects of size, complexity, and ownership on administrative intensity. Administrative Science Quarterly, 1969, 14, $47-60$.

Porter, L. W. A study of perceived job satisfaction in bottom and middle management jobs. Journal of Applied Psychology, 1961, 45, 1-10.

Porter, L. W. Job attitudes in management l: Perceived deficiencies in need fulfillment as a function of job level. Journal of Applied Psychology, 1962, 46, 375-384.

Porter, L. W. Onganizational patterns of managerial job attitudes. jew York: American Foundation for Management Research, 1964.

Porter, L. W., E Lawler, E. E. Properties of organization structure in relation to job attitudes and job behavior. Psychological Bulletin, 1965, I, 23-51.

Porter, L. W., E Lawler, E. E. Managerial attitudes and performance. Hornewood, IL: Richard Irwin, 1968. 
Porter, L. W., E Siegel, J. P. Relationships of tall and flat organization structures to the satisfactions of foreign managers. Personnel Psychology, 1965, $\underline{7}, 23-51$.

Porter, L. W., \& Steers, R. M. Organizational, work and personal factors in employee turnover and absenteeism. Psychological Bulletin, 1973, 80, 151-176.

Prien, E. P., $\varepsilon$ Ronan, W. W. An analysis of organizational characteristics. Organizational Behavior and Human Performance, 1971, 6, $215-234$.

Price, J. L. Handbook of organizational measurement. Lexington, MA: D. C. Heath and Company, 1972.

Pugh, D. S., Hickson, D. J., E Hinings, C. R. An empirical taxonomy of structures of work organizations. Administrative Science Quarterly, 1969, 14, 115-127.

Pugh, D. S., Hickson, D. J., Hinings, C. R., MacDonald, K. M., Turner, C., E Lupton, T. A conceptual scheme of organizational analysis. Administrative Science Quarterly, 1963, $\underline{8}, 289-315$.

Pugh, D. S., Hickson, D. J. Hinings, C. R., \& Turner, C. Dimensions of organizational structure. Administrative Science Quarterly, $1968,13,65-105$.

Pugh, D. S., Hickson, D. J., Hinings, C. R., $\varepsilon$ Turner, C. The context of organizational structure. Administrative Science Quarterly, $1969,14,94-114$.

Rice, L. E., E. Mitchell, T. R. Structural determinants of individual behavior in organizations. Administrative Science Quarterly, $1973,18,56-70$.

Rosen, H. Desirable attributes of work: Four levels of management describe their job environments. Journal of Applied Psychology, $1961,45,156-160$.

Rosengren, W., $\varepsilon$ Lefton, M. (Eds.). Organizations and clients: Essays in the sociology of service. Columbus, OH: Charles E. Merrill Publishing Company, 1970.

Roth, J. A. Professionalism: The sociologist's decoy. Sociology of Work and Occupations, 1974, 1, 6-23.

Rousseau, D. M. Characteristics of departments, positions, and individuals: Contexts for attitudes and behavior. Administrative Science Quarterly, 1978, 23, 521-540. 
Saleh, S. D. A study of attitude change in the preretirement period. Journal of Applied Psychology, 1964, 48, 310-312.

Saleh, S. D., \& Hyde, J. Intrinsic versus extrinsic orientation and job satisfaction. Occupational Psychology, 1969, 43, 47-53.

Schwab, D. P., \& Cummings, L. L. Employee performance and satisfaction with work roles: A review and interpretation of theory. Industrial Relations, 1970,9 , 408-430.

Schwartz, M. M., Jenusaitis, E., \& Stark, H. Motivational factors among supervisors in the utility industry. Personnel Psychology, $1963,16,45-53$.

Scott, W. G. Organization theory: An overview and appraisal. Academy of Management Journal, 1961, 4, 7-27.

Seashore, S. E., \& Tabor, T. D. Job satisfaction indicators and their correlates. American Behavioral Scientist, 1975, 18, 333-368.

Sells, S. B. An interactionist looks at the environment. American Psychologist, 1963, 18, 696-702.

Selznick, P. T.V.A. and the grass roots: A study in the sociology of formal organizations. Berkeley: University of California Press, 1949.

Seybolt, J. W. Work satisfaction as a function of the person-environment interaction. Organizational Behavior and Human Performance, $1976,17,66-75$.

Shepard, J. M. Functional specialization, alienation, and job satisfaction. Industrial and Labor Relations Review, 1970, 23, 207-219.

Simpson, R. L., \& Gulley, W. H. Goals, environmental pressures, and organizational characteristics. American Sociological Review, $1967,32,891-903$.

Sisk, H. L. Principles of management. Cincinnati: South-Western Publishing Co., 1969.

Smith, F. J., Scott, K. D., \& Hulin, C. L. Trends in job related attitudes of managerial and professional employees. Academy of Management Journal, $1977,20,454-460$.

Smith, P. C., E Cranny, C. G. Psychology of men at work. Annual Review of Psychology, 1964, 19, 467-496.

Smith, P. C., Kendall, L. M., \& Hulin, C. L. The measurement of satisfaction in work and retirement. Chicago: Rand-McNally, 1969 . 
Talacchio, S. Organization size, individual attitudes and behavior: An empirical study. Administrative Science Quarterly, 1960, 5, $398-420$.

Tannenbaum, A. S., E Smith C. G. Effects of member influence in an organization: Phenomenology versus organization structure. Journal of Abnormal and Social Psychology, 1964, 401-410.

Taylor, F. W. Scientific management. New York: Harper and Row, 1911.

Terrien, F. C., E Mills, C. C. The effect of changing size upon the internal structure of an organization. American Sociological Review, 1955, 20, 11-14.

Terryberry, S. The evolution of organizational environments. Administrative Science Review, 1968, 12, 309-324.

Thompson, J. D. Organizations in action. New York: McGraw-Hill, 1967.

Thompson, J. D., E McEwen, W. J. Organizational goals and environment: Goal setting as an interaction process. American Sociological Review, 1958, 23, 23-31.

Titmuss, R. M. Essays on the welfare state. New Haven: Yale University Press, 1959.

Tsouderos, J. E. Organizational change in terms of a series of selected variables. American Sociological Review, 1955, 20, 206-210.

Turner, A. N., E Lawrence, P. R. Industrial jobs and the worker. Boston: Harvard University Division of Research, Graduate School of Business Adninistration, 1965.

Vroom, V. H. Work and motivation. New York: Wiley Publishing, 1964.

Wanous, J. P., E Lawler, E. E. Measurement and meaning of job satisfaction. Journal of Applied Psychology, 1972, 56, 95-103.

Weber, M. Theory of social and economic organization (A. M. Henderson and T. Parsons, Trans.). New York: Oxford, 1947.

Wilensky, H. L. The welfare state and equality. Berkeley: University of California Press, 1975.

Wilensky, H. I., E Lebeaux, C. N. Industrial society and social welFare (2nd ed.). Glencoe, IL: Free Press, 1965. 
Yuctman, E., E Seashore, S. E. A resource approach to organizational effectiveness. American Sociological Review, 1967, 32, 891-903.

Zald, M. N. (Ed.). Social welfare institutions: A sociological reader. New York: John Wiley \& Sons, Inc., 1965. 